OPEN ACCESS

Edited by:

Maria Angela Sortino, University of Catania, Italy

Reviewed by:

Robin Polt,

University of Arizona, United States Christian Waeber,

University College Cork, Ireland Kazuaki Yoshioka,

Kanazawa University, Japan

*Correspondence:

Mohammad Hossein Pourgholami

m.pourgholami@modares.ac.ir

Specialty section:

This article was submitted to Experimental Pharmacology and Drug

Discovery,

a section of the journal

Frontiers in Pharmacology

Received: 02 November 2021

Accepted: 31 January 2022

Published: 16 February 2022

Citation:

Pournajaf S, Dargahi L, Javan M and Pourgholami MH (2022) Molecular

Pharmacology and Novel Potential

Therapeutic Applications

of Fingolimod.

Front. Pharmacol. 13:807639.

doi: 10.3389/fphar.2022.807639

\section{Molecular Pharmacology and Novel Potential Therapeutic Applications of Fingolimod}

\author{
Safura Pournajaf ${ }^{1}$, Leila Dargahi ${ }^{2}$, Mohammad Javan ${ }^{1}$ and \\ Mohammad Hossein Pourgholami ${ }^{1 *}$
}

${ }^{1}$ Department of Physiology, Faculty of Medical Sciences, Tarbiat Modares University, Tehran, Iran, ${ }^{2}$ Neuroscience Research Center, Shahid Beheshti University of Medical Sciences, Tehran, Iran

Fingolimod is a well-tolerated, highly effective disease-modifying therapy successfully utilized in the management of multiple sclerosis. The active metabolite, fingolimodphosphate, acts on sphingosine-1-phosphate receptors (S1PRs) to bring about an array of pharmacological effects. While being initially recognized as a novel agent that can profoundly reduce T-cell numbers in circulation and the CNS, thereby suppressing inflammation and MS, there is now rapidly increasing knowledge on its previously unrecognized molecular and potential therapeutic effects in diverse pathological conditions. In addition to exerting inhibitory effects on sphingolipid pathway enzymes, fingolimod also inhibits histone deacetylases, transient receptor potential cation channel subfamily $M$ member 7 (TRMP7), cytosolic phospholipase A2 $\alpha$ (CPLA2 $\alpha$ ), reduces lysophosphatidic acid (LPA) plasma levels, and activates protein phosphatase 2A (PP2A). Furthermore, fingolimod induces apoptosis, autophagy, cell cycle arrest, epigenetic regulations, macrophages M1/M2 shift and enhances BDNF expression. According to recent evidence, fingolimod modulates a range of other molecular pathways deeply rooted in disease initiation or progression. Experimental reports have firmly associated the drug with potentially beneficial therapeutic effects in immunomodulatory diseases, CNS injuries, and diseases including Alzheimer's disease $(A D)$, Parkinson's disease (PD), epilepsy, and even cancer. Attractive pharmacological effects, relative safety, favorable pharmacokinetics, and positive experimental data have collectively led to its testing in clinical trials. Based on the recent reports, fingolimod may soon find its way as an adjunct therapy in various disparate pathological conditions. This review summarizes the up-to-date knowledge about molecular pharmacology and potential therapeutic uses of fingolimod.

Keywords: fingolimod, immunomodulation, inflammation, apoptosis, autophagy

\section{INTRODUCTION}

Fingolimod (FTY720, Gilenya) is a fungal metabolite derivate that was approved by the Food and Drug Administration (FDA) in September 2010 as the first orally administered disease-modifying drug for the treatment of relapsing-remitting multiple sclerosis (RRMS) (Chiba, 2020). Known as a sphingosine 1-phosphate (S1P) receptor modulator, fingolimod induces immunomodulation through lymphocyte sequestration (Brinkmann et al., 2004). However, more than two decades 

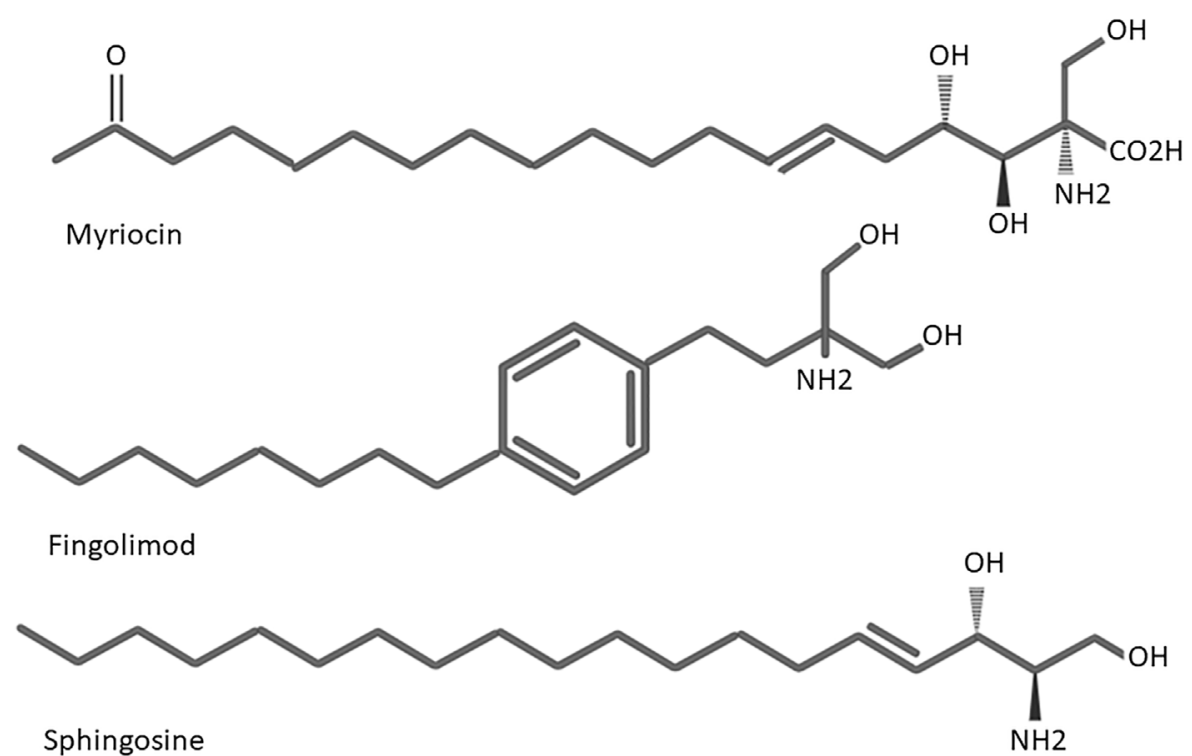

Created with Biorender.com

FIGURE 1 | Structure of myriocin, fingolimod, and Sphingosine.

past fingolimod synthesis, it is thought that the mechanism (s) of action of fingolimod may be more than just lymphocytes confinement (Sica et al., 2019). This view partly stems from the studies reporting its effects on various diseases. While some recent reviews have focused on specific aspects of fingolimod actions and use, there is a lack of holistic review regarding piling up recent evidence in fingolimod pharmacology and potential applications. This review highlights the fingolimod history, development, pharmacological effects, and expanding potential therapeutic applications.

\section{CHEMICAL STRUCTURE AND SYNTHESIS HISTORY}

Fingolimod (2-amino-2[2-(4-octylphenyl) ethyl]-1, 3propanediol) was first synthesized in 1995 by Adachi et al. from Isaria sinclairii metabolite named myriocin (ISP-1), a fungus used in Chinese traditional herbal medicine (Adachi et al., 1995). Structural simplification and modification of myriocin led to discovering several compounds with potent immunosuppressive activities more powerful than cyclosporine. During the modification process, the side chain functionalities and asymmetric centers of myriocin were removed, and a hydroxymethyl group instead of the carboxylic acid was substituted. In the next step, chimeric carbons elimination introduced much more simplified compounds. Then, the alkyl chains length were optimized. Finally, a phenyl ring inserted within the side chains introduced fingolimod (Chiba, 2020). Fingolimod was the most potent among these compounds and displayed noticeable immunosuppressive activity in vivo (Adachi et al., 1995). The structural components of fingolimod are different from conventional immunosuppressants, including an amino diol polar head group, a 1,4 di substituted phenyl ring, and a lipophilic alkyl tail (Brinkmann et al., 2010). A more detailed structural description of fingolimod is available in Marciniak's work (Marciniak et al., 2018). As it can be seen in Figure 1, a highly close structural resemblance exists between fingolimod and Sphingosine, a member of the sphingolipid family and metabolite of sphingomyelin (a major component of the cell membrane), which led to the idea of fingolimod action on S1P receptors as the principal mode of action (Mandala et al., 2002).

\section{PHARMACOKINETICS}

Following oral administration, slow and food-independent absorption of fingolimod is achieved with around $93 \%$ oral bioavailability and maximal plasma concentration reached after 12-16 h. In the body, fingolimod is metabolized via three main pathways. The first is rapid and reversible phosphorylation by sphingosine kinases (SPHKs) to fingolimod-phosphate (fingolimod-P). Lipid phosphate phosphohydrolases (LPP1a and LPP3) dephosphorylate fingolimod-P to fingolimod. Specific sphingosine 1phosphate phosphatase (SPP1) is also involved in intracellular dephosphorylation of fingolimod-P to a lower degree. The second is hydroxylation/oxidation by cytochrome P450 (CYP) 4F2 to inactive metabolites, eliminated by the renal system (81\%). In the third pathway, inactive non-polar ceramides are produced by the (dihydro) ceramide synthase and ceramidase for the reverse 
reaction. Generally, fingolimod-related components detected in the blood are fingolimod (23.3\%) and fingolimod-P $(10.3 \%)$, followed by inactive metabolites butanoic acid (8.3\%), ceramide metabolites M29 (8.9\%), and M30 (7.3\%). In the urine, butanoic acid is the major recovered metabolite (36\%) of the total dose administered (David et al., 2012). The parent drug fingolimod highly distributes in red blood cells (86\%), while in its phosphorylated form, fingolimod-P has lower uptake into red blood cells (17\%). The distribution of fingolimod in body tissues is widespread, with a distribution volume of about $1,200 \pm 260$ L. Fingolimod has $>99.7 \%$ plasma protein binding (mainly albumin) (David et al., 2012). While there are no reports showing fingolimod binding to ApoM/HDL, S1P ApoM/HDL binding seems essential for exerting its physiological effects (Christoffersen and Nielsen, 2013). Slow blood clearance results in an average terminal half-life of 6-9 days after repetitive administration. One-to-two months after once-daily drug intake, steady-state blood accumulation will be nearly 10 -fold higher than the concentrations achieved following the initial dose (David et al., 2012). Having the same elimination profile, fingolimod and fingolimod-P levels stay nearly equal in the blood (Volpi et al., 2019).

\section{SAFETY, ADVERSE EFFECTS, AND CONTRAINDICATIONS}

Fingolimod treatment is usually well tolerated. However, by virtue of acting on the various $\mathrm{S} 1 \mathrm{P}$ receptors, fingolimod induces numerous biological effects, including endothelial cell-cell adhesion, angiogenesis, vascular integrity, and cardiovascular function. The most common side effects observed in clinical studies in multiple sclerosis (MS) are reported to be lymphopenia, influenza, infections, nasopharyngitis, fatigue, back pain, diarrhea, bronchitis, dyspnea, nausea, and abnormal liver function tests (Kappos et al., 2006). Bradycardia with a possible atrioventricular blockade is a transient side effect observed following the first dose of fingolimod. Thus, pulse rate and blood pressure monitoring for at least 6 hours following the first application is needed (Széplaki and Merkely, 2012). In addition, during the first 3-4 months of fingolimod treatment, macular edema with or without visual symptoms has been reported (Yeh and Weinstock-Guttman, 2011). Naturally reducing peripheral lymphocyte count, fingolimod use may increase the risk of infections. So, patients must be warned about the signs of infection during and until 2 months post-fingolimod treatment (Yeh and Weinstock-Guttman, 2011; Fazekas et al., 2012). Fingolimod is a pregnancy risk category C drug. Congenital abnormalities have also been reported as fingolimod adverse effects in animal studies. Hence, in Europe, the drug is contraindicated in pregnancy, and its discontinuation is highly recommended at least 2 months before inception (Gilenya Contraindicated in Pregnant Women in EU, 2019; Mendibe Bilbao et al., 2019). Peripheral-vascular adverse effects like purplish blotches, itching, and edema on the distal phalanges are also among the rare adverse effects of the drug (Russo et al., 2015).

\section{MECHANISMS OF ACTION}

Sphingosine kinase 2 (SPHK2) and with lesser efficacy (30 folds lower), sphingosine kinasel (SPHK1) can phosphorylate fingolimod to Fingolimod-P (Billich et al., 2003; Paugh et al., 2003). Fingolimod-P binds with high affinity $\left(\mathrm{EC}_{50} \sim 0.3-3 \mathrm{nM}\right)$ to G-protein coupled receptors (GPCRs) S1PR (1, 3, 4, and 5), except S1P receptor 2, which shows a very low affinity with $\mathrm{EC}_{50}$ values more than 10,000 nM (Brinkmann et al., 2002; Mandala et al., 2002; Albert et al., 2005). Both SPHKs phosphorylate sphingosine to S1P within the cell. S1P is then exported outside the cell with the aid of $\mathrm{ABC}$ transporters and spinster 2 transporter to act on all S1PR1-5 (Nagahashi et al., 2014). S1P is a pivotal molecule in intracellular signaling (Lee et al., 1998; Maceyka et al., 2005), and based on the location of production, has distinct functions (Kumar et al., 2017). S1P phosphatase, located in the endoplasmic reticulum (Hla et al., 2008), and S1P lyase, found in both nucleus and endoplasmic reticulum (Ebenezer et al., 2021), maintain the intracellular concentration of S1P (Hla et al., 2008). The first dephosphorylates S1P to sphingosine, and the latter irreversibly degrades S1P to ethanolamine phosphate and hexadecenal (Spiegel, 2000). While interstitial fluid levels of S1P are low, S1P is highly augmented in blood and lymph in the sub-micromolar range $(\sim 1 \mu \mathrm{M})$, generating an intense S1P gradient (Hla et al., 2008). Mediated also by SPHKs, and S1P transporters (Tsai and Han, 2016), this S1P gradient, along with surface residence of S1PR1 on immune cells, sets as a cue for regulating immune cells such as lymphocytes and hematopoietic progenitor cells egress process (Obinata and Hla, 2019); thus, disruption of this principal gradient can induce lymphopenia by interfering in lymphocytes trafficking (Schwab et al., 2005). Affinity and potency of S1P and fingolimod-P for S1PR isoforms differ (fingolimod-P has high potency for S1PRs and has higher efficacy than S1P). Therefore, it promotes distinct responses in the target cells (Huwiler and Zangemeister-Wittke, 2018). Figure 2 depicts the primary mechanism through which fingolimod modulates inflammatory responses (further discussed in the following sections).

\section{Sphingosine 1 Phosphate Receptors S1PR1}

The affinity of fingolimod-P for the S1P receptor1 (S1PR1) is high (Brinkmann et al., 2002), which is the first identified and the most studied S1P receptor (Roggeri et al., 2020). It is the only S1PR that couples exclusively to Gai/o (Lee et al., 1998). Binding to Gai/o, it activates numerous signaling pathways including phosphatidylinositol-3-kinase (PI3K)/Akt, PI3K/Rac, signal transducer and activator of transcription (STAT3), and phospholipase C (PLC), which are involved in cell survival, proliferation, and migration (Wang et al., 2019). The most prominent functions of S1PR1 occur on lymphocytes, natural killer cells, dendritic cells, macrophages, neutrophils, hematopoietic progenitors, mast cells, and osteoclasts (Matloubian et al., 2004; Kihara et al., 2014). Detecting high levels of S1P in the blood and lymph, S1PR1 initiates egress of the lymphocytes from the lymphoid organs into the blood via the Gai 


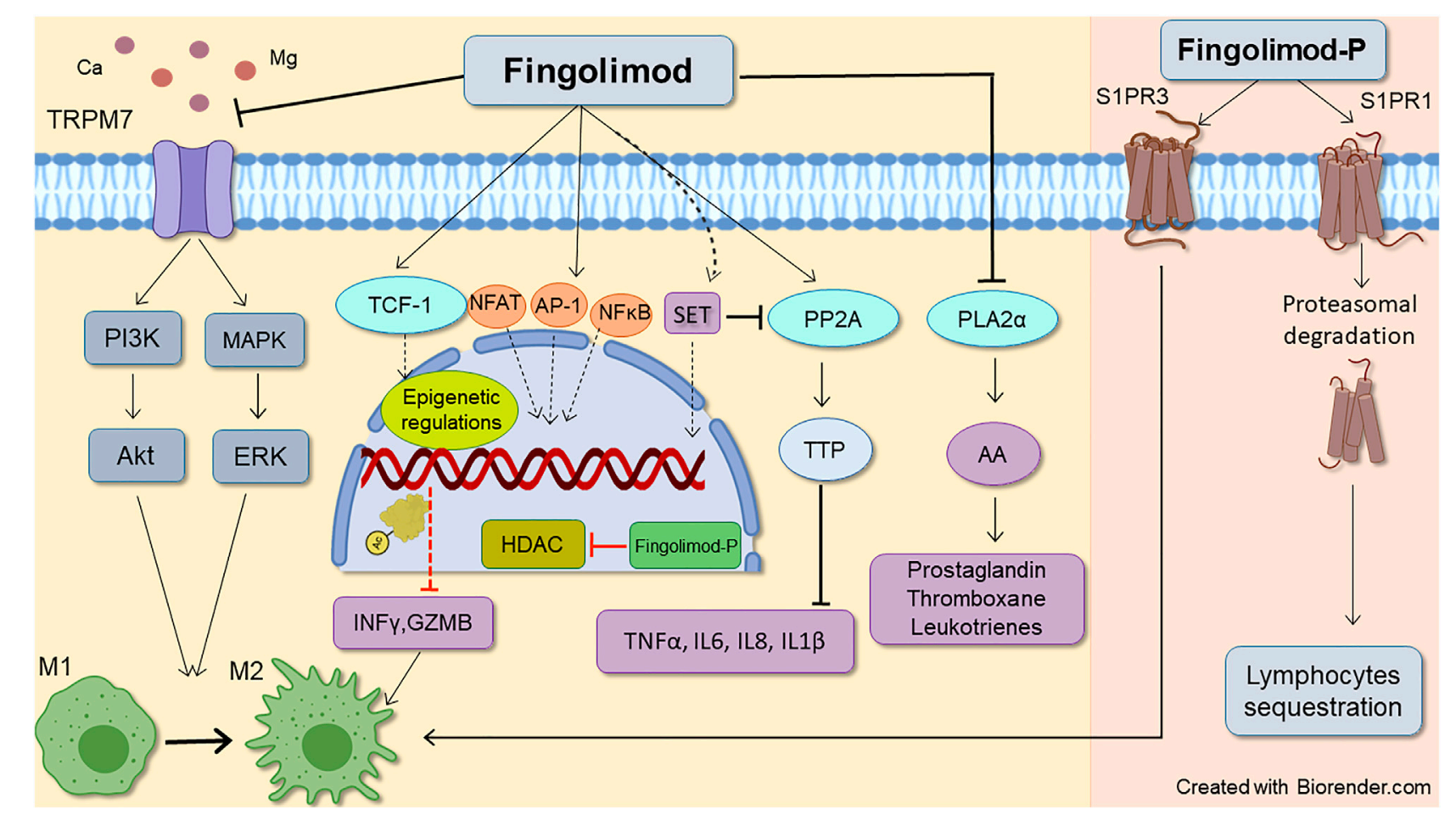

FIGURE 2| Schematic representative of fingolimod anti-inflammatory mode of action. Fingolimod main immunomodulatory action occurs through downregulating S1P receptors1, leading to lymphocytes sequestration. Its action on S1P receptors3 also favors lymphocytes M2 anti-inflammatory phenotype which is mediated by STAT3 phosphorylation. Besides, non-S1P related actions of fingolimod also can reduce inflammatory response by decreasing inflammatory molecules, T-cell inhibition, and shifting microglia and macrophages toward M2 phenotype. Enhancing histone acetylation by epigenetic regulation, phospholipase A2a inhibition, and activation of PL2A (through inhibition of SET expression) by fingolimod reduces inflammatory cytokines such as TNF $\alpha$, IL6, IL8, and IL-1 $\beta$. The drug also inhibits PLA2 $\alpha$ (which contributes to AA release and subsequent prostaglandins production), and TRPM7 chanzyme (which can induce both pro and anti-inflammatory phenotypes in macrophages). AA, Acid arachidonic; AP-1, Activator protein 1; Fingolimod-P, Fingolimod phosphate; GZMB, granzyme B; HDACi, Histone deacetylate inhibition, IL (6, 8), Interleukin (6, 8); INFY, interferon-gamma; M1, Pro-inflammatory macrophage/microglia; M2, Anti-inflammatory macrophage/microglia NFAT1, Nuclear factor of activated T-cells 1; NFKB, Nuclear factor-kappa B; PLA2 $\alpha$, Phospholipase 2 $\alpha$; PP2A, Protein phosphatase 2A; TCF-1, T cell factor 1; TNF $\alpha$, Tumor necrosis factor alpha; TTP, Tristetraprolin.

PI3K pathway and the small GTPase Rac activation (Cyster and Schwab, 2012). Down-regulation or desensitization of S1PR1s activates lymphocyte migration from the blood into the tissues. S1PR1 signaling regulates downstream molecules of the prosurvival PI3K/Akt proteins, necessary for apoptosis prevention (Schwab and Cyster, 2007). Binding S1P to S1PR1 activates the Rho family of small GTPases and downstream assembly of adherens junction and tight junction, and focal adhesion formation (Wang and Dudek, 2009). In humans, S1PR1 affects cardiovascular function and is the primary driver of bradycardia. At the very first hours of use, fingolimod acts as S1PR1 agonist and activates G-protein-coupled inwardly-rectifying potassium (GIRK) channels on atrial myocytes and endothelial cells, leading to bradycardia, eNOS activation, and ultimately, blood pressure decrease (Ochi et al., 2006; Fryer et al., 2012). However, this is transient as functional antagonistic activity of fingolimod on S1PR1 appears. The dominant and first known effect of fingolimod is immunomodulation through lymphocyte sequestration. Unlike conventional immunomodulatory drugs that act on calcineurin, fingolimod does not affect the proliferation and activation of lymphocytes. Instead, it induces a marked decrease of circulating lymphocytes (Chiba et al., 1998). As a pharmacological agent, the mechanism through which this happens is quite exciting and perhaps seldom seen. Upon fingolimod-P or S1P binding to the S1PRs, all receptors are internalized, dissociated in endosomes, and then recycled back to the cell membrane, except S1PR1, which is permanently downregulated by fingolimod-P (S1P lyase catabolizes the S1P, but not the fingolimod-P). Then through consistent binding, fingolimod-P induces its functional antagonistic effects leading to lymphocytes traffic perturbation (Schwab et al., 2005; Brinkmann, 2007). With the high affinity for the S1PR1, fingolimod-P causes irreversible receptor downregulation. Subsequently, desensitization to the serum S1P occurs and eventually leads to lymphocyte immobilization in the lymphoid organs and reduces their infiltration into the central nervous system (Matloubian et al., 2004). This persistent internalization is brought about through strong polyubiquitination by fingolimod-P and consequent degradation of S1PR1, evoking a massive decline in the S1PR1 level (Oo et al., 2007). In contrast, S1P causes c-terminal tail phosphorylation of S1PR1, inducing the agonistic response of 
S1PR1, leading to temporary internalization via clathrinmediated endocytosis (Liu et al., 1999). S1PRs1 are highly expressed on the endothelial cells, supporting vascular development and endothelial barrier integrity augmentation (Proia and Hla, 2015). By acting on S1PR1, fingolimod maintains vascular integrity through enhancing adherens junction assembly and endothelial barrier function (Brinkmann et al., 2004). Upon treatment of endothelial cells with fingolimod-P, phosphorylated extracellular signal-activated kinase (pERK) and pAkt lead to cell survival. Furthermore, vascular permeability induced by vascular endothelial growth factor (VEGF) is blocked by fingolimod (Sanchez et al., 2003). As a consequence of allergy, inflammation, or cancer, vascular permeability increases, hence barrier protective properties of S1P signaling are of therapeutic interest (Huwiler and Zangemeister-Wittke, 2018). In experimental autoimmune encephalomyelitis (EAE), fingolimod decreased the matrix metalloproteinase (MMP) gene-9 and increased its counter regulator, tissue inhibitor of metalloproteinase (TIMP-1). Resulting in preserving blood-brain-barrier (BBB) integrity (Foster et al., 2009). In a murine model of gut ischemia/ reperfusion (I/R), fingolimod protected against the inflammatory cascade by protecting vascular barrier integrity (Potì et al., 2020). In an animal model of septic shock, fingolimod diminished levels of Evans blue leakage from the blood into the liver and lung, decreased hematocrit values, and lowered plasma levels of VEGF-A (Hemdan et al., 2016). However, while S1PR1s are known to strengthen adherens junctions between endothelial cells (Gaengel et al., 2012) and maintain vascular barrier integrity, involvement of other receptor subtypes are also suggested (Potì et al., 2020). It has been shown that fingolimod improves the pulmonary endothelial cell barrier in a way independent of S1PR1 ligation (Dudek et al., 2007). Preservative effects of fingolimod on endothelial integrity seem to be dose-dependent. While low concentrations tend to be barrier augmentative, higher concentrations may induce irreversible barrier breakdown accompanied by induction of apoptosis (Müller et al., 2011). Other preclinical studies have also reported induction of vascular leakage at higher concentrations (Oo et al., 2011; Wang et al., 2014). These contradictory effects of fingolimod suggest that agonistic activity of S1PR1 augments endothelial barrier integrity while antagonist activity of fingolimod (which occurs after prolonged exposure) induces barrier disruption and increases vascular leakage (Huwiler and Zangemeister-Wittke, 2018). Moreover, fingolimod has been shown to inhibit angiogenesis under both in vitro (Ho et al., 2005) and in vivo (Schmid et al., 2005) conditions leading to antitumor effects (Chua et al., 2005; Ho et al., 2005; Schmid et al., 2005; LaMontagne et al., 2006). As S1P seems to play a dominant role in angiogenesis, fingolimod as its regulator can thus be regarded as an antiangiogenic. It has been shown that fingolimod impairs angiogenesis in mechanical force-induced abnormal scars (Aoki et al., 2020) and inhibits tumor angiogenesis via the S1PR1 (Schmid et al., 2007). Interestingly, depending on the setting and context, there are reports that fingolimod may also promote angiogenesis, where the phenomenon leads to a therapeutic effect. One such example is the photothrombotic model of mice brain ischemia, where fingolimod treatment enhanced angiogenesis by modulation of the microglial anti-inflammatory phenotype (M2) polarization in vivo and in vitro (Shang et al., 2020). In line with this, fingolimod promoted angiogenesis in mice after stroke (Zou et al., 2020). Following fingolimod use, S1PR1 dependent endothelial NOS (eNOS) activation and eNOS release lead to short-term vasodilation and subsequent blood pressure drop. This is why some patients experience a transient reduction in blood pressure when starting fingolimod therapy (Camm et al., 2014). Another way of regulating S1PR1 by fingolimod is through STAT1. It has recently been shown that fingolimod can suppress lipopolysaccharide (LPS) induced STAT1 activity (Hu et al., 2021), and STAT1 can transcriptionally stimulate S1PR1 by binding its promoter region (Xin et al., 2020). Additionally, activation of S1PR1 is involved in opioid-induced-hyperalgesia and fingolimod, by antagonistic effects on S1PR1, attenuates the development of morphine-induced persistent neuropathic pain in rats (Doyle et al., 2020).

\section{S1PR3}

$\mathrm{S} 1 \mathrm{P}$ receptor3 (S1PR3) recruits multiple G-proteins, including Gai/o, Ga12/13, and Gaq, with the most frequent action on the latter (Chun et al., 2010). The coupling of Gaq to S1PR3 generates inositol trisphosphate and diacylglycerol. Then calcium mobilization and activation of PKC, respectively, occur (Kihara et al., 2014). S1PR3 also contributes to angiogenesis, although less strongly than S1PR1 (Lee et al., 1999). It has been shown that S1PR3 depletion inhibits neurite retraction, suggesting a role of S1PR3 in nerve regeneration (Anastasiadou and Knöll, 2016; Quarta et al., 2017). Bradycardia induction has been attributed to S1P3 modulation. However, it is a species-specific function only seen in mice and rats (Sanna et al., 2016). In rats, bradycardia and hypertension induced by fingolimod are subtype-specific, attributed to S1PR1 and S1PR3, respectively, (Forrest et al., 2004; Fryer et al., 2012). Phagocytosis, polarization to M1 Phenotype, and reactive oxygen species (ROS) production in macrophages occur through S1PR3 (Hou et al., 2017; Gaire et al., 2018; Bryan et al., 2020). S1PR3 has been recognized as the receptor responsible for fingolimod-induced arterial vasodilation (Tölle et al., 2005). S1PR3 in macrophages can be considered an inflammatory receptor (Weigert et al., 2019). Fingolimod treatment interferes with S1PR3 signaling by opposing Gaq, leading to reduced ROS production and phagocytosis and M2 polarization of macrophages (Bryan et al., 2020). Amelioration of neuroinflammatory response occurs through fingolimod's ability to polarize microglia toward the M2 anti-inflammatory phenotype (Shang et al., 2020). This microglial polarization toward the M2 phenotype is mediated by the STAT3 pathway (Qin et al., 2017). Fingolimod-P's protective role in astrocytes against oxygen-glucose deprivationinduced neuroinflammation is also S1PR3-dependent, done through TLR2/4-PI3K-NFkB signaling pathway inhibition (Dong et al., 2018). It has been suggested that, like S1PR1, S1PR3 is also has a role in cancer metastasis (Calis et al., 2017). S1PR3 upregulation occurs in different cancers like breast cancer and brain tumor metastasis (Filipenko et al., 2016; Gril et al., 2018). 
So, it is intriguing that fingolimod by modulating S1PR3 and S1PR1s may provide anticancer effects.

\section{S1PR4}

Fingolimod binds to S1P receptor4 (S1PR4) that has a restricted distribution in the body (Stepanovska et al., 2020) and is primarily expressed in lymphocytes and hematopoietic tissues. Specifically abundant in immune cells, S1P/S1PR4 axis plays a significant role in immunity (Olesch et al., 2017). Recent studies emphasize the S1PR4 signaling role in activating immune cells differentiation and trafficking (Olesch et al., 2017). It acts on Gai and Ga12/13, which induces mitogen-activated protein kinase (MAPK) activity, and activates RhoA/ROCK. Activating RhoA/ ROCK affects actin dynamics and regulates trafficking of other receptors as a typical feature of S1PR4 biological action in immune cells (Olesch et al., 2017). In addition to S1PR1, S1PR4 also plays a crucial role in mediating the S1P migratory effect on satellite cells (Calise et al., 2012). It has a role in neutrophil traffic (Maceyka and Spiegel, 2014) as S1PR4 knockout in mice and zebrafish demonstrate reduced amounts of circulating neutrophils (Pankratz et al., 2016). S1PR4 mediates immunosuppressive effects of S1P through inhibition of $\mathrm{T}$ cell proliferation and modulation of cytokines (Wang et al., 2005). In addition to S1PR1, S1PR4 is also involved in the migratory response of migratory $\mathrm{T}$ cells toward S1P (Matsuyuki et al., 2006). S1PR4 signaling regulates the function of dendritic cells and Th17 T-cell differentiation (Schulze et al., 2011). It has recently been shown that S1PR4 deficiency affects the migration and positioning of activated peritoneal $\mathrm{B}$ cells to secondary lymphoid organs resulting in a significant drop in numbers of splenic innate response activator B cells after LPSinduced peritonitis (Riese et al., 2021). S1PR4 physiological roles are not yet fully elucidated. Hence, fingolimod effects through S1PR4 signaling are unclear so far (Stepanovska et al., 2020).

\section{S1PR5}

Fingolimod binds with high affinity to S1P5 receptor5 (S1PR5), which has limited expression in the CNS (Ishii et al., 2004). After coupling with multiple G-proteins, the S1PR5 binds primarily to Ga12/13. Functional consequences of S1PR5 modulation are associated with activation of signaling pathway molecules such as ERK1/2 (Jaillard et al., 2005). S1PR5 is dominantly expressed in oligodendrocytes and NK cells (O'Sullivan and Dev, 2017) and increases the survival of mature oligodendrocytes (Jaillard et al., 2005). Besides inhibition of oligodendrocyte precursor cell migration (Novgorodov et al., 2007), through S1PR1s and S1PR5s regulation, fingolimod also regulates survival, differentiation, and the extension of the cellular process in oligodendrocyte progenitors (Jaillard et al., 2005; Miron et al., 2008). It has been shown that fingolimod can decrease the expression of S1PRs, specially S1PR5, thus inhibiting the proliferation of multiple myeloma cells (Fu et al., 2017). Expression of S1PR5 on brain endothelial cells enhances the integrity of the brain endothelial barrier (van Doorn et al., 2012). S1PR5 also promotes lymphocytes and NK cell trafficking and their guidance to the inflammation sites, like S1PR1 and S1PR3 (Walzer et al., 2007).

\section{Sphingolipid Pathway Enzymes}

Although fingolimod exerts much of its therapeutic effects through modulation of S1PRs, other sites of action have also been suggested (Ntranos et al., 2014; Mazzola et al., 2015). Specific protein-binding, intracellular signaling pathways activation, and epigenetic transcriptions modulation are among these receptor-independent mechanisms of fingolimod (Hait et al., 2014).

\section{SPHKs}

Fingolimod, but not fingolimod-P, is a competitive SPHK1 inhibitor (to sphingosine) and induces its ubiquitinproteasomal degradation in HPASMC, MCF-7, and LNCaP-AI cells (Tonelli et al., 2010). Moreover, fingolimod can inhibit SPHK2 in neuroblastoma cells (Li et al., 2013). These two enzymes have different developmental and tissue distribution and play opposing roles in cell survival and apoptosis (Maceyka et al., 2005). Predominantly cytosolic, SPHK1 is anti-apoptotic and pro-survival, while SPHK2 is mainly localized in the plasma membrane, and the nucleus is pro-apoptotic (Kumar et al., 2017). Since SPHK1 activation is associated with cancer development with poor prognosis (Pyne and Pyne, 2010), the ability of fingolimod in inhibiting SPHK1 is quite intriguing and needs further investigations. However, fingolimod $\mathrm{IC}_{50}$ for SPHK1 is $50 \mu \mathrm{M}$ concentration with no clinical relevance. That encourages the search for drugs with higher potency for SPHK1 inhibition.

\section{S1P Lyase}

Fingolimod can inhibit S1P lyase activity (Bandhuvula et al., 2005) that induces S1P irreversible degradation, so its pharmacological inhibition by fingolimod can change the S1P chemotactic gradient that plays in thymocytes egression (Schwab et al., 2005). Alongside affecting S1P signaling, S1P lyase affects different biological functions involved in cell survival, migration, inflammation, and oncogenesis. S1P lyase deficiency in gut epithelial cells has been associated with colitis and the development of colitis-associated cancer (Kumar et al., 2017). Hence, its inhibition by fingolimod has to be considered in cancer therapy.

\section{Ceramidase Synthase}

Modulation of ceramide synthesis is another action of fingolimod (Lahiri et al., 2009). Fingolimod inhibits ceramide synthase 2 in a competitive behavior toward dihydrosphingosine (Berdyshev et al., 2009) and is noncompetitive toward acyl-CoA. It also modulates the intracellular balance of signaling sphingolipids. Fingolimod inhibits ceramide synthesis at high $(500 \mathrm{nM}-5 \mu \mathrm{M})$ but not low ( $<200 \mathrm{nM})$ Sphinganine concentrations, which seems to be acyl-CoA chain length-dependent (Lahiri et al., 2009). It also has been shown that fingolimod reduces the light-induced retinal ceramide increase by de novo ceramide biosynthetic inhibition (Chen et al., 2013).

\section{Acid Sphingomyelinase}

Through proteolytic degradation, fingolimod inhibits enzyme acid sphingomyelinase (A-SMase) as a catalyzer of hydrolysis of sphingomyelin to ceramide. However, this effect seems indirect 
and cumulatively increased (Dawson and Qin, 2011; Henry et al., 2013). By reducing A-SMase activity, fingolimod decreases the production of monocytes-derived micro-vesicles and IL- $1 \beta$ in patients with MS (Amoruso et al., 2018). Extracellular vesicles participate in BBB dysfunction, and the accelerated level of extracellular vesicles in biological fluids of MS patients contributes to MS pathogenesis (Dolcetti et al., 2020). This mode of action of fingolimod deserves further investigation.

\section{Epigenetic Regulation: Histone Deacetylase Inhibition}

Epigenetic regulation is also involved in the receptorindependent functions of fingolimod. Fingolimod acts as a histone deacetylases inhibitor (HDACi) (Hashemian et al., 2019; Ji et al., 2019; Rohrbach et al., 2019). After phosphorylation in the nucleus, fingolimod binds and inhibits class 1 histone deacetylases (HDACs), enhancing specific acetylation (Ji et al., 2019) and rescuing memory deficits independent of its immunosuppressive actions (Hait et al., 2014). Clinically relevant oral doses of fingolimod $(1 \mathrm{mg} / \mathrm{kg})$ suppressed development, progression, and aggressiveness of spontaneous breast tumors in MMTVPyMT transgenic mice and reduced HDAC activity that reactivated estrogen receptor- $\alpha(E R \alpha)$ expression (Hait et al., 2015). Preliminary evidence shows that besides H1 acetylation enhancement by fingolimod, H3 histone acetylation is also increased. Fingolimod increased $\mathrm{H} 3$ acetylation at brain-derived neurotrophic factor (BDNF) promoter in OLN-93 cell line and increased BDNF expression in oligodendroglial cells (Segura-Ulate et al., 2017). Antitumor activity in medulloblastoma cells treated by 7.5 or $10 \mu \mathrm{M}$ concentrations of fingolimod attributed to the induced $\mathrm{H} 3$ acetylation (Perla et al., 2020). It has also been shown that after myocardial infarction, HDAC inhibition induces M2 macrophages and increases non-inflammatory cytokines alongside angiogenesis (Kimbrough et al., 2018). HDAC inhibition by fingolimod also causes a reduction in activated $\mathrm{T}$ cells, upregulation in antiepileptogenic effect, neurotrophic factor generation enhancement, and memory deficit rescue (Hait et al., 2014; Leo et al., 2017; SeguraUlate et al., 2017; Baer et al., 2018). Fingolimod induces expression of $\mathrm{T}$ cell factor 1 (TCF-1), which then binds to the promoter/enhancer regions and causes inhibition of some inflammatory genes like interferon-gamma (IFN- $\Upsilon$ ) and granzyme B (GZMB) (Mazzola et al., 2015). Besides, fingolimod induces parts of its neuroprotective effects by enhancing neurotrophic factors. Fingolimod enhances BDNF expression in vitro in different cells, including epidermal neural crest stem cells (EPI-NCSCs) (Pournajaf et al., 2020), primary mouse cortical neurons (Doi et al., 2013), microglia (Noda et al., 2013), Schwann cells (Heinen et al., 2015), and oligodendrocytes (Segura-Ulate et al., 2017). Fingolimod-induced enhancement of BDNF has also been shown. In a mouse model of Rett syndrome, fingolimod counteracted NMDA-induced neuronal death in a BDNFdependent manner (Deogracias et al., 2012). Fingolimod reduced synucleinopathy in mouse models of Parkinson's disease and improved behavior by increasing BDNF levels (Vidal-Martínez et al., 2016; Vidal-Martinez et al., 2019). In an animal model of MS, fingolimod protected brain tissue from atrophy attributed to the promotion in the BDNF (Smith et al., 2018). In patients with MS, treatment with fingolimod significantly increased BDNF secretion from $\mathrm{T}$ cells, suggesting that neuroprotective effects of fingolimod therapy are through BDNF enhancement (Golan et al., 2019). Fingolimod regulates dendritic architecture and morphology of healthy mature primary hippocampal neurons alongside BDNF dependent enhancement in c-Fos and pERK1/2 proteins (Patnaik et al., 2020). We have recently shown that BDNF enhancement by fingolimod correlates with upregulation in oligodendrocyte mRNA levels in the EPINCSCs (Pournajaf et al., 2020). BDNF activates tropomyosin-related kinase B (TrkB), the MAPK/ERK1/2 signaling, and eventually causes oligodendrocyte differentiation and myelination (Fletcher et al., 2018). This myelination enhancement can partly explain the neuroprotective effects of fingolimod. Histone deacetylase inhibitory ability of fingolimod is involved in BDNF enhancement. The BDNF gene reacts to different epigenetic factors, especially HDAC inhibitors (Bagheri et al., 2019). Recently, it has been reported that HDAC inhibition increases neurotrophic (especially BDNF) expression after traumatic brain injury (TBI) (Sada et al., 2020). SeguraUlate and others also found that fingolimod increases histone $\mathrm{H} 3$ acetylation in OLN-93. With the aid of chromatin immunoprecipitation assays, they found acetylated histone 3 enhancement at BDNF promoter-1 after fingolimod exposure, suggesting that fingolimodassociated histone deacetylase inhibition stimulates BDNF expression in oligodendroglia cells (Segura-Ulate et al., 2017). However, in an MTPT mouse model of Parkinson's disease, fingolimod did not increase BDNF sustainably (Komnig et al., 2018). Moreover, in a recent trial evaluating fingolimod in patients with Rett syndrome (FINGORETT study), 12-month treatment with the drug did not lead to BDNF enhancement in children with Rett syndrome (Naegelin et al., 2021). Therefore, further trials under different clinical settings are required to determine whether or not fingolimod treatment leads to BDNF enhancement.

Besides decreasing S1PR1 expression in macrophages that cause phenotypic transformation of macrophages from a proinflammatory (M1) to M2 anti-inflammatory phenotype (Hughes et al., 2008), fingolimod facilitates M1 to M2 shifts of macrophages and microglia (Sun et al., 2018; Ji et al., 2019), enhances their phagocytic function, and modulates their proliferation, morphology, and cytokine release via suppressing HDAC1-Mediated Krüppel-like factor 4 (KLF4) deacetylation (Ji et al., 2019). However, inhibition of the transient receptor potential cation channel, subfamily M, member 7 (TRPM7) by fingolimod prevents polarization of macrophages towards the anti-inflammatory M2 phenotype (Schilling et al., 2014). Suppressing autophagy via the STAT1 pathway is considered another mechanism of fingolimod-mediated microglial 
transform to an anti-inflammatory phenotype (Hu et al., 2021). Along with changing absolute lymphocyte numbers, fingolimod selectively changes peripheral blood lymphocyte subsets. Indicating that although the number of peripheral memory lymphocytes is reduced by fingolimod, significant parts of the immunological memory are preserved (Hjorth et al., 2020).

Another effect of fingolimod is modulating $\mathrm{T}$ cell phenotype and regulatory $\mathrm{T}$ cell plasticity. In patients with RRMS, $0.5 \mathrm{mg} / \mathrm{kg}$ of fingolimod induces an exhausted-like phenotype, characterized by the inhibition of IL-17 and IFN $\gamma$ expression, augmentation of IL-10 and TGF $\beta$, and increased expression of exhaustion markers such as programmed cell death-1 (PD-1) and T-cell immunoglobulin and mucin domain-containing protein 3 (Tim-3) (Dominguez-Villar et al., 2019). Suppression of T cell activation by fingolimod occurs through inhibition of distal $\mathrm{T}$ cell receptor signaling. As shown in Figure 2, aberrant nuclear translocation and activation of nuclear factor of activated T-cells 1 (NFAT1), activator protein 1 (AP-1), and nuclear factor-kappa $\mathrm{B}(\mathrm{NF \kappa B})$ by fingolimod enhances histone $\mathrm{H} 3$ lysine 9 acetylation (H3K9Ac), leading to $\mathrm{T}$ cell inhibition and immunomodulation (Baer et al., 2018).

\section{The Chanzyme TRPM7 Inhibition}

TRPM7 is an ion channel and protein kinase that, by regulating $\mathrm{Ca}^{2+}$ and $\mathrm{Mg}^{2+}$, mediates several physiological and pathological processes like cell proliferation, survival, migration, and apoptosis (Abumaria et al., 2019). Mounting evidence implies that TRPM7 chanzyme is critical in several aspects of cancer (Yee, 2017). Fingolimod is a potent inhibitor of TRPM7 $\left(\mathrm{IC}_{50}=0.72 \mu \mathrm{M}\right)$ that contributes to the drug's anti-proliferative and anti-migratory effects (Qin et al., 2013). TRPM7 is abundant in macrophages, and its activation is essential for the polarization of macrophages into anti-inflammatory M2 phenotype. As shown in Figure 2, pharmacological inhibition of TRPM7 by fingolimod hinders macrophage M1/M2 shift (Schilling et al., 2014). It has also been suggested that loss of TRPM7-mediated $\mathrm{Ca}^{2+}$ influx in response to LPS after TRPM7 inhibition is involved in macrophage inactivation (Schappe et al., 2018). Moreover, TRPM7 inhibition decreases PI3K and ERK1/2 phosphorylation (Fang et al., 2013), required for macrophages to shift towards the M2 phenotype (Zhang et al., 2011). Inhibiting TRPM7 channel activity by fingolimod causes IL-2 sensitization, leading to upregulation of Foxp3 in thymocytes and the development of T regulatory (Treg) cells (Mendu et al., 2020). However, recently Li et al. showed the opposite role of TRPM7 in macrophage polarization, suggesting that M1 macrophages highly express TRPM7, and its blockade could drive macrophages to M2 polarization. The proposed mechanism for this regulation of macrophage phenotype is thought to involve inhibition of STAT1 phosphorylation and promotion of STAT6 phosphorylation after TRPM7 inhibition (Li L. et al., 2020). It has been shown that pathological triggers such as ischemic, hypoxic, and traumatic injuries can over-activate TRPM7, leading to neuronal death and toxicity (Abumaria et al., 2019). Fingolimod inhibitory effects on TRPM7 can be investigated for new therapeutic applications in diseases affected by these triggers.

\section{Cytosolic Phospholipase A2a Inhibition}

Part of fingolimod-induced changes occurs by inhibition of cytosolic phospholipase A2 $\alpha$ inhibition (cPLA2 $\alpha$ ), which regulates arachidonic acid (AA) release and its subsequent synthesis (Payne et al., 2007; Ntranos et al., 2014). In 2007, Payne et al. found that fingolimod, but not fingolimod-P inhibits antigen-induced AA release and subsequently thromboxane and prostaglandin secretion in an independent way from S1P receptors (Figure 2). This inhibition of cPLA2 $\alpha$ occurs at picomolar concentrations that stay within the range of FTY720 plasma concentrations, which is $30 \mathrm{nM}$ at the steadystate level (Zemann et al., 2006). They concluded that fingolimod directly and specifically inhibits CPLA2 $\alpha$ under in vivo and in vitro conditions (Payne et al., 2007). This direct antiinflammatory action of fingolimod may expand its therapeutics uses, as it has been shown that cPLA2 $\alpha$ inhibitors can alleviate collagen-induced arthritis (Tai et al., 2010; Feuerherm et al., 2019). cPLA2 $\alpha$ is involved in cancer angiogenesis and tumorigenesis (Wen et al., 2013). As a result, cPLA2 $\alpha$ inhibitor AVX235 has been shown to reduce vascularization and growth in breast cancer tumors (Kim et al., 2016), adding weight to the studies suggesting the feasibility of fingolimod use for cancer therapy. The cPLA2 $\alpha$ inhibition can have several potential therapeutic benefits in inflammatory diseases, and we thus anticipate profound future interest in this area.

\section{Lysophosphatidic Acid Synthesis Reduction}

Lysophosphatidic acid (LPA), produced by autotaxin, plays roles in different physiological and cellular processes like differentiation, proliferation, migration, survival, and pathological processes like inflammation and invasion of cancer cells (Valdés-Rives and González-Arenas, 2017). In vitro, fingolimod-P competitively inhibits autotaxin $\left(\mathrm{IC}_{50}=\right.$ $0.3-0.4 \mu \mathrm{M})$ and orally administered fingolimod $(3 \mathrm{mg} / \mathrm{kg})$ reduces plasma levels of LPA in mice (van Meeteren et al., 2008). Through modulating LPA, fingolimod can promote peripheral nerve myelination (Szepanowski et al., 2016). Exploring the autotaxin/LPA axis may lead to the discovery of further fingolimod anticancer properties (van Meeteren et al., 2008).

\section{Protein Phosphatase 2A Activation}

Fingolimod is also a well-known activator of Protein phosphatase 2 (PP2A) (Nagahara et al., 2001; Matsuoka et al., 2003), that plays a principal role as a regulator of cell cycle/division and growth, apoptosis, and regulation of various signal transduction pathways relevant to inflammation (Oaks and Ogretmen, 2015). The mechanisms of how fingolimod regulates PP2A are not fully known. However, disruption of interaction of PP2A to SET (endogenous inhibitor of PP2A) seems the most likely event (De Palma et al., 2019). Fingolimod binding induces chemical changes at the N-terminal residues of SET, making SET unavailable for dimerization or oligomerization. Fingolimod binding eventually separates SET from PP2Aca, thus leading to PP2A activation (De Palma et al., 2019). As depicted in Figure 2, fingolimod also reduces the inhibition of PP2A by 
the accumulation of SET into the nucleus, allowing PP2A to recover its activity in the cytoplasmic compartment (Pippa et al., 2014). Phosphorylation of the tyrosine residue Tyr307 causes Leu 309 methylation, resulting in PP2A inactivation (Clark and Ohlmeyer, 2019). Dephosphorylation of PP2A subunit C at Tyr307 site by fingolimod activates PP2A (Zhong et al., 2020). Additionally, fingolimod further dephosphorylates AMPKa at the Thr172 site, then decreases eEF2 and induces cell death in multiple myeloma cells (Zhong et al., 2020). This pharmacological event is believed to contribute to fingolimod's general antitumor and anti-inflammatory. As noted before, PP2A activation by fingolimod causes activation of tristetraprolin (TTP), thus reducing inflammatory cytokines and improving neurological function, suppression of brain edema, and inhibiting apoptosis (Yin et al., 2018). Decreased phosphorylation of PP2A targets, Akt, and ERK $1 / 2$ is also a consequence of PP2A activation by fingolimod attributed to anticancer manifestations in colorectal cancer (Cristóbal et al., 2014).

\section{Autophagy Modulation}

Another fingolimod action is the induction of autophagy. In many cells, the autophagy markers such as microtubuleassociated protein-1 light chain 3 (LC3) and Beclin 1 are enhanced by fingolimod. Fingolimod-induced death of ovarian cancer cells is caspase- 3 independent and includes cellular swelling and cytoplasmic vacuolization with apparent features of necrotic cell death and enhanced number of autophagosomes and LC3-II, and p62 degradation (Zhang et al., 2010). The caspase-independent cell death by fingolimod was also observed in lymphoblastic leukemia cells, accompanied by an increase in autophagosomes and LC3-II. However, since fingolimod-P also induced autophagy but not cell death, it was concluded that autophagy was prosurvival in that setting, and cytotoxic effects of the fingolimod were attributed to ROS induction (Wallington-Beddoe et al., 2011). Fingolimod also killed melanoma and myeloma cells by ROS enhancement. So, it was concluded that ROS acts as a regulator of fingolimod-induced apoptosis and autophagy (Liao et al., 2012; Li et al., 2013). In mantle cell lymphoma, fingolimod treatment affected autophagic flux in two ways: first, activation of upstream steps shown by the accumulation of autolysosomes and increased LC3-II, followed by disruption of autophagy at late stages (Alinari et al., 2011). In TBI, the acquired neuroprotection by fingolimod has been attributed to the enhancement in the expression of LC3 and Beclin 1, known as autophagy markers, and activation of the PI3/Akt pathway (Zhang et al., 2016). ROS-induced autophagy has been proposed as an antitumor effect of fingolimod in glioblastoma, oral squamous cancer cells, and ovarian cancer cells (Zhang et al., 2015; Bai et al., 2017). Fingolimod induces ROS-c-Jun N-terminal kinaseprotein 53 (ROS-JNK-p53) loop-dependent autophagy, alongside apoptosis and necroptosis, in human glioblastoma cells. This autophagy is mediated by the PI3K/Akt/mTOR/p70S6K pathway (Zhang et al., 2015). However, in pancreatic stellate cells, fingolimod inhibited autophagy via suppressing AMPK and activating the mTOR pathway (Cui et al., 2019). It seems that the pharmacological effects produced by fingolimod under different pathological conditions do vary depending on the best-required outcome for the tissue. In an ischemic stroke model in mice, fingolimod dose-dependently decreased the induction of autophagosome proteins, LC3-II and, Beclin-1 leading to infarct volume reduction. Attenuated neuronal autophagy was shown to be mediated through the mTOR/p70S6K pathway and modulation of S1P signaling (Li et al., 2017). Accordingly, fingolimod modulation of autophagy is celltype and context-dependent; so, depending on the context, autophagy functions are either pro-death or pro-survival (140). Presented in Table 1 are studies reporting both pro or anti survival effects of fingolimod under different pathological conditions.

\section{Cell Cycle Arrest and Apoptosis Induction}

Another significant pharmacological effect of fingolimod is the drug's ability and the capacity to induce apoptosis in pathological conditions. The revelation began in 1996 when Suzuki et al. reported that fingolimod promptly induced lymphocyte apoptosis (Suzuki et al., 1996). Interestingly, it was later shown that fingolimod acts by homing $\mathrm{T}$ cells without affecting the total number of $\mathrm{T}$ cells (Chiba et al., 1998). However, its apoptotic inducing effect occurs in various cancer cells under in vitro and in vivo conditions. The reports include but are not limited to gastric cancer, breast cancer, renal cancer, pancreatic cancer, prostate cancer, multiple myeloma, different forms of leukemia, hepatocellular carcinoma, and glioma (White et al., 2016). The ability of fingolimod to induce apoptosis is mediated through multiple cell death signaling pathways. Apart from regulating S1P receptors, fingolimod induces $\mathrm{G} 0 / \mathrm{G} 1$ cell cycle arrest and apoptosis in the human lymphoma cell lines HL-60 and Jurkat via affecting mitochondrial permeability transition and cytochrome $c$ release (Nagahara et al., 2000). Modulation of mitogenic signaling, cell-cycle regulators, induction of $\mathrm{G} 1$ arrest, and apoptotic death are also reported in DU145 cells as androgen-independent prostate cancer cell lines (Permpongkosol et al., 2002). In T98G human glioma cells, fingolimod induced apoptosis through the focal adhesion kinase (FAK) dephosphorylation and cutting off the FAK-PI3-kinase pathway. Caspase-6 activation was responsible for apoptosis induction by fingolimod in these cells (Sonoda et al., 2001). Both intrinsic (caspase and mitochondrial-dependent) and extrinsic apoptotic pathways are involved in the apoptotic death triggered by fingolimod (Fujino et al., 2002; Zhang and Wang, 2020). Apoptotic activation of caspase cascade in fingolimodtreated Jurkat cells may be initiated by activation of mitochondria (Fujino et al., 2001). Other most fingolimod noted apoptotic pathways are inactivation of ERK/MAP kinase (Estrada-Bernal et al., 2012), inhibition of PI3K/Akt/mTOR signaling pathway and subsequent reduction in phosphorylated p70S6k levels, caspases-3, and 9 activations (Estrada-Bernal et al., 2012), cleavage of Poly (ADP-ribose) polymerase (PARP), MMP loss (Zhao et al., 2018), down-regulating anti-apoptotic proteins 
TABLE 1 | Fingolimod as an autophagy inducer/blocker and its role in cell death/survivals.

\begin{tabular}{|c|c|c|c|}
\hline Author/Year & Model & Findings & Evidence \\
\hline Zhang 2010 & Ovarian cancer cells & $\begin{array}{l}\uparrow \text { Autophagosomes and formation and accumulation of } \\
\text { LC3-II }\end{array}$ & Pro-survival \\
\hline Zhang et al. (2010) & & $\begin{array}{l}\uparrow \text { Autophagic flux } \\
\uparrow L C 3 \text { turnover and p62 degradation }\end{array}$ & \\
\hline $\begin{array}{l}\text { Wallington-Beddoe } 2011 \\
\text { Wallington-Beddoe et al. } \\
\text { (2011) }\end{array}$ & Acute lymphoblastic leukemia Cell lines & $\uparrow$ Autophagosomes, LC3II expression $\uparrow$ Autophagic flux & Pro-survival \\
\hline $\begin{array}{l}\text { Liao } 2011 \\
\text { Liao et al. (2011) }\end{array}$ & Multiple myeloma (MM) cell line U266 & $\uparrow L C 3 B-\|$ & Pro-death \\
\hline $\begin{array}{l}\text { Romero Rosales } 2011 \\
\text { Romero Rosales et al. (2011) }\end{array}$ & Murine hematopoietic cell line FL5.12 and In vivo & $\begin{array}{l}\uparrow L C 3-\| \\
\uparrow \text { Autophagosomes } \\
\uparrow \text { Autophagic flux }\end{array}$ & Pro-survival \\
\hline Alinari 2011 & Mantle cell lymphoma (MCL) cell lines & $\begin{array}{l}\text { Accumulation of autolysosomes and increased LC3-II and } \\
\text { p62 levels }\end{array}$ & Pro-death \\
\hline Alinari et al. (2011) & & $\uparrow C D 74$ & \\
\hline $\begin{array}{l}\text { Liao } 2012 \\
\text { Liao et al. (2012) }\end{array}$ & Multiple myeloma (MM) cell line U266 & $\begin{array}{l}\uparrow \text { Conversion of LC3-I to LC3-II } \\
\uparrow \text { Autophagic flux }\end{array}$ & Pro-death \\
\hline $\begin{array}{l}\text { Li } 2013 \\
\text { Li et al. (2013) }\end{array}$ & Multiple myeloma cell line U266 & $\uparrow L C 3 B-\|$ & Pro-death \\
\hline $\begin{array}{l}\text { Tay } 2014 \\
\text { Tay et al. (2015) }\end{array}$ & Human melanoma cells Mel-RM and MM200 cells & 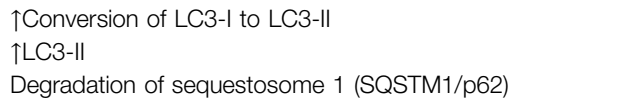 & Pro-death \\
\hline $\begin{array}{l}\text { Zhang } 2015 \\
\text { Zhang et al. (2015) }\end{array}$ & $\begin{array}{l}\text { U251MG, U87MG, SHG44 and A172 glioblastoma cell lines } \\
\text { and In vivo }\end{array}$ & $\begin{array}{l}\uparrow \text { Conversion of LC3-I to LC3-II } \\
\uparrow L C 3-\| \\
\uparrow \text { Beclin } 1 \\
\uparrow \text { Autophagosomes } \\
\downarrow \text { p62/SQSTM1 } \\
\uparrow \text { Autophagic flux }\end{array}$ & Pro-death \\
\hline $\begin{array}{l}\text { Ahmed } 2015 \\
\text { Ahmed et al. (2015) }\end{array}$ & Hepatocellular carcinoma cell lines Huh7 and HepG2 & $\begin{array}{l}\uparrow L C 3-\| \\
\uparrow p 62\end{array}$ & Pro-death \\
\hline $\begin{array}{l}\text { Zhang } 2016 \\
\text { Zhang et al. (2016) }\end{array}$ & Mouse model of TBI & $\begin{array}{l}\uparrow L C 3-\| \\
\uparrow B e c l i n 1 \\
\downarrow p 62\end{array}$ & Pro-survival \\
\hline $\begin{array}{l}\text { Li } 2016 \\
\text { Li et al. (2016) }\end{array}$ & Colorectal cancer cells & $\begin{array}{l}\text { 个LC3B-II accumulation } \\
\uparrow \text { Autophagosomes }\end{array}$ & Pro-death \\
\hline $\begin{array}{l}\text { Bai } 2017 \\
\text { Bai et al. (2017) }\end{array}$ & $\begin{array}{l}\text { Oral squamous cell carcinoma cellsSCC4, SCC25, and } \\
\text { SCC2095 }\end{array}$ & 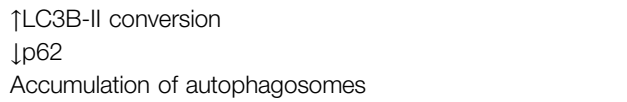 & Pro-death \\
\hline $\begin{array}{l}\text { Li } 2017 \\
\text { Li et al. (2017) }\end{array}$ & Ischemic brain stroke in mice & $\begin{array}{l}\downarrow \text { Induction of autophagosome proteins } \\
\downarrow \text { LC3-II } \\
\downarrow \text { Beclin } 1\end{array}$ & Pro-survival \\
\hline $\begin{array}{l}\text { Sun } 2018 \\
\text { Sun et al. (2018) }\end{array}$ & Foam cells & $\uparrow L C 3 \|$ & Pro-survival \\
\hline $\begin{array}{l}\text { Cui } 2019 \\
\text { Cui et al. (2019) }\end{array}$ & Pancreatic stellate cells & $\begin{array}{l}\downarrow \text { LC3B-॥ } \\
\downarrow \text { Atg5 } \\
\uparrow p 62\end{array}$ & Pro-death \\
\hline $\begin{array}{l}\text { Ota } 2019 \\
\text { Ota et al. (2019) }\end{array}$ & Non-small cell lung cancer cell line A549 & $\begin{array}{l}\uparrow \text { MAP1 LC3B-II } \\
\text { Accumulation of SQSTM1 } \\
\downarrow \text { Autophagic flux }\end{array}$ & Pro-death \\
\hline $\begin{array}{l}\text { Hu } 2021 \\
\text { Hu et al. (2021) }\end{array}$ & Primary microglia cells & $\begin{array}{l}\downarrow \text { LC3-II/LC3-| } \\
\downarrow \text { Beclin } 1 \\
\uparrow p 62 \\
\downarrow \text { Autophagic flux }\end{array}$ & Pro-survival \\
\hline
\end{tabular}

Mcl-1, BCl-2, and cleavage of Bid and Bim (Kiyota et al., 2013). An increase in phosphatase and tensin homolog (PTEN), which inhibits pAkt and murine double minute 2 (MDM2), followed by increased p53 (Zheng et al., 2010), and ceramide levels and activation of PP2A (Chen et al., 2014) are also included. However, the complete and exact mechanisms behind the apoptotic properties of fingolimod remain to be determined through future studies. Interestingly, an anti-apoptotic role of fingolimod has also been reported in other pathological conditions such as brain injury, where the inhibition is highly beneficial in the process of treatment. Here, fingolimod reduced apoptosis following brain insults shown by the increase in $\mathrm{Bcl}-2, \mathrm{Bcl}-\mathrm{xL}$, and decrease in the 
TABLE 2 | Molecular targets of fingolimod and its relevant effective concentrations/doses.

\begin{tabular}{|c|c|c|c|c|}
\hline Author/Year & $\begin{array}{l}\text { Model/ } \\
\text { Therapeutic } \\
\text { dose }\end{array}$ & $\begin{array}{c}\text { Molecular target/ } \\
\text { Form }\end{array}$ & Effect & Mechanisms of action \\
\hline $\begin{array}{l}\text { Chiba } 1998 \\
\text { Chiba et al. (1998) }\end{array}$ & $\begin{array}{l}\text { Rats } \\
0.1-1 \mathrm{mg} / \mathrm{kg} \text { oral }\end{array}$ & - & Decreases Circulating Lymphocytes & Lymphocyte homing acceleration \\
\hline $\begin{array}{l}\text { Mandala } 2002 \\
\text { Mandala et al. } \\
\text { (2002) }\end{array}$ & $\begin{array}{l}\text { Mice and Rats } \\
2.5 \mathrm{mg} / \mathrm{kg} \mathrm{IV}\end{array}$ & $\begin{array}{l}\text { S1P receptors/ } \\
\text { Phosphorylated }\end{array}$ & Rapid peripheral lymphopenia & Lymphocytes sequestration \\
\hline $\begin{array}{l}\text { Brinkmann } 2002 \\
\text { Brinkmann et al. } \\
(2002)\end{array}$ & $\begin{array}{l}\text { Rats } \\
0.1-1 \mathrm{mg} / \mathrm{kg} \text { oral }\end{array}$ & $\begin{array}{l}\text { S1P receptors } \\
(1,3-5) / \text { Phosphorylated }\end{array}$ & Decreases Circulating Lymphocytes & $\begin{array}{l}\text { Lymphocytes sequestration in secondary } \\
\text { lymphatic tissues and away from inflammatory } \\
\text { lesions and graft sites }\end{array}$ \\
\hline $\begin{array}{l}\text { Sanchez } 2003 \\
\text { Sanchez et al. } \\
\text { (2003) }\end{array}$ & $\begin{array}{l}\text { Mice } \\
50 \mu g \text { by gavage }\end{array}$ & $\begin{array}{l}\text { S1P receptors/ } \\
\text { Phosphorylated }\end{array}$ & $\begin{array}{l}\text { Decrease in VEGF-induced vascular permeability, } \\
\text { maintains the integrity and functionality of } \\
\text { endothelial cells }\end{array}$ & $\begin{array}{l}\text { stimulates VE-cadherin and } B \text {-catenin } \\
\text { translocation and assembly into cell-cell } \\
\text { junctions }\end{array}$ \\
\hline $\begin{array}{l}\text { Matloubian } 2004 \\
\text { Matloubian et al. } \\
\text { (2004) }\end{array}$ & $\begin{array}{l}\text { Mice } \\
1.1 \text { or } 1 \mathrm{mg} / \mathrm{kg} \mathrm{IP}\end{array}$ & S1P1/Phosphorylated & Lymphopenia & S1P1 downregulation \\
\hline $\begin{array}{l}\text { Bandhuvula } 2005 \\
\text { Bandhuvula et al. } \\
\text { (2005) }\end{array}$ & $\begin{array}{l}\text { Mice } \\
1 \mathrm{mg} \text { IP }\end{array}$ & $\begin{array}{l}\text { S1P Iyase/Non- } \\
\text { Phosphorylated }\end{array}$ & Lymphopenia & S1P lyase inhibition \\
\hline $\begin{array}{l}\text { Lamontagne } 2006 \\
\text { LaMontagne et al. } \\
\text { (2006) }\end{array}$ & $\begin{array}{l}\text { Mice } \\
0.3 \text { or } 3 \mathrm{mg} / \mathrm{kg} \\
\text { oral }\end{array}$ & S1P1/Phosphorylated & Inhibition of tumor-associated angiogenesis & S1P1 internalization \\
\hline $\begin{array}{l}\text { Payne } 2007 \\
\text { Payne et al. (2007) }\end{array}$ & $\begin{array}{l}\text { In vitro } \\
200-800 \text { p.m. }\end{array}$ & $\begin{array}{l}\text { cPLA2 } 2 \text { /Non- } \\
\text { Phosphorylated }\end{array}$ & Inflammation inhibition & cPLA2 $\alpha$ inhibition \\
\hline $\begin{array}{l}\text { Schmid } 2007 \\
\text { Schmid et al. } \\
(2007)\end{array}$ & $\begin{array}{l}\text { Mice } \\
10 \mathrm{mg} / \mathrm{kg} \mathrm{IP}\end{array}$ & S1P1/Phosphorylated & Inhibition of tumor-associated angiogenesis & \\
\hline $\begin{array}{l}\text { Toneli2010 } \\
\text { Tonelli et al. (2010) }\end{array}$ & $\begin{array}{l}\text { In vitro } \\
50 \mu \mathrm{M}\end{array}$ & $\begin{array}{l}\text { SK1/Non- } \\
\text { Phosphorylated }\end{array}$ & Induces apoptosis in cancer cells & ubiquitin-proteasomal degradation \\
\hline $\begin{array}{l}\text { Lahiri } 2009 \\
\text { Lahiri et al. (2009) }\end{array}$ & $\begin{array}{l}\text { In vitro } \\
25-100 \mu \mathrm{M}\end{array}$ & $\begin{array}{l}\text { Ceramide synthase/ } \\
\text { Non-Phosphorylated }\end{array}$ & 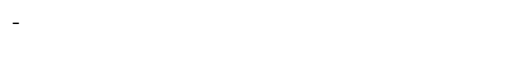 & $\begin{array}{l}\text { noncompetitive inhibition toward acyl-CoA and } \\
\text { sphinganine }\end{array}$ \\
\hline $\begin{array}{l}\text { Chen } 2013 \\
\text { Chen et al. (2013) }\end{array}$ & $\begin{array}{l}\text { Rats } \\
10 \mathrm{mg} / \mathrm{kg} \mathrm{IP}\end{array}$ & $\begin{array}{l}\text { Ceramide synthase/ } \\
\text { Non-Phosphorylated }\end{array}$ & Protects retina from light-induce degeneration & De novo Ceramide synthase inhibition \\
\hline $\begin{array}{l}\text { Dawson } 2011 \\
\text { Dawson and Qin, } \\
\text { (2011) }\end{array}$ & $\begin{array}{l}\text { In vitro } \\
10 \mu \mathrm{M}\end{array}$ & $\begin{array}{l}\text { ASMase/Non- } \\
\text { Phosphorylated }\end{array}$ & 然 & proteolytic degradation of the enzyme complex \\
\hline $\begin{array}{l}\text { Hait } 2014 \\
\text { Hait et al. (2014) } \\
\text { Hait } 2015 \\
\text { Hait et al. (2015) }\end{array}$ & $\begin{array}{l}\text { In vitro } \\
5 \mu \mathrm{M} \\
\text { Mice } \\
1 \mathrm{mg} / \mathrm{kg} \text { oral }\end{array}$ & $\begin{array}{l}\text { class I HDACs/ } \\
\text { Phosphorylated }\end{array}$ & $\begin{array}{l}\text { facilitates fear extinction memory reactivates ERa } \\
\text { expression }\end{array}$ & $\begin{array}{l}\text { Binding to active site of class I HDACs leading to } \\
\text { enzymatic activity inhibition }\end{array}$ \\
\hline $\begin{array}{l}\text { Segura-Ulate } \\
2017\end{array}$ & In vitro & HDAC/- & $\begin{array}{l}\text { reverses a-synuclein-induced downregulation of } \\
\text { BDNF }\end{array}$ & increased histone 3 acetylation \\
\hline $\begin{array}{l}\text { Segura-Ulate et al. } \\
(2017)\end{array}$ & $150 \mathrm{nM}$ & & & \\
\hline $\begin{array}{l}\text { Perla } 2020 \\
\text { Perla et al. (2020) }\end{array}$ & $\begin{array}{l}\text { In vitro } \\
7.5 \text { or } 10 \mu \mathrm{M}\end{array}$ & HDAC/- & $\begin{array}{l}\text { induces antitumor activities in medulloblastoma } \\
\text { cells }\end{array}$ & increased histone 3 acetylation \\
\hline $\begin{array}{l}\text { Ji } 2019 \\
\text { Ji et al. (2019) }\end{array}$ & $\begin{array}{l}\text { Rat } \\
2 \mathrm{mg} / \mathrm{kg} \mathrm{IP}\end{array}$ & HDAC/Phosphorylated & $\begin{array}{l}\text { M1 to M2 shift decrease pro-inflammatory factors } \\
\text { prevent ischemia-induced brain injury }\end{array}$ & prevents KLF4 to interact with HDAC1 \\
\hline $\begin{array}{l}\text { Qin } 2013 \\
\text { Qin et al. (2013) }\end{array}$ & $\begin{array}{l}\text { In vitro } \\
1 \mu \mathrm{M}\end{array}$ & $\begin{array}{l}\text { TRPM7/Non- } \\
\text { Phosphorylated }\end{array}$ & inhibits cell proliferation and migration & TRPM7 inhibition \\
\hline $\begin{array}{l}\text { Schilling } 2014 \\
\text { Schilling et al. } \\
(2014)\end{array}$ & $\begin{array}{l}\text { In vitro } \\
3 \mu \mathrm{M}\end{array}$ & TRPM7/- & $\begin{array}{l}\text { inhibits cell proliferation and polarization of } \\
\text { macrophages }\end{array}$ & TRPM7 inhibition \\
\hline $\begin{array}{l}\text { Van meeteren } \\
2008\end{array}$ & In vitro & $\begin{array}{l}\text { Autotaxin/LPA axis/ } \\
\text { Phosphorylated }\end{array}$ & reduces plasma levels of LPA & Autotaxin inhibition \\
\hline $\begin{array}{l}\text { van Meeteren } \\
\text { et al. (2008) }\end{array}$ & $\begin{array}{l}100-250 \mathrm{nM} \\
\text { Mice }\end{array}$ & & & \\
\hline $\begin{array}{l}\text { Szepanowski } \\
2016\end{array}$ & $\begin{array}{l}1 \mathrm{mg} / \mathrm{kg} \text { oral } \\
\text { Mice }\end{array}$ & & & \\
\hline $\begin{array}{l}\text { Szepanowski } \\
\text { et al. (2016) }\end{array}$ & $1 \mathrm{mg} / \mathrm{kg} \mathrm{IP}$ & Phosphorylated & LPA reduction & LPA synthesis inhibition \\
\hline $\begin{array}{l}\text { Matouska } 2003 \\
\text { Matsuoka et al. }\end{array}$ & $\begin{array}{l}\text { In vitro } \\
2.5-10 \mu \mathrm{M}\end{array}$ & $\begin{array}{l}\text { PP2A/Non- } \\
\text { Phosphorylated }\end{array}$ & $\begin{array}{l}\text { Akt and p7056k/p85S6k dephosphorylation } \\
\text { leading to cell apoptosis }\end{array}$ & $\begin{array}{l}\text { disruption of interaction of PP2A to SET, leading } \\
\text { to PP2A activation }\end{array}$ \\
\hline
\end{tabular}


cleaved caspase-3 and cytoplasmic cytochrome c expression (Zhang et al., 2016; Yin et al., 2018). A summary of the main molecular targets of fingolimod is presented in Table 2.

\section{THERAPEUTIC APPLICATIONS}

As discussed above, fingolimod affects several processes and cellular signaling pathways, making it suitable for use in diverse pathological conditions. Besides its clinical efficacy in MS, under its immunomodulatory effect and depletion of peripheral lymphocytes, the drug has been nominated as a potential therapy for other immune-related diseases. However, therapeutic indications of fingolimod are not just confined to immune-related diseases. The following sections summarize fingolimod's most studied potential therapeutic uses, ranging from immune-related diseases to CNS injuries and cancer.

\section{Immune-Mediated Diseases Multiple Sclerosis}

The only FDA-approved therapeutic use of fingolimod is for treating MS. Generally considered an autoimmune disease; it is long believed that the entering of autoreactive $\mathrm{T}$ cells into the CNS ignites inflammatory responses resulting in demyelination and axon loss (Lubetzki and Stankoff, 2014). In 1998, Chiba et al. reported that fingolimod acts through lymphocyte (mainly T cells) sequestration into main lymphoid organs by the acceleration of lymphocytes homing (Chiba et al., 1998) inducing systemic lymphopenia, and also by inhibiting $\mathrm{T}$ cell functions (Luo et al., 1999). Further investigations suggested that the drug acts differently from classical immunosuppressants (mainly calcineurin inhibitors) and suppresses in vivo immune functions mainly by acting on GPCRs (Brinkmann and Lynch, 2002; Mandala et al., 2002). With more knowledge about fingolimod mechanism of action, several in vivo preclinical experiments evaluating fingolimod efficacy in animal models of MS were conducted between 2002 and 2006 (Brinkmann and Lynch, 2002; Rausch et al., 2004; Kataoka et al., 2005; Kappos et al., 2006), confirming that inhibition of T-cell responses or their migration into the CNS plays a significant role in the anti-inflammatory effect of fingolimod (Volpi et al., 2019). The studies have been further expanded, thus revealing more information on the activity of the drug. In an attempt to reproduce the inflammatory pathology of MS, scientists widely use EAE. Magnetic resonance imaging (MRI) and histological assessments showed that in the EAE model, oral fingolimod preserved inflammatory lesions and improved neurologic function in the rat's central nervous system (Fujino et al., 2003; Rausch et al., 2004). In 2007, Balatoni et al. reported that pretreatment with fingolimod $(0.4 \mathrm{mg} / \mathrm{kg})$ prevented distractions to the visual and somatosensory evoked potentials as symptoms of the EAE. Treatment from day 25-45 inhibited EAE induced paralysis development and normalized the electrophysiological responses, alongside brain and spinal cord demyelination decrease (Balatoni et al., 2007). These encouraging results suggested fingolimod as a promising candidate for clinical studies in the treatment of MS. Subsequent successful trials proved the efficacy of fingolimod in the management of RRMS (Kappos et al., 2006; Cohen et al., 2010; Kappos et al., 2010). Eventually, in September 2010, fingolimod was approved by the FDA for use to treat relapsing-remitting MS. In May 2018, FDA extended the fingolimod approval to include the treatment of pediatric RRMS. Since FDA approval, noticeable information regarding the various effects of the drug in the management of MS has been generated. In a model of EAE, it was found that fingolimod efficacy is way more than immunological effects on lymphocytes and requires astrocytes S1P1 modulation (Choi et al., 2011). What is now certain is that fingolimod possesses more than just anti-inflammatory effects in MS (Yazdi et al., 2020). There are some conflicting data about fingolimod's ability to reduce anxiety-like behaviors in EAE models of MS. While It was previously shown that fingolimod reduces anxiety-like behavior (Bonfiglio et al., 2017), a new study fails to show anxiety-like symptoms in EAE mice models of MS (Kocovski et al., 2021). Mounting evidence suggests that fingolimod also has neuroprotective activity (Slowik et al., 2015; Sternberg et al., 2018; Yang et al., 2021) and acts as a myelin regeneration booster by affecting neural precursor cells and oligodendrocytes lineage (Coelho et al., 2007; Miron et al., 2010; Heinen et al., 2015; Qin et al., 2017). Our published studies show that fingolimod enhances oligodendrocytes lineage markers in EPI-NCSCs in vitro (Pournajaf et al., 2020) and in vivo in neural precursor cells to participate in myelin repair (Yazdi et al., 2015). We also found that following fingolimod administration in an animal model of demyelination induced by local injection of lysolecithin, inflammatory indices are reduced, and remyelination is enhanced (Yazdi et al., 2015).

\section{Other Immunomodulatory Diseases}

T-cells are considered the culprits of many other autoimmune diseases, including diabetes mellitus, psoriasis, systemic lupus erythematosus (SLE), and rheumatoid arthritis (RA) Consequently, S1P receptor modulators may have broader beneficial therapeutic effects worth considering. Indeed, preclinical surveys have found that fingolimod can halt the development of different models of RA by acting on the S1P signaling pathway (Yoshida et al., 2016; Zhu et al., 2021), neuropsychiatric SLE (Mike et al., 2018), and also ameliorate clinical and histological signs of psoriasiform dermatitis (Okura et al., 2021). Fingolimod is considered a treatment to prevent diabetes development by preserving $\beta$-cell mass (Maki et al., 2005; Moon et al., 2013). However, there are no published reports on the clinical efficacy of fingolimod in diabetes yet. Furthermore, it has been recently revealed that fingolimod may act as a prophylactic therapy through humoral immune response regulation and alleviate experimental autoimmune myasthenia gravis (EAMG). On this basis, it has been nominated as an adjunct pharmacological therapy in managing myasthenia gravis (Liu et al., 2021). In addition, other immune-related diseases like inflammatory bowel disease have shown 
promising results following the use of more selective S1P receptor modulators rather than fingolimod (Pérez-Jeldres et al., 2021).

\section{CNS Injuries}

\section{Brain Injury}

Fingolimod has protective effects in various kinds of brain injuries, including ischemic stroke, intracerebral hemorrhage, and TBI. Additionally, through suppressing both neuronal apoptosis and autophagy, the drug exerts beneficial therapeutic effects after stroke. This phenomenon is thought to be aided by the anti-inflammatory mechanisms rather than direct effects on neurons (Wei et al., 2011). In a study performed by Kraft et al., in 2013, they compared the effect of $1 \mathrm{mg} / \mathrm{kg}$ fingolimod on the ischemic stroke in wild type and Rag1 $1^{-/-}$mice (that lack T cells and $\mathrm{B}$ cells and are profoundly protected from ischemic neurodegeneration in the transient middle cerebral artery occlusion (tMCAO) model). They found that fingolimod caused more minor strokes and improved functional outcomes in wild-type mice. However, it failed to reduce infarct volume or improve function in $\mathrm{Rag}^{-/-}$mice (Kraft et al., 2013). They also showed that fingolimod could diminish thrombosis formation and microvascular dysfunction. They concluded that lymphopenia induction and consequent microvascular thrombosis reduction are the principal fingolimod effects in stroke (Kraft et al., 2013). Since fingolimod reduces platelet aggregation and some coagulation parameters, it has been proposed as an adjunct treatment in ischemic conditions (Zhao Z. et al., 2017). In different models of stroke and TBI, alongside a decrease in circulating lymphocytes, fingolimod reduces inflammatory cytokines like TNFa, IL-1 $\beta$ and enhances anti-inflammatory cytokines including IL-6 and TGF $\beta$ (Liesz et al., 2011; Dong et al., 2018; Ji et al., 2019). Fingolimod attenuated early accumulation of endothelialmonocyte activating polypeptide II (EMAP-II $(+)$ and major histocompatibility complex class II (MHC-II $(+)$ reactive monocytes following TBI, that candidate the drug to inhibit brain inflammatory response after TBI (Zhang et al., 2007). Activating PP2A by fingolimod leads to dephosphorylation and activation of mRNA-destabilizing protein tristetraprolin and reduces the production of TNF- $\alpha$, IL- 6 , and IL-8 in early brain injury (Yin et al., 2018). Anti-inflammatory effects of fingolimod $(0.5 \mathrm{mg} / \mathrm{kg})$ after TBI or ischemic stroke also occurs via restoration of the neurovascular unit by decreasing endothelial cell apoptosis and attenuating the activation of astrocytes (Cheng et al., 2021) or preventing the tight junction protein redistribution (Wang Z. et al., 2020). Attenuation of iron deposition is also an outcome of fingolimod use in intracerebral hemorrhage (Yang et al., 2019). Inactivation of microglia/ macrophage or modulating microglia toward M2 polarization via STAT3 pathway also has been taken into account for fingolimod beneficial effects in models of stroke or TBI (Czech et al., 2009; Moon et al., 2015; Gao et al., 2017; Qin et al., 2017). S1PR1 activation is another proposed mechanism for reducing neuronal injury after ischemic stroke in rats (Hasegawa et al., 2013). However, although experimental stroke prognosis improves by fingolimod activation of S1P receptors, this is not the only protective effect of fingolimod (Hasegawa et al., 2017).
However, there are also doubts about the effectiveness of fingolimod treatment in the brain injury context. Herz et al., in 2018 reported that a single injection of fingolimod $(1 \mathrm{mg} / \mathrm{kg})$ exacerbates hypoxic-ischemic brain injury in neonatal rats. Concomitant with the increase in the infiltration of innate immune cells, fingolimod significantly reduced cerebral infiltration of $\mathrm{CD} 4 \mathrm{~T}$ cells, leading to provoked brain injury (Herz et al., 2018). Parts of neuroprotective effects of fingolimod after TBI are through the activation of the PI3K/Akt pathway and autophagy (Zhang et al., 2016). How fingolimod regulates PI3K/ Akt pathway is not clearly known. It has been reported that phosphorylated fingolimod acts through S1PR3 to inhibit the TLR2/4-PI3K-NFkB signaling pathway (Dong et al., 2018). Affecting PTEN as PI3K/Akt regulator is another proposed mechanism (Zhang and Wang, 2020), yet further investigations have to be performed to unravel the exact mechanism. The promising results of fingolimod in different models of brain injury led to its use in clinical trials. A clinical trial in acute ischemic stroke (NCT04675762) showed that 3 days combination of $0.5 \mathrm{mg}$ fingolimod with alteplase at the very first hours of ischemic stroke onset diminished reperfusion injury. The decrease in reperfusion injury was parallel with improving patients' clinical outcomes (Zhu et al., 2015). Currently, two other clinical trials evaluate the effects of fingolimod in endovascular treatment for acute ischemic stroke (NCT04629872) and as a treatment for cerebral edema after intracerebral hemorrhage (NCT04088630). Presented in Table $\mathbf{3}$ is a summary of fingolimod mechanisms of action in various experimental models of brain injury.

\section{Spinal Cord Injury}

With the knowledge of the immunomodulatory actions of fingolimod, its effects in spinal cord injury (SCI) have also been explored. Inflammation is a pivotal component of secondary injury following SCI, with numerous cells involved as mediators, including astrocytes, resident microglia, infiltrating immune cells, and endothelial cells (Hausmann, 2003). The release of inflammatory cytokines in or near the SCI site activates the immune cells and triggers them to move toward the lesion area, ultimately inducing an inflammatory response (Jones and Ren, 2016). The use of fingolimod treatment led to a drastic reduction of T-cell infiltration into the SCI lesion site at four and 7 days post-injury while not influencing other inflammatory cell populations. In the treated animals, better functional performance was following higher white matter sparing at the lesion epicenter. Improved bladder function and lower incidence of hemorrhagic cystitis were also observed compared to the control group (Lee et al., 2009). In another study, after rat SCI, functional recovery improved after combining $0.5 \mathrm{mg} / \mathrm{kg}$ fingolimod and tacrolimus. The combination therapy could also enhance electrophysiological results evaluated via amplitude and latency of somatosensory evoked potentials (Zhang et al., 2009). In a study by Norimatsu et al., fingolimod improved motor function after SCI and induced lymphopenia, reduced vascular permeability, T-cell infiltration, and astrocyte accumulation into the injury site while not affecting inflammatory cytokines, highlighting the immune-independent 
TABLE 3 | Summary of studies evaluating the effect of fingolimod in brain injuries.

Molecular findings

Histologic and clinical

findings

LEMAP-II+ and MHC-\| +

monocytes

|lL16(+) cells

Zhang 2008

(weight drop)

TBI (Weight drop)

Zhang et al. (2008)

Shichita 2009

Shichita et al.

(2009)

Czech $2009 \quad$ Focal cerebral ischemia

Czech et al. (2009)

Hashegawa 2010

Hasegawa et al.

(2010)

Wei 2011

Wei et al. (2011)

Leisz 2011

Liesz et al. (2011)

Rolland 2011

Rolland et al.

(2011)

Pfeilschifter 2011

Pfeilschifter et al.

(2011)

Rolland 2013

Rolland et al.

(2013)

Brunkhorst 2013

Brunkhorst et al.

(2013)

Campos 2013

Campos et al.

(2013)

Kraft 2013

Kraft et al. (2013)

Hashegawa 2013

Hasegawa et al.

(2013)

Mencl 2014

Mencl et al. (2014)

\section{Lu 2014}

Lu et al. (2014)

Moon 2015

Moon et al. (2015)

Schuhmann 2016

Schuhmann et al

(2016)

Schlunk 2016

Schlunk et al.

(2016)

Nazari $2016 \quad$ MCAO

Nazari et al. (2016)
Cerebral ischemia-reperfusion

Ischemic stroke

Focal cerebral ischemia

Permanent and transient cortical ischemia

Intracerebral hemorrhage

(collagenase)

Ischemic stroke (tMCAO)

Intracerebral hemorrhage

(collagenase)

$\downarrow$ Infiltrating T lymphocytes

No change in macrophage

infiltration

Neutrophils

$\downarrow$ Activated macrophage/microglia

$\downarrow$ Circulating blood leukocytes

$\uparrow$ Akt and ERK-1 phosphorylation

$\uparrow \mathrm{Bcl} 2$

$\downarrow$ Cleaved caspase 3

$\downarrow$ Activated macrophage/microglia

$\downarrow$ Inflammation

$\downarrow$ Neutrophil infiltration

لICAM-1-positive blood vessels

LLymphocyte brain invasion

$\downarrow I L-1 \beta$ and IFN- $\gamma$

$\uparrow I L-6$ and TNF- $\alpha$

$\downarrow$ Lymphocytes

$\downarrow($ ICAM-1), (INF- $\gamma)$, and (IL-17)

Photothrombotic stroke

Ischemic stroke

MCAO

TBI (Focal cortical cryolesion)

Intracerebral hemorrhage (collagenase)

MCAO

tMCAO

Intracerebral hemorrhage $\uparrow$ Postsynaptic densities

$\uparrow$ VEGFa

$\downarrow$ Hemorrhagic transformation (in

combination with tissue

Plasminogen Activator)

$\downarrow$ Lymphocyte circulation

$\downarrow$ Microvascular thrombosis

$\downarrow$ S1PR1 expression on neurons

$\downarrow$ Circulating lymphocytes

No change in CD68 (a marker for macrophage and microglia)

$\downarrow$ Microglial activation and astrogliosis

$\downarrow$ TNF- $\alpha$

No change in astrogliosis, BDNF

expression, and synaptogenesis

No change in MMP-9

$\uparrow$ LTP magnitude without any effects on presynaptic plasticity and neurotransmitter release probability $\uparrow$ Neurologic function

$\downarrow$ apoptotic cell death

$\downarrow$ Infarct volume

$\uparrow$ Neurologic function

$\downarrow$ Edema

$\downarrow$ Infarct size

$\downarrow$ Neurological deficit

$\downarrow$ Brain water content

$\downarrow$ Apoptotic cell death

No change in infarct volume and

$\downarrow$ Brian edema

$\uparrow$ Neurological function

$\downarrow$ Lesion size

$\downarrow$ pulmonary infections

$\uparrow$ Neurological function

$\downarrow$ Brain edema

$\downarrow$ Brain atrophy and neurona

cell death

\Infarct volume

$\downarrow$ Neurological deficits

$\downarrow$ Stroke size

$\uparrow$ Functional outcome

$\uparrow$ Cerebral perfusion

$\uparrow$ Neurological function

$\downarrow$ Infarct volume

No change in lesion size,

functional outcomes, and BBB disruption

$\downarrow$ Edema, apoptosis and brain atrophy

$\uparrow$ Neurologic function

$\downarrow$ Infarct volume

$\downarrow$ Motor deficits

No change in

mortality,neurological

outcomes, and edema

$\downarrow$ Lesion volume

$\uparrow$ Memory behavioral dysfunction

$\uparrow$ Functional outcomes
Proposed

mechanisms of action

Activation of Akt and ERK via S1PR1, which prevented apoptosis

Fingolimod might decrease tissue damage by limiting the levels of cytotoxic agents, rather than by a direct neuroprotective effect

Fingolimod does not aggravate immune depression after stroke despite reducing number of circulating leukocytes Fingolimod reduced cerebral inflammation by reducing brain infiltration of T-lymphocytes

Lymphocytopenia induction

Fingolimod reduced neuronal injury possibly via S1PR1 activation

Protective effects of fingolimod may involve mechanisms other than inflammation

Key mode of fingolimod action in stroke is the reduction of microvascular thrombosis

Fingolimod has no beneficial effects in the acute phase of experimental $\mathrm{ICH}$

Fingolimod improved the memory performance after MCAO by LTP induction via post-synaptic mechanism (Continued on following page) 
TABLE 3 | (Continued) Summary of studies evaluating the effect of fingolimod in brain injuries.

Author/Year
Zhang 2016
Zhang et al. (2016)
Gao 2017
Gao et al. (2017)
Liu 2017
Liu et al. (2017)
Qin 2017
Hasegawa et al.
Ro17)
(2017)
Rolland 2017

Neonatal germinal matrix hemorrhage

Subarachnoid hemorrhage

White matter (WM) ischemic injury (bilateral carotid artery stenosis)

Li 2017
Li et al. (2017)
Herz 2018
Herz et al. (2018)
Dong 2018
Dong et al. (2018)
Salas-Perdomo
2019
Salas-Perdomo
et al. (2019)
Shang 2020
Shang et al. (2020)
Li 2020

Ischemic stroke

Hypoxic-ischemic $(\mathrm{HI})$ brain injury

In vitro model of cerebral ischemia and reperfusion injury, oxygenglucose deprivation (OGD)

Ischemia/reperfusion

Photothrombotic (PT) Ischemic stroke

TMCAO in diabetic mice
Molecular findings

Histologic and clinica findings

$\downarrow$ Cleaved caspase 3, PARP, Bax $\uparrow$ Neurobehavioral function and cytochrome $\mathrm{C}$

$\uparrow \mathrm{Bcl}-2$ and $\mathrm{Bcl}-\mathrm{xL}$ and

mitochondrial cytochrome C

$\uparrow$ Phospho-Akt

个LC3-II and Beclin 1

$\downarrow p 62$

$\downarrow$ Infiltrated T lymphocytes and NK

个percentage of regulatory $\mathrm{T}$ (Treg)

cells and IL-10

$\uparrow M 2 / M 1$ microglia

$\downarrow$ Inflammatory cytokines

$\downarrow$ Micro vesicle

$\downarrow$ amoeboid-like cells with P2X7R-ir

$\downarrow I L-1 \beta$

$\downarrow$ Phosphorylated p38

IGFAP-ir cells

$\uparrow$ ZO1, Occludin, and Claudin-3

Expression

$\uparrow$ Akt phosphorylation

$\uparrow$ Rac activation

IMicroglial activation

$\uparrow$ Oligogenesis and OPCs

maturation

IIL- $1 \beta$ and TNF- $\alpha$

$\uparrow I L-13$ and TGF- $\beta$

\LC3-II and Beclin1

†mTOR and p70s6K

CD4 \&CD8 Tcells

$\downarrow M A P 2$ and MBP

\HMGB1 \&TNF- $\alpha$

$\downarrow$ TLR2

$\downarrow$ PI3K phosphorylation

$\downarrow N F-\kappa B$ activation

\lymphocyte infiltration

$\downarrow \beta$-catenin degradation

No change in Evans blue

extravasation

$\downarrow C D 16$ and NOS

$\uparrow$ CD206 and Arg-1

$\downarrow Z O-1$

$\downarrow$ Occludin

$\downarrow$ S1PR1 protein levels

$\uparrow \mathrm{Bcl}-2 / \mathrm{Bax}$ Ratio

$\downarrow \mathrm{TNF} \alpha$

$\downarrow$ lba1

$\downarrow$ CD68-positive macrophages

$\uparrow Z \mathrm{O}-1$ and VE-cadherin proteins ate cells lamellipodia

$\downarrow$ Brain edema

$\downarrow$ Apoptotic cell death

$\uparrow$ Neurological functions

$\downarrow$ Brain edema

$\downarrow$ BBB damage

$\downarrow$ Apoptotic neuron death

$l$ long-term neurocognitive

loss

$\downarrow$ Brain water content

$\downarrow$ Neurological deficits

$\downarrow$ Brain edema the disruption of Ranvier's nodes

$\downarrow$ OPC apoptosis differentiation

$\downarrow$ infarct volumes $\downarrow$ neuronal apoptosis

$\downarrow$ Functional deficits

$\uparrow$ Brain tissue injury

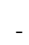

Neuronal loss

$\uparrow$ Motor function

$\downarrow$ Mortality rate

No change in neurologica score and infarct volume $\uparrow$ Brain edema

$\downarrow$ Mortality $\downarrow$ Infarct Size $\uparrow$ Functional Recovery

$\downarrow$ Apoptotic cell death
Proposed

mechanisms of action

Fingolimod reduced TBI neuronal apoptosis via Activating modulation of PI3K/Akt and autophagy

$\uparrow$ Neurobehavioral outcomes

performance and $\downarrow$ brain tissue

$\downarrow$ Cognitive decline ameliorate

$\uparrow$ Oligodendrocytes survival and
Fingolimod administration extensively modulates multiple immunoinflammatory responses

Fingolimod treatment tempered acute post-hemorrhagic BBB disruption via the activation of the S1PR1/Akt/Rac1 pathway

Fingolimod reduction of injury was associated with pleiotropic actions of the drug

Fingolimod modulated microglia toward M2 polarization via STAT3 pathway

Fingolimod suppresses neuronal autophagy through the mTOR/p70S6K pathway

Peripheral T Cell depletion by fingolimod Exacerbates hypoxic-ischemic brain injury in neonatal mice

Fingolimod acts on S1PR3 to regulate the inflammatory cascades via inhibiting $\mathrm{PI}$ KK/NFKB signaling pathway

Fingolimod attenuated HT after cerebral ischemia/reperfusion in a lymphocyteindependent fashion

Fingolimod treatment could skew microglial polarization directly to the M2 phenotype

Due to negative impact of fingolimod on BBB integrity, it should be used with caution for ischemic stroke with diabetic comorbidity

Fingolimod protected BBB integrity by preventing the redistribution of lamellipodia-located tight and adherens junctions into the cytoplasm via S1PR1 receptor signaling

(Continued on following page) 
TABLE 3 | (Continued) Summary of studies evaluating the effect of fingolimod in brain injuries.

\begin{tabular}{|c|c|c|c|c|}
\hline Author/Year & Model & Molecular findings & $\begin{array}{l}\text { Histologic and clinical } \\
\text { findings }\end{array}$ & $\begin{array}{c}\text { Proposed } \\
\text { mechanisms of action }\end{array}$ \\
\hline $\begin{array}{l}\text { Wang } 2020 \\
\text { Wang et al. } \\
(2020 \mathrm{a})\end{array}$ & Subarachnoid Hemorrhage (SAH) & $\begin{array}{l}\uparrow \mathrm{ERK} 1 / 2 \\
\downarrow I L-6 \text { and } \mathrm{TNF} \alpha \\
\uparrow I L-10 \text { \&TGF- } \beta 1 \\
\uparrow T r e g \text { cell } \\
\downarrow N K \text { cells }\end{array}$ & $\begin{array}{l}\downarrow \text { Neuroinflammation } \\
\uparrow \text { Neurologic function } \\
\downarrow \text { Brain water content }\end{array}$ & - \\
\hline $\begin{array}{l}\text { Diaz Diaz } 2021 \\
\text { Diaz Diaz et al. } \\
(2020)\end{array}$ & $\begin{array}{l}\text { Intracerebral hemorrhage } \\
\text { (collagenase) }\end{array}$ & $\begin{array}{l}\downarrow \text { Circulating lymphocytes }\left(\mathrm{CD}^{+} \text {, }\right. \\
\left.\mathrm{CD}^{+} \text {, and } \mathrm{CD}^{+}\right)\end{array}$ & $\begin{array}{l}\text { } \text { Survival } \\
\text { No change in lesion size and } \\
\text { functional outcomes }\end{array}$ & - \\
\hline $\begin{array}{l}\text { Cheng } 2021 \\
\text { Cheng et al. (2021) }\end{array}$ & TBI (Weight drop) & $\begin{array}{l}\uparrow \text { Occludin and claudin-5 } \\
\text { \ERK1/2 } \\
\text { \S1PR1 } \\
\downarrow \text { Activated microglia and astrocytes }\end{array}$ & $\begin{array}{l}\downarrow \text { Endothelial cell apoptosis } \\
\uparrow \text { Neurologic function } \\
\uparrow \text { Survival rate } \\
\uparrow \text { Neurologic function } \\
\downarrow \text { BBB breakdown }\end{array}$ & - \\
\hline
\end{tabular}

actions of fingolimod (Norimatsu et al., 2012). In another study, it was shown that fingolimod reduces astrocyte migration and proliferation. After SCI, local delivery of fingolimod with polycaprolactone (PCL) membrane attenuated neuron loss, reduced astrocytes accumulation, and lymphocytes infiltration into the injury site leading to functional recovery (Wang et al., 2015). Neuropathic pain, systemic and local inflammation, size of the damaged area, and astrogliosis after SCI was significantly reduced by $1.5 \mathrm{mg} / \mathrm{kg}$ fingolimod, administered $24 \mathrm{~h}$ after injury, resulting in motor recovery. Induction of lymphopenia and preservation of $\mathrm{BBB}$ are also linked to fingolimod's beneficial effects in enhancing survival and allodynia amelioration (Yamazaki et al., 2020). However, unlike brain injuries, the number of studies evaluating the effects of fingolimod in SCI are scarce, so the underlined mechanisms of fingolimod action are not yet fully understood.

\section{CNS Diseases}

\section{Alzheimer's Disease}

As the multimodal abilities of fingolimod and its efficacy and safety in MS are well established, its use in other neurodegenerative diseases such as Alzheimer's disease (AD) has been considered. In $\mathrm{AD}$, where insoluble fibrillar amyloid $\beta(A \beta)$ containing plaques are considered the main culprits, known as the most common cause of dementia pathogenesis, S1P metabolism and signaling imbalance are also involved (Angelopoulou and Piperi, 2019). S1P activation has been shown protective in different $\mathrm{AD}$ models by preserving neurons and counteracting AD's induced memory loss (AsleRousta et al., 2013; Hemmati et al., 2013; Takasugi et al., 2013). We have previously shown that chronic administration of $1 \mathrm{mg} / \mathrm{kg}$ fingolimod for 14 days causes significant mitigation in learning and memory loss induced by $\mathrm{A} \beta$ (42) and preserved hippocampal neurons from damage (Asle-Rousta et al., 2013). The beneficial effects of fingolimod in the $\mathrm{AD}$ context were attributed to central S1P modulation and downregulation of ceramide metabolism genes (Asle-Rousta et al., 2014; Joshi et al., 2017; Jęśko et al., 2020). However, in the report by Takasaki et al., a decrease in $\mathrm{A} \beta$ production in cultured neurons was S1PR1 and Gi independent (Takasugi et al.,
2013). Upregulation in neurotrophic factors is one of the mechanisms behind the neuroprotective effects of fingolimod in AD (Fukumoto et al., 2014). In 2013, Doi and others found that fingolimod-P can suppress Amyloid $\beta$-induced neurotoxicity in primary mouse cortical neurons by enhancing BDNF expression and acting on TrkB/ERK1/2 signaling pathway (Doi et al., 2013). Recently, it has been shown that with the aid of BDNF, $10 \mathrm{nM}$ fingolimod can modulate dysregulated dendritic architecture in primary hippocampal neurons (Patnaik et al., 2020). Moreover, fingolimod can downregulate AD's neuroinflammation by reducing activated microglia, astrocytosis, and plaque density (Aytan et al., 2016; Kartalou et al., 2020). Antineuroinflammatory effects of the fingolimod on microglia and astrocytes also can rescue synaptic pathology in $\mathrm{AD}$ (Kartalou et al., 2020). Another mechanism for fingolimod reduction in $A \beta$ neurotoxicity is the relocation of neurotoxic NMDA receptors from the extra-synaptic area to synapses and altering their ratio. This ratio change leads to a decrease in neuronal calcium responsiveness to neurotoxic soluble $A \beta$ 1-42, making neurons resistant to changes of calcium homeostasis (Joshi et al., 2017). Since the lower doses of fingolimod $(0.03 \mathrm{mg} / \mathrm{kg} / \mathrm{day})$ in an AD model in mice could also rescue memory loss and reduce activated microglia/astrocytes alongside the restoration of hippocampal GABA levels without inducing lymphopenia, it was suggested that therapeutic benefits of fingolimod are not related to lymphopenia (Carreras et al., 2019). In CNS tissue affected by $\mathrm{AD}, \mathrm{PP} 2 \mathrm{~A}$ activity is reduced to $50 \%$ (Clark and Ohlmeyer, 2019). So, the PP2A activation ability of fingolimod may also be considered a therapeutic clue in AD. The accumulating data suggest the potential beneficial effects of fingolimod in $\mathrm{AD}$ treatment.

\section{Parkinson's Disease}

Fingolimod can also attenuate 6-hydroxydopamine or rotenoneinduced neurotoxicity used as models to simulate Parkinson's disease (PD) pathology. Fingolimod $(0.5 \mathrm{mg} / \mathrm{kg})$ reduced neuroinflammation and preserved motor function by reducing apoptosis, dampening astrogliosis, and enhancing ERK 1/2 signaling phosphorylation (Zhao P. et al., 2017; Ren et al., 2017). Enhanced BDNF and S1PR1 expression are also 
involved in the fingolimod neuroprotection (Vidal-Martinez et al., 2019; Pépin et al., 2020). In a 1-methyl-4-phenyl-1,2,3,6tetrahydropyridine (MPTP) mouse model of the PD, $1 \mathrm{mg} / \mathrm{kg}$ fingolimod also exerts neuroprotection and enhanced motor function related to the S1PR/Akt kinase signaling pathways (Motyl et al., 2018). Investigations revealed that upregulation of protective micro RNAs (miRNAs) is another proposed mechanism of action for fingolimod. These miRNAs can downregulate alpha-synuclein, reduce apoptosis and thus be beneficial in alleviating PD complications (Vargas-Medrano et al., 2019). Fingolimod ( $2 \mathrm{mg} / \mathrm{kg})$ has been reported to reduce microglial activation induced by MPTP in vivo and in 1-methyl-4-phenylpyridinium (MPP) treated BV-2 microglial cells. Moreover, in MPP + -treated BV-2 cells and primary microglia, fingolimod caused a significant reduction in phosphorylation of $\mathrm{PI} 3 / \mathrm{K} / \mathrm{Akt} / \mathrm{GSK} 3 \beta$ signaling pathway, reduced ROS generation and p65 phosphorylation by inhibition of NLRP3 inflammasome indicating potential strategy against PD (Yao et al., 2019). However, there is no consensus about the neuroprotective functions of fingolimod, as Koming et al. reported there was no neuroprotection after fingolimod pretreatment in an MPTP model of Parkinson's disease, nor was there any sustainable BDNF enhancement (Komnig et al., 2018).

\section{Epilepsy}

With proven benefits in preserving neurons and BBB integrity and the ability to reduce inflammation, fingolimod was investigated as a potential therapy for epilepsy (Bascuñana et al., 2020). Gao et al. were the first to report that $1 \mathrm{mg} / \mathrm{kg}$ fingolimod has anti-inflammatory and antiepileptogenic effects in a lithium-pilocarpine experimental model of epilepsy. In fingolimod-treated rats, reduced IL-1 $\beta$ and TNFa levels in the hippocampus were accompanied by decreased incidence, duration, frequency, and severity of spontaneous convulsions (Gao et al., 2012). They later showed that through S1PR1 inhibition, $1 \mathrm{mg} / \mathrm{kg}$ fingolimod reduces seizure-induced P-glycoprotein (P-gp) overexpression (Gao et al., 2018). We found that fingolimod enhances remyelination in the pentylenetetrazol-induced kindling model, along with reducing hippocampal neuronal death (Gol et al., 2017). In an animal model of genetic absence epilepsy, fingolimod ( $1 \mathrm{mg} / \mathrm{kg})$ showed transient antiepileptic effects and longer-lasting anti-cognition decline (Leo et al., 2017). During the chronic epileptic phase of the mouse kainate model, $6 \mathrm{mg} / \mathrm{kg}$ of the drug also showed neuroprotective and anti-gliotic effects besides reducing seizure frequency (Pitsch et al., 2019). Fingolimod's ability to reduce seizure severity, prevent anxiety-like behavior, and reverse cognition impairment has also been shown in a more recent study in a rat model of the hypoxia-induced seizure (Najafian et al., 2021). Based on the cumulated experimental evidence so far, it would certainly be worth investigating the potential benefits of fingolimod as adjuvant therapy in drug-resistant epilepsy.

\section{Other CNS Diseases}

As neuroprotective and anti-inflammatory effects of fingolimod emerge, the drug proposed as a potential treatment in diverse neurologic diseases, including Huntington's (Di Pardo et al., 2014), Amyotrophic lateral sclerosis (ALS) (Potenza et al., 2016), Rett syndrome (Deogracias et al., 2012), and schizophrenia (Francis et al., 2020). The phase 2 clinical trial for the effects of fingolimod on schizophrenia (NCT01786174) has been completed. For ALS, The results of a phase IIa trial of fingolimod demonstrated short-term safety and tolerability of $0.5 \mathrm{mg}$ /day (Berry et al., 2017). However, it remains to be seen whether further clinical trials will eventually lead to the drug's approval in ALS.

\section{Cancer}

Since its discovery, a substantial number of studies have been conducted to explore the potential effects of fingolimod on uncontrolled cell proliferation, apoptosis, and cancer. Initially, in 1996 Suzuki et al. reported apoptotic lymphocyte reduction in rat spleen cells (Suzuki et al., 1996). Next, the Matsuda group described fingolimod-induced apoptosis in WR19L mouse lymphoma cells in vitro (Matsuda et al., 1998). In 2002, Permpongkosol reported antiproliferative effects of fingolimod in DU145 human prostate cancer cells (Permpongkosol et al., 2002). However, the most exciting piece of information regarding the possible antitumor effects of fingolimod came through Azuma's publication showing the efficacy of fingolimod in inhibiting JygMC (A) breast cancer cells under both in vitro (2 or $10 \mu \mathrm{M})$ and in vivo $(5 \mathrm{mg} / \mathrm{kg}$ in subcutaneous xenograft bearing nude mice) conditions. Induction of apoptosis together with reduced expression of integrins on the cancer cell surface, reduced cell adherence, and migration (metastasis) were regarded as the mechanism behind the fingolimod effect (Azuma et al., 2002). Since then, the interest and the information on the potential efficacy of fingolimod in breast cancer have been rapidly growing. Parallel with this work; fingolimod has been shown to inhibit human $\mathrm{T}$ cell leukemia Jurkat and B cell leukemia BALL-1 cells through dephosphorylation of Akt. Additionally, fingolimod has been shown to inhibit critical signaling pathways involved in tumor growth and metastasis, including mTOR, PIK3/Akt, and MAPK/ ERK signaling pathways (Chen et al., 2018; Hou et al., 2018). Activating PP2A by fingolimod (Matsuoka et al., 2003) is another critical fingolimod effect in this context. PP2A is a tumor suppressor with decreased activity in various human cancers and a prominent target in anticancer drug development. Existing reports are suggestive of the antitumor activity of fingolimod in various experimental models of cancer, including gastric (Zheng et al., 2010), colon (Nagaoka et al., 2008), pancreatic (Shen et al., 2007), liver (Hung et al., 2008), lung (Booth et al., 2019), prostate (Pchejetski et al., 2010), ovarian (Zhang et al., 2013), and breast cancers (Rupp et al., 2021). However, it has been shown that not all of these fingolimodinduced antitumor effects are S1PR related. Indeed, activation of PP2A and the inhibition of the oncoprotein SphK1 are examples of S1PR-independent effects of fingolimod (Matsuoka et al., 2003; Vessey et al., 2007). Furthermore, analysis of human multiple myeloma samples and cell lines has revealed that $5 \mu \mathrm{M}$ fingolimod induces ferroptosis (an iron-dependent type of cell death) and autophagy through the PP2A/AMPK pathways 


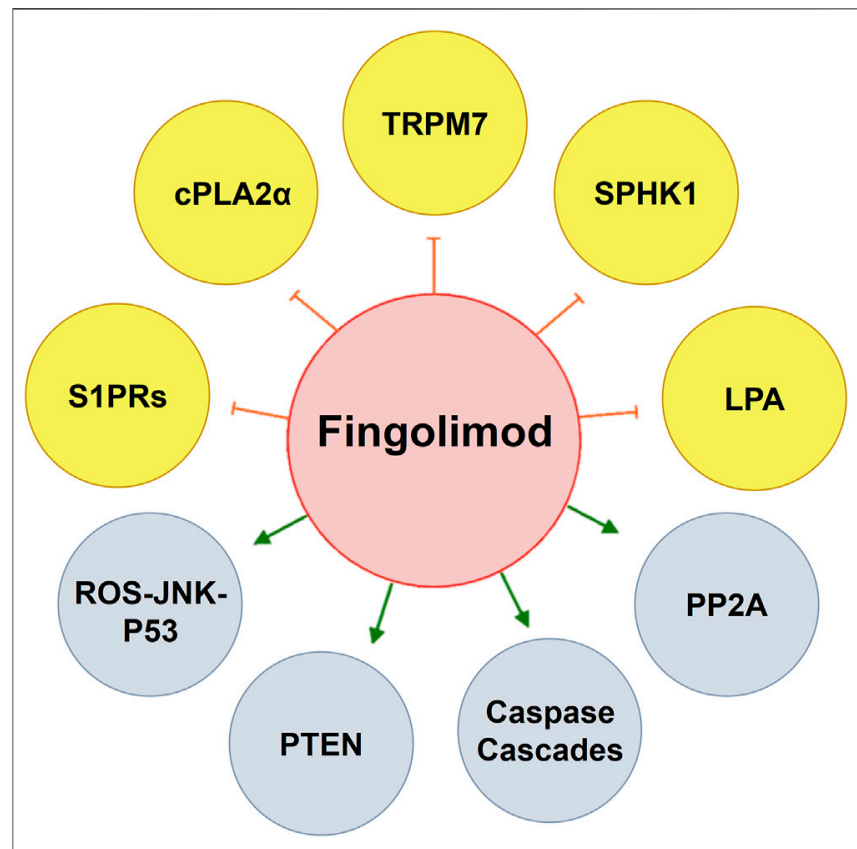

FIGURE 3 |By modulating key pathways in oncogenesis, fingolimod has the potential use for cancer therapy. Fingolimod activates PP2A that plays a principal role as a regulator of cell cycle/division and growth. Fingolimod can induce apoptotic pathways by activation of caspase cascades, enhancing PTEN which inhibits pAkt, and inducing (ROS-JNK-p53) loopdependent autophagy. By modulating S1PRs, fingolimod anti-angiogenesis activity is also a help in cancer treatment. Antiproliferative effects on fingolimod at some points occur by inhibiting TRPM7, CPLA2 $\alpha$, SPHK1, and LPA which makes the drug an interesting object in cancer research. cPLA2 $\alpha$, cytosolic phospholipase A2; LPA, lysophosphatidic acid; PP2A, protein phosphatase 2A; PTEN, phosphatase and tensin homolog; S1PR, sphingosine 1phosphate receptor; SPHK, sphingosine kinase; TRPM7, transient receptor potential cation channel, subfamily M; ROS-JNK-P53, reactive oxygen species-c-Jun N-terminal kinase-protein 53.

(Zhong et al., 2020). They also showed that fingolimod inhibits other critical regulators of ferroptosis, including Glutathione peroxidase 4 (GPX4) and soluble carrier family 7 member 11 (SLC7A11) at both the mRNA and protein levels (Zhong et al., 2020). These results are perhaps not too surprising as prior to these discoveries, it was found that S1P contributes to inflammation and cancer (Nagahashi et al., 2018). As a pleiotropic lipid mediator, S1P regulates cell survival, proliferation, migration, angiogenesis, and lymph angiogenesis together with immune cell recruitment (Nagahashi et al., 2018). The area which has attracted the most attention regarding fingolimod antitumor activity is perhaps breast cancer. S1P and another component of the S1P signaling, Sphingosine Kinase 1, are significantly upregulated in breast cancer (Nava et al., 2002; Ling et al., 2011). These recent results suggest a potential role for S1P modulators and fingolimod in the future management of breast cancer. Another potential area is the addition of fingolimod to the existing chemotherapeutic agents. Indeed, the initial experimental results here are promising and await clinical confirmation. It has also been shown that fingolimod mitigates cancer-induced bone pain and neuroinflammation in mice (Grenald et al., 2017) and alleviates bortezomib-induced neuropathic pain in rats by S1PR1 antagonism (Stockstill et al., 2018). Despite all the findings so far, the complete antitumor mechanism of fingolimod is not yet fully known and remains to be elucidated through future investigations. However, a literature review reveals that the range of concentrations and doses employed both in vitro and in vivo experiments to achieve cell or tumor growth inhibition are above and beyond the currently accepted concentrations achieved in fingolimod-treated MS patients. Therefore, it remains to be seen whether fingolimod can be effective at therapeutically acceptable doses in clinical trials in cancer patients. Figure 3 shows some of the most important targets of fingolimod in oncogenesis.

\section{OTHER S1P RECEPTOR MODULATORS}

Since fingolimod approval for MS therapy, other S1P receptor modulators have been developed. More S1PR selectivity (especially towards S1P1R) is of particular interest (Subei and Cohen, 2015). Currently, three more selective S1P receptor modulators, ozanimod, siponimod, and ponesimod, have received FDA approval (Shipley and Darais, 2015). These drugs have shown more selectivity for S1P receptors, shorter half-lives than fingolimod, and reduced adverse effects. Acting independently of phosphorylation of these second generation of S1PR modulators has led to faster onset of action (McGinley and Cohen, 2021; Roy et al., 2021). The success of S1PR modulators in MS and the extensive preclinical evidence in other diseases has opened a new era in pharmacology regarding the use of more selective and specific S1PR modulators. However, these newer S1PR modulators may also act other than S1PR modulation like fingolimod. Hence further investigations are warranted.

\section{SUMMARY}

Fingolimod has emerged as an exciting drug molecule that can be utilized in diverse pathological conditions. This phenomenon has resulted from the progressive and accelerated discoveries made on the drug's pharmacological properties. Its close structural resemblance to sphingosine is probably a principal part of its displayed effects. Conversion in the body to fingolimod 1phosphate allows the active metabolite to act as a potent sphingosine receptor modulator leading to immunomodulation through lymphocyte sequestration. As a functional antagonist of the S1PR1, fingolimod-P causes irreversible receptor downregulation, causing lymphocyte sequestration in lymphoid organs, leading to a marked decrease in circulating lymphocytes and endothelial barrier disruption.

With S1P being a pivotal molecule in intracellular signaling, the high-affinity binding of fingolimod to the S1PR1 leads to Gai/ $\mathrm{o}$ inactivation of several signaling pathways, including the PI3K/ Akt/mTOR, PI3K/Rac, STAT3, STAT1, PLC, and VEGF amongst others. Fingolimod does not seem to act through the S1PR2 due to its low affinity for the receptor. It has been proposed to act as a 
functional antagonist of S1PR3, while effects mediated through the S1PR4 are not fully elucidated. It elicits a number of its pharmacological effects through high-affinity binding to S1PR5.

In terms of pharmacological activity, fingolimod acts as an oligodendrocyte precursor cell migration inhibitor through S1PR1 and S1PR5 regulation. Fingolimod also regulates survival, differentiation, and extension of cellular processes in oligodendrocytes. As a class 1 histone deacetylase inhibitor (HDACi), it promotes therapeutic efficacy in MS and experimental models of epilepsy and cancer, particularly in breast cancer. Clinically relevant doses of fingolimod have been shown to suppress spontaneous breast tumors development, progression, and aggressiveness in laboratory animals, and this is currently an excellent area of interest. While the rationale behind this approach is sound, it remains if it does translate to a therapeutic effect in the clinic.

Another area of interest for fingolimod is enhancing BDNF expression and anti-inflammatory effects contributing to its neuroprotective activity. While this is all well established in MS, it remains to be seen if fingolimod or any of its newer analogs can elicit similar therapeutic effects in other neurodegenerative conditions. In part from BDNF enhancement.

Various studies have firmly documented the effect of fingolimod on apoptosis. It has been proven to have the capacity to induce apoptosis in various pathological conditions, a cell-type and context-dependent property. Similarly, fingolimod enhances the autophagy markers; its

\section{REFERENCES}

Abumaria, N., Li, W., and Clarkson, A. N. (2019). Role of the Chanzyme TRPM7 in the Nervous System in Health and Disease. Cell Mol Life Sci 76 (17), 3301-3310. doi:10.1007/s00018-019-03124-2

Adachi, K., Kohara, T., Nakao, N., Arita, M., Chiba, K., Mishina, T., et al. (1995). Design, Synthesis, and Structure-Activity Relationships of 2-Substituted-2-Amino-1,3Propanediols: Discovery of a Novel Immunosuppressant, FTY720. Bioorg. Med. Chem. Lett. 5 (8), 853-856. doi:10.1016/0960-894X(95)00127-F

Ahmed, D., de Verdier, P. J., Ryk, C., Lunqe, O., Stål, P., and Flygare, J. (2015). FTY720 (Fingolimod) Sensitizes Hepatocellular Carcinoma Cells to SorafenibMediated Cytotoxicity. Pharmacol. Res. Perspect. 3 (5), e00171. doi:10.1002/ prp2.171

Albert, R., Hinterding, K., Brinkmann, V., Guerini, D., Müller-Hartwieg, C., Knecht, H., et al. (2005). Novel Immunomodulator FTY720 Is Phosphorylated in Rats and Humans to Form a Single Stereoisomer. Identification, Chemical Proof, and Biological Characterization of the Biologically Active Species and its Enantiomer. J. Med. Chem. 48 (16), 5373-5377. doi:10.1021/jm050242f

Alinari, L., Mahoney, E., Patton, J., Zhang, X., Huynh, L., Earl, C. T., et al. (2011). FTY720 Increases CD74 Expression and Sensitizes Mantle Cell Lymphoma Cells to Milatuzumab-Mediated Cell Death. Blood 118 (26), 6893-6903. doi:10. 1182/blood-2011-06-363879

Amoruso, A., Blonda, M., D’Arrigo, G., Grasso, R., Di Francescantonio, V., Verderio, C., et al. (2018). Effect of Fingolimod Action on the Release of Monocyte-Derived Microvesicles in Multiple Sclerosis Patients. J. Neuroimmunol 323, 43-48. doi:10.1016/j.jneuroim.2018.07.008

Anastasiadou, S., and Knöll, B. (2016). The Multiple Sclerosis Drug Fingolimod (FTY720) Stimulates Neuronal Gene Expression, Axonal Growth and Regeneration. Exp. Neurol. 279, 243-260. doi:10.1016/j.expneurol.2016.03.012

Angelopoulou, E., and Piperi, C. (2019). Beneficial Effects of Fingolimod in Alzheimer's Disease: Molecular Mechanisms and Therapeutic Potential. Neuromolecular Med. 21 (3), 227-238. doi:10.1007/s12017-019-08558-2 effects depend on the cell context and the condition so that autophagy functions can be either pro-death or pro-survival. These fingolimod properties have been shown to account for therapeutic benefits in diverse experimental pathological conditions in laboratory animal models. On this basis, there are currently several ongoing clinical trials evaluating fingolimod in patients with MS disease or stroke.

Protein phosphatase 2 (PP2A) is another well-established target of fingolimod. By activating PP2A, fingolimod plays a principal role as a regulator of cell cycle/division and growth, apoptosis, and an inhibitor of various signal transduction pathways relevant to inflammation. Coupled with its other anti-inflammatory properties, such as inhibition of phospholipase $\mathrm{C}$, it theoretically provides the rationale for its evaluation as an anti-inflammatory agent.

Furthermore, novel fingolimod derivatives have been synthesized and are currently being evaluated for safety and selective efficacy in various diseases. It, therefore, remains to be seen if fingolimod and or its novel derivatives may gain approval in other pathological conditions and in particular in other neurodegenerative conditions.

\section{AUTHOR CONTRIBUTIONS}

MP devised the conceptual idea of the article. SP wrote the manuscript with significant intellectual inputs from LD and MJ.

Aoki, M., Kondo, A., Matsunaga, N., Honda, A., Okubo, Y., Takabe, K., et al. (2020). The Immunosuppressant Fingolimod (FTY720) for the Treatment of Mechanical Force-Induced Abnormal Scars. J. Immunol. Res. 2020, 7057195. doi:10.1155/2020/7057195

Asle-Rousta, M., Kolahdooz, Z., Dargahi, L., Ahmadiani, A., and Nasoohi, S. (2014). Prominence of central Sphingosine-1-Phosphate Receptor-1 in Attenuating A $\beta$-Induced Injury by Fingolimod. J. Mol. Neurosci. 54 (4), 698-703. doi:10.1007/s12031-014-0423-3

Asle-Rousta, M., Kolahdooz, Z., Oryan, S., Ahmadiani, A., and Dargahi, L. (2013). FTY720 (Fingolimod) Attenuates Beta-Amyloid Peptide (A $\beta 42)$-Induced Impairment of Spatial Learning and Memory in Rats. J. Mol. Neurosci. 50 (3), 524-532. doi:10.1007/s12031-013-9979-6

Aytan, N., Choi, J. K., Carreras, I., Brinkmann, V., Kowall, N. W., Jenkins, B. G., et al. (2016). Fingolimod Modulates Multiple Neuroinflammatory Markers in a Mouse Model of Alzheimer's Disease. Sci. Rep. 6, 24939. doi:10.1038/srep24939

Azuma, H., Takahara, S., Ichimaru, N., Wang, J. D., Itoh, Y., Otsuki, Y., et al. (2002). Marked Prevention of Tumor Growth and Metastasis by a Novel Immunosuppressive Agent, FTY720, in Mouse Breast Cancer Models. Cancer Res. 62 (5), 1410-1419.

Baer, A., Colon-Moran, W., and Bhattarai, N. (2018). Characterization of the Effects of Immunomodulatory Drug Fingolimod (FTY720) on Human T Cell Receptor Signaling Pathways. Sci. Rep. 8 (1), 10910. doi:10.1038/s41598-018-29355-0

Bagheri, A., Habibzadeh, P., Razavipour, S. F., Volmar, C. H., Chee, N. T., Brothers, S. P., et al. (2019). HDAC Inhibitors Induce BDNF Expression and Promote Neurite Outgrowth in Human Neural Progenitor Cells-Derived Neurons. Int. J. Mol. Sci. 20 (5), 1109. doi:10.3390/ijms20051109

Bai, L. Y., Chiu, C. F., Chiu, S. J., Chu, P. C., and Weng, J. R. (2017). FTY720 Induces Autophagy-Associated Apoptosis in Human Oral Squamous Carcinoma Cells, in Part, through a Reactive Oxygen Species/Mcl-1dependent Mechanism. Sci. Rep. 7 (1), 5600. doi:10.1038/s41598-017-06047-9

Balatoni, B., Storch, M. K., Swoboda, E. M., Schönborn, V., Koziel, A., Lambrou, G. N., et al. (2007). FTY720 Sustains and Restores Neuronal Function in the DA Rat Model of MOG-Induced Experimental Autoimmune Encephalomyelitis. Brain Res. Bull. 74 (5), 307-316. doi:10.1016/j.brainresbull.2007.06.023 
Bandhuvula, P., Tam, Y. Y., Oskouian, B., and Saba, J. D. (2005). The Immune Modulator FTY720 Inhibits Sphingosine-1-Phosphate Lyase Activity. J. Biol. Chem. 280 (40), 33697-33700. doi:10.1074/jbc.C500294200

Bascuñana, P., Möhle, L., Brackhan, M., and Pahnke, J. (2020). Fingolimod as a Treatment in Neurologic Disorders beyond Multiple Sclerosis. Drugs R. D 20 (3), 197-207. doi:10.1007/s40268-020-00316-1

Berdyshev, E. V., Gorshkova, I., Skobeleva, A., Bittman, R., Lu, X., Dudek, S. M., et al. (2009). FTY720 Inhibits Ceramide Synthases and Up-Regulates Dihydrosphingosine 1-phosphate Formation in Human Lung Endothelial Cells. J. Biol. Chem. 284 (9), 5467-5477. doi:10.1074/jbc.M805186200

Berry, J. D., Paganoni, S., Atassi, N., Macklin, E. A., Goyal, N., Rivner, M., et al. (2017). Phase IIa Trial of Fingolimod for Amyotrophic Lateral Sclerosis Demonstrates Acceptable Acute Safety and Tolerability. Muscle Nerve 56 (6), 1077-1084. doi:10.1002/mus.25733

Billich, A., Bornancin, F., Dévay, P., Mechtcheriakova, D., Urtz, N., and Baumruker, T. (2003). Phosphorylation of the Immunomodulatory Drug FTY720 by Sphingosine Kinases. J. Biol. Chem. 278 (48), 47408-47415. doi:10.1074/jbc.M307687200

Bonfiglio, T., Olivero, G., Merega, E., Di Prisco, S., Padolecchia, C., Grilli, M., et al. (2017). Prophylactic versus Therapeutic Fingolimod: Restoration of Presynaptic Defects in Mice Suffering from Experimental Autoimmune Encephalomyelitis. PLoS One 12 (1), e0170825. doi:10.1371/journal.pone.0170825

Booth, L., Roberts, J. L., Spiegel, S., Poklepovic, A., and Dent, P. (2019). Fingolimod Augments Pemetrexed Killing of Non-small Cell Lung Cancer and Overcomes Resistance to ERBB Inhibition. Cancer Biol. Ther. 20 (5), 597-607. doi:10.1080/ 15384047.2018.1538616

Brinkmann, V., Billich, A., Baumruker, T., Heining, P., Schmouder, R., Francis, G., et al. (2010). Fingolimod (FTY720): Discovery and Development of an Oral Drug to Treat Multiple Sclerosis. Nat. Rev. Drug Discov. 9 (11), 883-897. doi:10. 1038/nrd3248

Brinkmann, V., Cyster, J. G., and Hla, T. (2004). FTY720: Sphingosine 1-phosphate Receptor-1 in the Control of Lymphocyte Egress and Endothelial Barrier Function. Am. J. Transpl. 4 (7), 1019-1025. doi:10.1111/j.1600-6143.2004. 00476.x

Brinkmann, V., Davis, M. D., Heise, C. E., Albert, R., Cottens, S., Hof, R., et al. (2002). The Immune Modulator FTY720 Targets Sphingosine 1-phosphate Receptors. J. Biol. Chem. 277 (24), 21453-21457. doi:10.1074/jbc.C200176200

Brinkmann, V., and Lynch, K. R. (2002). FTY720: Targeting G-Protein-Coupled Receptors for Sphingosine 1-phosphate in Transplantation and Autoimmunity. Curr. Opin. Immunol. 14 (5), 569-575. doi:10.1016/s0952-7915(02)00374-6

Brinkmann, V. (2007). Sphingosine 1-phosphate Receptors in Health and Disease: Mechanistic Insights from Gene Deletion Studies and Reverse Pharmacology. Pharmacol. Ther. 115 (1), 84-105. doi:10.1016/j.pharmthera.2007.04.006

Brunkhorst, R., Kanaan, N., Koch, A., Ferreirós, N., Mirceska, A., Zeiner, P., et al. (2013). FTY720 Treatment in the Convalescence Period Improves Functional Recovery and Reduces Reactive Astrogliosis in Photothrombotic Stroke. PLoS One 8 (7), e70124. doi:10.1371/journal.pone.0070124

Bryan, A. M., You, J. K., McQuiston, T., Lazzarini, C., Qiu, Z., Sheridan, B., et al. (2020). FTY720 Reactivates Cryptococcal Granulomas in Mice through S1P Receptor 3 on Macrophages. J. Clin. Invest. 130 (9), 4546-4560. doi:10.1172/ jcil36068

Calis, I. U., Cosan, D. T., and Mutlu, F. (2017). Effects of S1P1 and S1P3 in ER+ and ER- Breast Cancer Cells. Anticancer Res. 37 (10), 5469-5475. doi:10.21873/ anticanres. 11976

Calise, S., Blescia, S., Cencetti, F., Bernacchioni, C., Donati, C., and Bruni, P. (2012). Sphingosine 1-phosphate Stimulates Proliferation and Migration of Satellite Cells: Role of S1P Receptors. Biochim. Biophys. Acta 1823 (2), 439-450. doi:10. 1016/j.bbamcr.2011.11.016

Camm, J., Hla, T., Bakshi, R., and Brinkmann, V. (2014). Cardiac and Vascular Effects of Fingolimod: Mechanistic Basis and Clinical Implications. Am. Heart J. 168 (5), 632-644. doi:10.1016/j.ahj.2014.06.028

Campos, F., Qin, T., Castillo, J., Seo, J. H., Arai, K., Lo, E. H., et al. (2013). Fingolimod Reduces Hemorrhagic Transformation Associated with Delayed Tissue Plasminogen Activator Treatment in a Mouse Thromboembolic Model. Stroke 44 (2), 505-511. doi:10.1161/strokeaha.112.679043

Carreras, I., Aytan, N., Choi, J. K., Tognoni, C. M., Kowall, N. W., Jenkins, B. G., et al. (2019). Dual Dose-dependent Effects of Fingolimod in a Mouse Model of Alzheimer's Disease. Sci. Rep. 9 (1), 10972. doi:10.1038/s41598-019-47287-1
Chen, H., Tran, J. T., Eckerd, A., Huynh, T. P., Elliott, M. H., Brush, R. S., et al. (2013). Inhibition of De Novo Ceramide Biosynthesis by FTY720 Protects Rat Retina from Light-Induced Degeneration. J. Lipid Res. 54 (6), 1616-1629. doi:10.1194/jlr.M035048

Chen, L., Luo, L. F., Lu, J., Li, L., Liu, Y. F., Wang, J., et al. (2014). FTY720 Induces Apoptosis of M2 Subtype Acute Myeloid Leukemia Cells by Targeting Sphingolipid Metabolism and Increasing Endogenous Ceramide Levels. PLoS One 9 (7), e103033. doi:10.1371/journal.pone.0103033

Chen, W., Ghobrial, R. M., Li, X. C., and Kloc, M. (2018). Inhibition of RhoA and mTORC2/Rictor by Fingolimod (FTY720) Induces P21-Activated Kinase 1, PAK-1 and Amplifies Podosomes in Mouse Peritoneal Macrophages. Immunobiology 223 (11), 634-647. doi:10.1016/j.imbio.2018.07.009

Cheng, H., Di, G., Gao, C. C., He, G., Wang, X., Han, Y. L., et al. (2021). FTY720 Reduces Endothelial Cell Apoptosis and Remodels Neurovascular Unit after Experimental Traumatic Brain Injury. Int. J. Med. Sci. 18 (2), 304-313. doi:10. 7150/ijms. 49066

Chiba, K. (2020). Discovery of Fingolimod Based on the Chemical Modification of a Natural Product from the Fungus, Isaria Sinclairii. J. Antibiot. (Tokyo) 73 (10), 666-678. doi:10.1038/s41429-020-0351-0

Chiba, K., Yanagawa, Y., Masubuchi, Y., Kataoka, H., Kawaguchi, T., Ohtsuki, M., et al. (1998). FTY720, a Novel Immunosuppressant, Induces Sequestration of Circulating Mature Lymphocytes by Acceleration of Lymphocyte Homing in Rats. I. FTY720 Selectively Decreases the Number of Circulating Mature Lymphocytes by Acceleration of Lymphocyte Homing. J. Immunol. 160 (10), 5037-5044.

Choi, J. W., Gardell, S. E., Herr, D. R., Rivera, R., Lee, C. W., Noguchi, K., et al. (2011). FTY720 (Fingolimod) Efficacy in an Animal Model of Multiple Sclerosis Requires Astrocyte Sphingosine 1-phosphate Receptor 1 (S1P1) Modulation. Proc. Natl. Acad. Sci. U S A. 108 (2), 751-756. doi:10.1073/pnas.1014154108

Christoffersen, C., and Nielsen, L. B. (2013). Apolipoprotein M: Bridging HDL and Endothelial Function. Curr. Opin. Lipidol. 24 (4), 295-300. doi:10.1097/MOL. ob013e328361f6ad

Chua, C. W., Lee, D. T., Ling, M. T., Zhou, C., Man, K., Ho, J., et al. (2005). FTY720, a Fungus Metabolite, Inhibits In Vivo Growth of Androgen-independent Prostate Cancer. Int. J. Cancer 117 (6), 1039-1048. doi:10.1002/ijc.21243

Chun, J., Hla, T., Lynch, K. R., Spiegel, S., and Moolenaar, W. H. (2010). International Union of Basic and Clinical Pharmacology. LXXVIII. Lysophospholipid Receptor Nomenclature. Pharmacol. Rev. 62 (4), 579-587. doi:10.1124/pr.110.003111

Clark, A. R., and Ohlmeyer, M. (2019). Protein Phosphatase 2A as a Therapeutic Target in Inflammation and Neurodegeneration. Pharmacol. Ther. 201, 181-201. doi:10.1016/j.pharmthera.2019.05.016

Clinical Trials Arena (2021). Ponesimod (Ponvory) for Multiple Sclerosis. Med. Lett. Drugs Ther. 63 (1630), 123-125.

Coelho, R. P., Payne, S. G., Bittman, R., Spiegel, S., and Sato-Bigbee, C. (2007). The Immunomodulator FTY720 Has a Direct Cytoprotective Effect in Oligodendrocyte Progenitors. J. Pharmacol. Exp. Ther. 323 (2), 626-635. doi:10.1124/jpet.107.123927

Cohen, J. A., Barkhof, F., Comi, G., Hartung, H. P., Khatri, B. O., Montalban, X., et al. (2010). Oral Fingolimod or Intramuscular Interferon for Relapsing Multiple Sclerosis. N. Engl. J. Med. 362 (5), 402-415. doi:10.1056/ NEJMoa0907839

Cristóbal, I., Manso, R., Rincón, R., Caramés, C., Senin, C., Borrero, A., et al. (2014). PP2A Inhibition Is a Common Event in Colorectal Cancer and its Restoration Using FTY720 Shows Promising Therapeutic Potential. Mol. Cancer Ther. 13 (4), 938-947. doi:10.1158/1535-7163.mct-13-0150

Cui, L., Li, C., Gao, G., Zhuo, Y., Yang, L., Cui, N., et al. (2019). FTY720 Inhibits the Activation of Pancreatic Stellate Cells by Promoting Apoptosis and Suppressing Autophagy via the AMPK/mTOR Pathway. Life Sci. 217, 243-250. doi:10.1016/ j.lfs.2018.12.019

Cyster, J. G., and Schwab, S. R. (2012). Sphingosine-1-phosphate and Lymphocyte Egress from Lymphoid Organs. Annu. Rev. Immunol. 30, 69-94. doi:10.1146/ annurev-immunol-020711-075011

Czech, B., Pfeilschifter, W., Mazaheri-Omrani, N., Strobel, M. A., Kahles, T., Neumann-Haefelin, T., et al. (2009). The Immunomodulatory Sphingosine 1phosphate Analog FTY720 Reduces Lesion Size and Improves Neurological Outcome in a Mouse Model of Cerebral Ischemia. Biochem. Biophys. Res. Commun. 389 (2), 251-256. doi:10.1016/j.bbrc.2009.08.142 
David, O. J., Kovarik, J. M., and Schmouder, R. L. (2012). Clinical Pharmacokinetics of Fingolimod. Clin. Pharmacokinet. 51 (1), 15-28. doi:10. 2165/11596550-000000000-00000

Dawson, G., and Qin, J. (2011). Gilenya (FTY720) Inhibits Acid Sphingomyelinase by a Mechanism Similar to Tricyclic Antidepressants. Biochem. Biophys. Res. Commun. 404 (1), 321-323. doi:10.1016/j.bbrc.2010.11.115

De Palma, R. M., Parnham, S. R., Li, Y., Oaks, J. J., Peterson, Y. K., Szulc, Z. M., et al. (2019). The NMR-Based Characterization of the FTY720-SET Complex Reveals an Alternative Mechanism for the Attenuation of the Inhibitory SET-Pp2a Interaction. FASEB J. 33 (6), 7647-7666. doi:10.1096/fj.201802264R

Deogracias, R., Yazdani, M., Dekkers, M. P., Guy, J., Ionescu, M. C., Vogt, K. E., et al. (2012). Fingolimod, a Sphingosine-1 Phosphate Receptor Modulator, Increases BDNF Levels and Improves Symptoms of a Mouse Model of Rett Syndrome. Proc. Natl. Acad. Sci. U S A. 109 (35), 14230-14235. doi:10.1073/ pnas.1206093109

Di Pardo, A., Amico, E., Favellato, M., Castrataro, R., Fucile, S., Squitieri, F., et al. (2014). FTY720 (Fingolimod) Is a Neuroprotective and Disease-Modifying Agent in Cellular and Mouse Models of Huntington Disease. Hum. Mol. Genet. 23 (9), 2251-2265. doi:10.1093/hmg/ddt615

Diaz Diaz, A. C., Shearer, J. A., Malone, K., and Waeber, C. (2020). Acute Treatment with Fingolimod Does Not Confer Long-Term Benefit in a Mouse Model of Intracerebral Haemorrhage. Front. Pharmacol. 11, 613103. doi:10.3389/fphar.2020.613103

Doi, Y., Takeuchi, H., Horiuchi, H., Hanyu, T., Kawanokuchi, J., Jin, S., et al. (2013). Fingolimod Phosphate Attenuates Oligomeric Amyloid $\beta$-induced Neurotoxicity via Increased Brain-Derived Neurotrophic Factor Expression in Neurons. PLoS One 8 (4), e61988. doi:10.1371/journal.pone.0061988

Dolcetti, E., Bruno, A., Guadalupi, L., Rizzo, F. R., Musella, A., Gentile, A., et al. (2020). Emerging Role of Extracellular Vesicles in the Pathophysiology of Multiple Sclerosis. Int. J. Mol. Sci. 21 (19), 7336. doi:10.3390/ijms21197336

Dominguez-Villar, M., Raddassi, K., Danielsen, A. C., Guarnaccia, J., and Hafler, D. A. (2019). Fingolimod Modulates T Cell Phenotype and Regulatory T Cell Plasticity In Vivo. J. Autoimmun. 96, 40-49. doi:10.1016/j.jaut.2018.08.002

Dong, Y. F., Guo, R. B., Ji, J., Cao, L. L., Zhang, L., Chen, Z. Z., et al. (2018). S1PR3 Is Essential for Phosphorylated Fingolimod to Protect Astrocytes against OxygenGlucose Deprivation-Induced Neuroinflammation via Inhibiting TLR2/4-Nfkb Signalling. J. Cell Mol Med 22 (6), 3159-3166. doi:10.1111/jcmm.13596

Doyle, T. M., Janes, K., Chen, Z., Grace, P. M., Esposito, E., Cuzzocrea, S., et al. (2020). Activation of Sphingosine-1-Phosphate Receptor Subtype 1 in the central Nervous System Contributes to Morphine-Induced Hyperalgesia and Antinociceptive Tolerance in Rodents. Pain 161 (9), 2107-2118. doi:10.1097/j. pain. 0000000000001888

Dudek, S. M., Camp, S. M., Chiang, E. T., Singleton, P. A., Usatyuk, P. V., Zhao, Y., et al. (2007). Pulmonary Endothelial Cell Barrier Enhancement by FTY720 Does Not Require the S1P1 Receptor. Cell Signal 19 (8), 1754-1764. doi:10. 1016/j.cellsig.2007.03.011

Ebenezer, D. L., Ramchandran, R., Fu, P., Mangio, L. A., Suryadevara, V., Ha, A. W., et al. (2021). Nuclear Sphingosine-1-Phosphate Lyase Generated $\Delta 2$ hexadecenal Is A Regulator of HDAC Activity and Chromatin Remodeling in Lung Epithelial Cells. Cell Biochem Biophys 79, 575-592. doi:10.1007/s12013021-01005-9

Estrada-Bernal, A., Palanichamy, K., Ray Chaudhury, A., and Van Brocklyn, J. R. (2012). Induction of Brain Tumor Stem Cell Apoptosis by FTY720: a Potential Therapeutic Agent for Glioblastoma. Neuro Oncol. 14 (4), 405-415. doi:10. 1093/neuonc/nos005

Fang, L., Zhan, S., Huang, C., Cheng, X., Lv, X., Si, H., et al. (2013). TRPM7 Channel Regulates PDGF-BB-Induced Proliferation of Hepatic Stellate Cells via PI3K and ERK Pathways. Toxicol. Appl. Pharmacol. 272 (3), 713-725. doi:10. 1016/j.taap.2013.08.009

Fazekas, F., Berger, T., Fabjan, T. H., Ledinek, A. H., Jakab, G., Komoly, S., et al. (20121946). Fingolimod in the Treatment Algorithm of Relapsing Remitting Multiple Sclerosis: a Statement of the Central and East European (CEE) MS Expert Group. Wien Med. Wochenschr 162 (15-16), 354-366. doi:10.1007/ s10354-012-0123-y

Feuerherm, A. J., Dennis, E. A., and Johansen, B. (2019). Cytosolic Group IVA Phospholipase A2 Inhibitors, AVX001 and AVX002, Ameliorate
Collagen-Induced Arthritis. Arthritis Res. Ther. 21 (1), 29. doi:10.1186/ s13075-018-1794-6

Filipenko, I., Schwalm, S., Reali, L., Pfeilschifter, J., Fabbro, D., Huwiler, A., et al. (2016). Upregulation of the S1P3 Receptor in Metastatic Breast Cancer Cells Increases Migration and Invasion by Induction of PGE2 and EP2/EP4 Activation. Biochim. Biophys. Acta 1861 (11), 1840-1851. doi:10.1016/j. bbalip.2016.09.005

Fletcher, J. L., Murray, S. S., and Xiao, J. (2018). Brain-Derived Neurotrophic Factor in Central Nervous System Myelination: A New Mechanism to Promote Myelin Plasticity and Repair. Int. J. Mol. Sci. 19 (12), 4131. doi:10.3390/ ijms 19124131

Forrest, M., Sun, S. Y., Hajdu, R., Bergstrom, J., Card, D., Doherty, G., et al. (2004). Immune Cell Regulation and Cardiovascular Effects of Sphingosine 1phosphate Receptor Agonists in Rodents Are Mediated via Distinct Receptor Subtypes. J. Pharmacol. Exp. Ther. 309 (2), 758-768. doi:10.1124/ jpet.103.062828

Foster, C. A., Mechtcheriakova, D., Storch, M. K., Balatoni, B., Howard, L. M., Bornancin, F., et al. (2009). FTY720 Rescue Therapy in the Dark Agouti Rat Model of Experimental Autoimmune Encephalomyelitis: Expression of Central Nervous System Genes and Reversal of Blood-Brain-Barrier Damage. Brain Pathol. 19 (2), 254-266. doi:10.1111/j.1750-3639.2008.00182.x

Francis, M. M., Hummer, T. A., Liffick, E., Vohs, J. L., Mehdiyoun, N. F., Visco, A. C., et al. (2020). Effects of Fingolimod, a Sphingosine-1-Phosphate (S1P) Receptor Agonist, on white Matter Microstructure, Cognition and Symptoms in Schizophrenia. Brain Imaging Behav. 15, 1802-1814. doi:10. 1007/s11682-020-00375-7

Fryer, R. M., Muthukumarana, A., Harrison, P. C., Nodop Mazurek, S., Chen, R. R., Harrington, K. E., et al. (2012). The Clinically-Tested S1P Receptor Agonists, FTY720 and BAF312, Demonstrate Subtype-specific Bradycardia $\left(\mathrm{S}_{1} \mathrm{P}_{1}\right)$ and Hypertension ( $\left.\mathrm{S}^{2} \mathrm{P}_{3}\right)$ in Rat. PLOS ONE 7 (12), e52985. doi:10.1371/journal. pone. 0052985

Fu, D., Li, Y., Li, J., Shi, X., Yang, R., Zhong, Y., et al. (2017). The Effect of S1P Receptor Signaling Pathway on the Survival and Drug Resistance in Multiple Myeloma Cells. Mol. Cell Biochem 424 (1), 185-193. doi:10.1007/s11010-0162854-3

Fujino, M., Funeshima, N., Kitazawa, Y., Kimura, H., Amemiya, H., Suzuki, S., et al. (2003). Amelioration of Experimental Autoimmune Encephalomyelitis in Lewis Rats by FTY720 Treatment. J. Pharmacol. Exp. Ther. 305 (1), 70-77. doi:10.1124/jpet.102.045658

Fujino, M., Li, X. K., Guo, L., Amano, T., and Suzuki, S. (2001). Activation of Caspases and Mitochondria in FTY720-Mediated Apoptosis in Human T Cell Line Jurkat. Int. Immunopharmacol 1 (11), 2011-2021. doi:10.1016/s15675769(01)00130-8

Fujino, M., Li, X. K., Kitazawa, Y., Guo, L., Kawasaki, M., Funeshima, N., et al. (2002). Distinct Pathways of Apoptosis Triggered by FTY720, Etoposide, and Anti-fas Antibody in Human T-Lymphoma Cell Line (Jurkat Cells). J. Pharmacol. Exp. Ther. 300 (3), 939-945. doi:10.1124/jpet.300.3.939

Fukumoto, K., Mizoguchi, H., Takeuchi, H., Horiuchi, H., Kawanokuchi, J., Jin, S., et al. (2014). Fingolimod Increases Brain-Derived Neurotrophic Factor Levels and Ameliorates Amyloid $\beta$-induced Memory Impairment. Behav. Brain Res. 268, 88-93. doi:10.1016/j.bbr.2014.03.046

Gaengel, K., Niaudet, C., Hagikura, K., Laviña, B., Siemsen, B. L., Muhl, L., et al. (2012). The Sphingosine-1-Phosphate Receptor S1PR1 Restricts Sprouting Angiogenesis by Regulating the Interplay between VE-Cadherin and VEGFR2. Dev. Cell 23 (3), 587-599. doi:10.1016/j.devcel.2012.08.005

Gaire, B. P., Song, M. R., and Choi, J. W. (2018). Sphingosine 1-phosphate Receptor Subtype 3 (S1P3) Contributes to Brain Injury after Transient Focal Cerebral Ischemia via Modulating Microglial Activation and Their M1 Polarization. J. Neuroinflammation 15 (1), 284. doi:10.1186/s12974-018-1323-1

Gao, C., Qian, Y., Huang, J., Wang, D., Su, W., Wang, P., et al. (2017). A Three-Day Consecutive Fingolimod Administration Improves Neurological Functions and Modulates Multiple Immune Responses of CCI Mice. Mol. Neurobiol. 54 (10), 8348-8360. doi:10.1007/s12035-016-0318-0

Gao, F., Gao, Y., Meng, F., Yang, C., Fu, J., and Li, Y. (2018). The Sphingosine 1Phosphate Analogue FTY720 Alleviates Seizure-Induced Overexpression of P-Glycoprotein in Rat Hippocampus. Basic Clin. Pharmacol. Toxicol. 123 (1), 14-20. doi:10.1111/bcpt.12973 
Gao, F., Liu, Y., Li, X., Wang, Y., Wei, D., and Jiang, W. (2012). Fingolimod (FTY720) Inhibits Neuroinflammation and Attenuates Spontaneous Convulsions in Lithium-Pilocarpine Induced Status Epilepticus in Rat Model. Pharmacol. Biochem. Behav. 103 (2), 187-196. doi:10.1016/j.pbb. 2012.08.025

Gilenya Contraindicated in Pregnant Women in EU (2019). Gilenya Contraindicated in Pregnant Women in EU. React. Weekly 1765 (1), 1. doi:10.1007/s40278-019-65758-8

Gol, M., Ghorbanian, D., Hassanzadeh, S., Javan, M., Mirnajafi-Zadeh, J., and Ghasemi-Kasman, M. (2017). Fingolimod Enhances Myelin Repair of hippocampus in Pentylenetetrazol-Induced Kindling Model. Eur. J. Pharm. Sci. 96, 72-83. doi:10.1016/j.ejps.2016.09.016

Golan, M., Mausner-Fainberg, K., Ibrahim, B., Benhamou, M., Wilf-Yarkoni, A., Kolb, H., et al. (2019). Fingolimod Increases Brain-Derived Neurotrophic Factor Level Secretion from Circulating T Cells of Patients with Multiple Sclerosis. CNS Drugs 33 (12), 1229-1237. doi:10.1007/s40263-019-00675-7

Grenald, S. A., Doyle, T. M., Zhang, H., Slosky, L. M., Chen, Z., Largent-Milnes, T. M., et al. (2017). Targeting the S1P/S1PR1 axis Mitigates Cancer-Induced Bone Pain and Neuroinflammation. Pain 158 (9), 1733-1742. doi:10.1097/j.pain. 0000000000000965

Gril, B., Paranjape, A. N., Woditschka, S., Hua, E., Dolan, E. L., Hanson, J., et al. (2018). Reactive Astrocytic S1P3 Signaling Modulates the Blood-Tumor Barrier in Brain Metastases. Nat. Commun. 9 (1), 2705. doi:10.1038/s41467-01805030-w

Hait, N. C., Avni, D., Yamada, A., Nagahashi, M., Aoyagi, T., Aoki, H., et al. (2015). The Phosphorylated Prodrug FTY720 Is a Histone Deacetylase Inhibitor that Reactivates ERa Expression and Enhances Hormonal Therapy for Breast Cancer. Oncogenesis 4 (6), e156. doi:10.1038/oncsis.2015.16

Hait, N. C., Wise, L. E., Allegood, J. C., O’Brien, M., Avni, D., Reeves, T. M., et al. (2014). Active, Phosphorylated Fingolimod Inhibits Histone Deacetylases and Facilitates Fear Extinction Memory. Nat. Neurosci. 17 (7), 971-980. doi:10. 1038/nn.3728

Hasegawa, Y., Suzuki, H., Altay, O., Rolland, W., and Zhang, J. H. (2013). Role of the Sphingosine Metabolism Pathway on Neurons against Experimental Cerebral Ischemia in Rats. Transl Stroke Res. 4 (5), 524-532. doi:10.1007/ s12975-013-0260-7

Hasegawa, Y., Suzuki, H., Sozen, T., Rolland, W., and Zhang, J. H. (2010). Activation of Sphingosine 1-phosphate Receptor-1 by FTY720 Is Neuroprotective after Ischemic Stroke in Rats. Stroke 41 (2), 368-374. doi:10.1161/strokeaha.109.568899

Hasegawa, Y., Uekawa, K., Kawano, T., Suzuki, H., and Kim-Mitsuyama, S. (2017). Blockage of Central Sphingosine-1-Phosphate Receptor Does Not Abolish the Protective Effect of FTY720 in Early Brain Injury after Experimental Subarachnoid Hemorrhage. Curr. Drug Deliv. 14 (6), 861-866. doi:10.2174/ 1567201813666160907094401

Hashemian, M., Ghasemi-Kasman, M., Parsian, H., and Sadeghi, F. (2019). Fingolimod (FTY720) Improves the Functional Recovery and Myelin Preservation of the Optic Pathway in Focal Demyelination Model of Rat Optic Chiasm. Brain Res. Bull. 153, 109-121. doi:10.1016/j.brainresbull.2019. 08.014

Hausmann, O. N. (2003). Post-traumatic Inflammation Following Spinal Cord Injury. Spinal Cord 41 (7), 369-378. doi:10.1038/sj.sc.3101483

Heinen, A., Beyer, F., Tzekova, N., Hartung, H. P., and Küry, P. (2015). Fingolimod Induces the Transition to a Nerve Regeneration Promoting Schwann Cell Phenotype. Exp. Neurol. 271, 25-35. doi:10.1016/j.expneurol.2015.05.002

Hemdan, N. Y., Weigel, C., Reimann, C. M., and Gräler, M. H. (2016). Modulating Sphingosine 1-phosphate Signaling with DOP or FTY720 Alleviates Vascular and Immune Defects in Mouse Sepsis. Eur. J. Immunol. 46 (12), 2767-2777. doi:10.1002/eji.201646417

Hemmati, F., Dargahi, L., Nasoohi, S., Omidbakhsh, R., Mohamed, Z., Chik, Z., et al. (2013). Neurorestorative Effect of FTY720 in a Rat Model of Alzheimer's Disease: Comparison with Memantine. Behav. Brain Res. 252, 415-421. doi:10. 1016/j.bbr.2013.06.016

Henry, B., Ziobro, R., Becker, K. A., Kolesnick, R., and Gulbins, E. (2013). Acid Sphingomyelinase. Handb Exp. Pharmacol. 215, 77-88. doi:10.1007/978-37091-1368-4_4

Herz, J., Köster, C., Crasmöller, M., Abberger, H., Hansen, W., Felderhoff-Müser, U., et al. (2018). Peripheral T Cell Depletion by FTY720 Exacerbates Hypoxic-Ischemic
Brain Injury in Neonatal Mice. Front. Immunol. 9, 1696. doi:10.3389/fimmu.2018. 01696

Hjorth, M., Dandu, N., and Mellergård, J. (2020). Treatment Effects of Fingolimod in Multiple Sclerosis: Selective Changes in Peripheral Blood Lymphocyte Subsets. PloS one 15 (2), e0228380. doi:10.1371/journal.pone.0228380

Hla, T., Venkataraman, K., and Michaud, J. (2008). The Vascular S1P GradientCellular Sources and Biological Significance. Biochim. Biophys. Acta 1781 (9), 477-482. doi:10.1016/j.bbalip.2008.07.003

Ho, J. W., Man, K., Sun, C. K., Lee, T. K., Poon, R. T., and Fan, S. T. (2005). Effects of a Novel Immunomodulating Agent, FTY720, on Tumor Growth and Angiogenesis in Hepatocellular Carcinoma. Mol. Cancer Ther. 4 (9), 1430-1438. doi:10.1158/1535-7163.mct-05-0021

Hou, H., Cao, R., Quan, M., Sun, Y., Sun, H., Zhang, J., et al. (2018). Rapamycin and Fingolimod Modulate Treg/Th17 Cells in Experimental Autoimmune Encephalomyelitis by Regulating the Akt-mTOR and MAPK/ERK Pathways. J. Neuroimmunol 324, 26-34. doi:10.1016/j.jneuroim.2018.08.012

Hou, J., Chen, Q., Wu, X., Zhao, D., Reuveni, H., Licht, T., et al. (2017). S1PR3 Signaling Drives Bacterial Killing and Is Required for Survival in Bacterial Sepsis. Am. J. Respir. Crit. Care Med. 196 (12), 1559-1570. doi:10.1164/rccm. 201701-0241OC

Hu, Z. W., Zhou, L. Q., Yang, S., Chen, M., Yu, H. H., Tao, R., et al. (2021). FTY720 Modulates Microglia toward Anti-inflammatory Phenotype by Suppressing Autophagy via STAT1 Pathway. Cell Mol Neurobiol 41 (2), 353-364. doi:10. 1007/s10571-020-00856-9

Hughes, J. E., Srinivasan, S., Lynch, K. R., Proia, R. L., Ferdek, P., and Hedrick, C. C. (2008). Sphingosine-1-phosphate Induces an Antiinflammatory Phenotype in Macrophages. Circ. Res. 102 (8), 950-958. doi:10.1161/circresaha.107.170779

Hung, J. H., Lu, Y. S., Wang, Y. C., Ma, Y. H., Wang, D. S., Kulp, S. K., et al. (2008). FTY720 Induces Apoptosis in Hepatocellular Carcinoma Cells through Activation of Protein Kinase C delta Signaling. Cancer Res. 68 (4), 1204-1212. doi:10.1158/0008-5472.can-07-2621

Huwiler, A., and Zangemeister-Wittke, U. (2018). The Sphingosine 1-phosphate Receptor Modulator Fingolimod as a Therapeutic Agent: Recent Findings and New Perspectives. Pharmacol. Ther. 185, 34-49. doi:10.1016/j.pharmthera. 2017.11.001

Ishii, I., Fukushima, N., Ye, X., and Chun, J. (2004). Lysophospholipid Receptors: Signaling and Biology. Annu. Rev. Biochem. 73 (1), 321-354. doi:10.1146/ annurev.biochem.73.011303.073731

Jaillard, C., Harrison, S., Stankoff, B., Aigrot, M. S., Calver, A. R., Duddy, G., et al. (2005). Edg8/S1P5: an Oligodendroglial Receptor with Dual Function on Process Retraction and Cell Survival. J. Neurosci. 25 (6), 1459-1469. doi:10. 1523/jneurosci.4645-04.2005

Jęśko, H., Wencel, P. L., Wójtowicz, S., Strosznajder, J., Lukiw, W. J., and Strosznajder, R. P. (2020). Fingolimod Affects Transcription of Genes Encoding Enzymes of Ceramide Metabolism in Animal Model of Alzheimer's Disease. Mol. Neurobiol. 57 (6), 2799-2811. doi:10.1007/s12035-020-01908-3

Ji, J., Wang, J., Yang, J., Wang, X. P., Huang, J. J., Xue, T. F., et al. (2019). The Intranuclear SphK2-S1p Axis Facilitates M1-To-M2 Shift of Microglia via Suppressing HDAC1-Mediated KLF4 Deacetylation. Front. Immunol. 10, 1241. doi:10.3389/fimmu.2019.01241

Jones, Z. B., and Ren, Y. (2016). Sphingolipids in Spinal Cord Injury. Int. J. Physiol. Pathophysiol Pharmacol. 8 (2), 52-69.

Joshi, P., Gabrielli, M., Ponzoni, L., Pelucchi, S., Stravalaci, M., Beeg, M., et al. (2017). Fingolimod Limits Acute A $\beta$ Neurotoxicity and Promotes Synaptic versus Extrasynaptic NMDA Receptor Functionality in Hippocampal Neurons. Sci. Rep. 7, 41734. doi:10.1038/srep41734

Kappos, L., Antel, J., Comi, G., Montalban, X., O'Connor, P., Polman, C. H., et al. (2006). Oral Fingolimod (FTY720) for Relapsing Multiple Sclerosis. N. Engl. J. Med. 355 (11), 1124-1140. doi:10.1056/NEJMoa052643

Kappos, L., Radue, E. W., O'Connor, P., Polman, C., Hohlfeld, R., Calabresi, P., et al. (2010). A Placebo-Controlled Trial of Oral Fingolimod in Relapsing Multiple Sclerosis. N. Engl. J. Med. 362 (5), 387-401. doi:10.1056/NEJMoa0909494

Kartalou, G. I., Salgueiro-Pereira, A. R., Endres, T., Lesnikova, A., Casarotto, P., Pousinha, P., et al. (2020). Anti-Inflammatory Treatment with FTY720 Starting after Onset of Symptoms Reverses Synaptic Deficits in an AD Mouse Model. Int. J. Mol. Sci. 21 (23). doi:10.3390/ijms21238957

Kataoka, H., Sugahara, K., Shimano, K., Teshima, K., Koyama, M., Fukunari, A., et al. (2005). FTY720, Sphingosine 1-phosphate Receptor Modulator, 
Ameliorates Experimental Autoimmune Encephalomyelitis by Inhibition of T Cell Infiltration. Cell Mol Immunol 2 (6), 439-448.

Kihara, Y., Maceyka, M., Spiegel, S., and Chun, J. (2014). Lysophospholipid Receptor Nomenclature Review: IUPHAR Review 8. Br. J. Pharmacol. 171 (15), 3575-3594. doi:10.1111/bph.12678

Kim, E., Tunset, H. M., Cebulla, J., Vettukattil, R., Helgesen, H., Feuerherm, A. J., et al. (2016). Anti-vascular Effects of the Cytosolic Phospholipase A2 Inhibitor AVX235 in a Patient-Derived Basal-like Breast Cancer Model. BMC Cancer 16 (1), 191. doi:10.1186/s12885-016-2225-1

Kimbrough, D., Wang, S. H., Wright, L. H., Mani, S. K., Kasiganesan, H., LaRue, A. C., et al. (2018). HDAC Inhibition Helps post-MI Healing by Modulating Macrophage Polarization. J. Mol. Cell Cardiol 119, 51-63. doi:10.1016/j.yjmcc. 2018.04.011

Kiyota, M., Kuroda, J., Yamamoto-Sugitani, M., Shimura, Y., Nakayama, R., Nagoshi, H., et al. (2013). FTY720 Induces Apoptosis of Chronic Myelogenous Leukemia Cells via Dual Activation of BIM and BID and Overcomes Various Types of Resistance to Tyrosine Kinase Inhibitors. Apoptosis 18 (11), 1437-1446. doi:10.1007/s10495-013-0882-y

Kocovski, P., Tabassum-Sheikh, N., Marinis, S., Dang, P. T., Hale, M. W., and Orian, J. M. (2021). Immunomodulation Eliminates Inflammation in the Hippocampus in Experimental Autoimmune Encephalomyelitis, but Does Not Ameliorate Anxiety-like Behavior. Front. Immunol. 12, 639650. doi:10. 3389/fimmu.2021.639650

Komnig, D., Dagli, T. C., Habib, P., Zeyen, T., Schulz, J. B., and Falkenburger, B. H. (2018). Fingolimod (FTY720) Is Not Protective in the Subacute MPTP Mouse Model of Parkinson's Disease and Does Not lead to a Sustainable Increase of Brain-Derived Neurotrophic Factor. J. Neurochem. 147 (5), 678-691. doi:10. 1111/jnc.14575

Kraft, P., Göb, E., Schuhmann, M. K., Göbel, K., Deppermann, C., Thielmann, I., et al. (2013). FTY720 Ameliorates Acute Ischemic Stroke in Mice by Reducing Thrombo-Inflammation but Not by Direct Neuroprotection. Stroke 44 (11), 3202-3210. doi:10.1161/strokeaha.113.002880

Kumar, A., Zamora-Pineda, J., Degagné, E., and Saba, J. D. (2017). S1P Lyase Regulation of Thymic Egress and Oncogenic Inflammatory Signaling. Mediators Inflamm. 2017, 7685142. doi:10.1155/2017/7685142

Lahiri, S., Park, H., Laviad, E. L., Lu, X., Bittman, R., and Futerman, A. H. (2009). Ceramide Synthesis Is Modulated by the Sphingosine Analog FTY720 via a Mixture of Uncompetitive and Noncompetitive Inhibition in an Acyl-CoA Chain Length-dependent Manner. J. Biol. Chem. 284 (24), 16090-16098. doi:10. 1074/jbc.M807438200

LaMontagne, K., Littlewood-Evans, A., Schnell, C., O’Reilly, T., Wyder, L., Sanchez, T., et al. (2006). Antagonism of Sphingosine-1-Phosphate Receptors by FTY720 Inhibits Angiogenesis and Tumor Vascularization. Cancer Res. 66 (1), 221-231. doi:10.1158/0008-5472.can-05-2001

Lee, K. D., Chow, W. N., Sato-Bigbee, C., Graf, M. R., Graham, R. S., Colello, R. J., et al. (2009). FTY720 Reduces Inflammation and Promotes Functional Recovery after Spinal Cord Injury. J. Neurotrauma 26 (12), 2335-2344. doi:10.1089/neu.2008.0840

Lee, M. J., Thangada, S., Claffey, K. P., Ancellin, N., Liu, C. H., Kluk, M., et al. (1999). Vascular Endothelial Cell Adherens junction Assembly and Morphogenesis Induced by Sphingosine-1-Phosphate. Cell 99 (3), 301-312. doi:10.1016/s0092-8674(00)81661-x

Lee, M. J., Van Brocklyn, J. R., Thangada, S., Liu, C. H., Hand, A. R., Menzeleev, R., et al. (1998). Sphingosine-1-phosphate as a Ligand for the G Protein-Coupled Receptor EDG-1. Science 279 (5356), 1552-1555. doi:10.1126/science.279.5356.1552

Leo, A., Citraro, R., Amodio, N., De Sarro, C., Gallo Cantafio, M. E., Constanti, A., et al. (2017). Fingolimod Exerts Only Temporary Antiepileptogenic Effects but Longer-Lasting Positive Effects on Behavior in the WAG/Rij Rat Absence Epilepsy Model. Neurotherapeutics 14 (4), 1134-1147. doi:10.1007/s13311-0170550-y

Li, J., Wang, S. W., Zhang, D. S., Sun, Y., Zhu, C. Y., Fei, Q., et al. (2016). FTY720induced Enhancement of Autophagy Protects Cells from FTY720 Cytotoxicity in Colorectal Cancer. Oncol. Rep. 35 (5), 2833-2842. doi:10.3892/or.2016.4668

Li, L., Wei, C., Cai, S., and Fang, L. (2020a). TRPM7 Modulates Macrophage Polarization by STAT1/STAT6 Pathways in RAW264.7 Cells. Biochem. Biophys. Res. Commun. 533 (4), 692-697. doi:10.1016/j.bbrc.2020.10.062

Li, W., He, T., Jiang, L., Shi, R., Song, Y., Mamtilahun, M., et al. (2020b). Fingolimod Inhibits Inflammation but Exacerbates Brain Edema in the
Acute Phases of Cerebral Ischemia in Diabetic Mice. Front. Neurosci. 14 (842), 842. doi:10.3389/fnins.2020.00842

Li, X., Wang, M. H., Qin, C., Fan, W. H., Tian, D. S., and Liu, J. L. (2017). Fingolimod Suppresses Neuronal Autophagy through the mTOR/p70S6K Pathway and Alleviates Ischemic Brain Damage in Mice. PLoS One 12 (11), e0188748. doi:10.1371/journal.pone. 0188748

Li, Y. C., Liu, Z. G., Yao, K., Wang, H. H., Hu, R., Yang, W., et al. (2013). Mechanisms of ROS in U266 Cell Death Induced by FTY720. Zhongguo Shi Yan Xиe Ye Xue Za Zhi 21 (3), 643-646. doi:10.7534/j.issn.1009-2137.2013.03.021

Liao, A., Hu, R., Zhao, Q., Li, J., Li, Y., Yao, K., et al. (2012). Autophagy Induced by FTY720 Promotes Apoptosis in U266 Cells. Eur. J. Pharm. Sci. 45 (5), 600-605. doi:10.1016/j.ejps.2011.12.014

Liao, A. J., Hu, R., Li, Y. C., Yao, K., Wang, H. H., Zhang, R., et al. (2011). The Study of FTY720 on Inducing Apoptosis and Autophagy in Multiple Myeloma Cell Line U266. Zhonghua Xue Ye Xue Za Zhi 32 (10), 664-667.

Liesz, A., Sun, L., Zhou, W., Schwarting, S., Mracsko, E., Zorn, M., et al. (2011). FTY720 Reduces post-ischemic Brain Lymphocyte Influx but Does Not Improve Outcome in Permanent Murine Cerebral Ischemia. PLoS One 6 (6), e21312. doi:10.1371/journal.pone.0021312

Ling, B., Chen, L., Alcorn, J., Ma, B., and Yang, J. (2011). Sphingosine-1-phosphate: a Potential Therapeutic Agent against Human Breast Cancer. Invest. New Drugs 29 (2), 396-399. doi:10.1007/s10637-009-9375-9

Liu, C. H., Thangada, S., Lee, M. J., Van Brocklyn, J. R., Spiegel, S., and Hla, T. (1999). Ligand-induced Trafficking of the Sphingosine-1-Phosphate Receptor EDG-1. Mol. Biol. Cell 10 (4), 1179-1190. doi:10.1091/mbc.10.4.1179

Liu, X., Zhao, Z., Ji, R., Zhu, J., Sui, Q. Q., Knight, G. E., et al. (2017). Inhibition of P2X7 Receptors Improves Outcomes after Traumatic Brain Injury in Rats. Purinergic Signal. 13 (4), 529-544. doi:10.1007/s11302-017-9579-y

Liu, Y., Yang, C. L., Yang, B., Du, T., Li, X. L., Zhang, P., et al. (2021). Prophylactic Administration of Fingolimod (FTY720) Ameliorated Experimental Autoimmune Myasthenia Gravis by Reducing the Number of Dendritic Cells, Follicular $\mathrm{T}$ Helper Cells and Antibody-Secreting Cells. Int. Immunopharmacol 96, 107511. doi:10.1016/j.intimp.2021.107511

Lu, L., Barfejani, A. H., Qin, T., Dong, Q., Ayata, C., and Waeber, C. (2014). Fingolimod Exerts Neuroprotective Effects in a Mouse Model of Intracerebral Hemorrhage. Brain Res. 1555, 89-96. doi:10.1016/j. brainres.2014.01.048

Lubetzki, C., and Stankoff, B. (2014). Demyelination in Multiple Sclerosis. Handb Clin. Neurol. 122, 89-99. doi:10.1016/B978-0-444-52001-2. 00004-2

Luo, Z. J., Tanaka, T., Kimura, F., and Miyasaka, M. (1999). Analysis of the Mode of Action of a Novel Immunosuppressant FTY720 in Mice. Immunopharmacology 41 (3), 199-207. doi:10.1016/s0162-3109(99)00004-1

Maceyka, M., Sankala, H., Hait, N. C., Le Stunff, H., Liu, H., Toman, R., et al. (2005). SphK1 and SphK2, Sphingosine Kinase Isoenzymes with Opposing Functions in Sphingolipid Metabolism. J. Biol. Chem. 280 (44), 37118-37129. doi:10.1074/jbc.M502207200

Maceyka, M., and Spiegel, S. (2014). Sphingolipid Metabolites in Inflammatory Disease. Nature 510 (7503), 58-67. doi:10.1038/nature13475

Maki, T., Gottschalk, R., Ogawa, N., and Monaco, A. P. (2005). Prevention and Cure of Autoimmune Diabetes in Nonobese Diabetic Mice by Continuous Administration of FTY720. Transplantation 79 (9), 1051-1055. doi:10.1097/01. tp.0000161220.87548.ee

Mandala, S., Hajdu, R., Bergstrom, J., Quackenbush, E., Xie, J., Milligan, J., et al. (2002). Alteration of Lymphocyte Trafficking by Sphingosine-1-Phosphate Receptor Agonists. Science 296 (5566), 346-349. doi:10.1126/science.1070238

Marciniak, A., Camp, S. M., Garcia, J. G. N., and Polt, R. (2018). An Update on Sphingosine-1-Phosphate Receptor 1 Modulators. Bioorg. Med. Chem. Lett. 28 (23-24), 3585-3591. doi:10.1016/j.bmcl.2018.10.042

Matloubian, M., Lo, C. G., Cinamon, G., Lesneski, M. J., Xu, Y., Brinkmann, V., et al. (2004). Lymphocyte Egress from Thymus and Peripheral Lymphoid Organs Is Dependent on S1P Receptor 1. Nature 427 (6972), 355-360. doi:10.1038/ nature 02284

Matsuda, T., Nakajima, H., Fujiwara, I., Mizuta, N., and Oka, T. (1998). Caspase Requirement for the Apoptotic Death of WR19L-Induced by FTY720. Transpl. Proc 30 (5), 2355-2357. doi:10.1016/s0041-1345(98)00652-6

Matsuoka, Y., Nagahara, Y., Ikekita, M., and Shinomiya, T. (2003). A Novel Immunosuppressive Agent FTY720 Induced Akt Dephosphorylation in 
Leukemia Cells. Br. J. Pharmacol. 138 (7), 1303-1312. doi:10.1038/sj.bjp. 0705182

Matsuyuki, H., Maeda, Y., Yano, K., Sugahara, K., Chiba, K., Kohno, T., et al. (2006). Involvement of Sphingosine 1-phosphate (S1P) Receptor Type 1 and Type 4 in Migratory Response of Mouse T Cells toward S1P. Cell Mol Immunol 3 (6), 429-437.

Mazzola, M. A., Raheja, R., Murugaiyan, G., Rajabi, H., Kumar, D., Pertel, T., et al. (2015). Identification of a Novel Mechanism of Action of Fingolimod (FTY720) on Human Effector $\mathrm{T}$ Cell Function through TCF-1 Upregulation. J. Neuroinflammation 12 (1), 245. doi:10.1186/s12974-015-0460-z

McGinley, M. P., and Cohen, J. A. (2021). Sphingosine 1-phosphate Receptor Modulators in Multiple Sclerosis and Other Conditions. The Lancet 398 (10306), 1184-1194. doi:10.1016/S0140-6736(21)00244-0

Mencl, S., Hennig, N., Hopp, S., Schuhmann, M. K., Albert-Weissenberger, C., Sirén, A. L., et al. (2014). FTY720 Does Not Protect from Traumatic Brain Injury in Mice Despite Reducing Posttraumatic Inflammation. J. Neuroimmunol 274 (1-2), 125-131. doi:10.1016/j.jneuroim.2014.07.010

Mendibe Bilbao, M., Boyero Durán, S., Bárcena Llona, J., and RodriguezAntigüedad, A. (2019). Multiple Sclerosis: Pregnancy and Women's Health Issues. Neurologia 34 (4), 259-269. doi:10.1016/j.nrleng.2016.06.01410.1016/j. nrl.2016.06.005

Mendu, S. K., Stremska, M. E., Schappe, M. S., Moser, E. K., Krupa, J. K., Rogers, J. S., et al. (2020). Targeting the Ion Channel TRPM7 Promotes the Thymic Development of Regulatory T cells by Promoting IL-2 Signaling. Sci Signal 13 (661)doi:10.1126/scisignal.abb0619

Mike, E. V., Makinde, H. M., Der, E., Stock, A., Gulinello, M., Gadhvi, G. T., et al. (2018). Neuropsychiatric Systemic Lupus Erythematosus Is Dependent on Sphingosine-1-Phosphate Signaling. Front. Immunol. 9, 2189. doi:10.3389/ fimmu.2018.02189

Miron, V. E., Jung, C. G., Kim, H. J., Kennedy, T. E., Soliven, B., and Antel, J. P. (2008). FTY720 Modulates Human Oligodendrocyte Progenitor Process Extension and Survival. Ann. Neurol. 63 (1), 61-71. doi:10.1002/ana.21227

Miron, V. E., Ludwin, S. K., Darlington, P. J., Jarjour, A. A., Soliven, B., Kennedy, T. E., et al. (2010). Fingolimod (FTY720) Enhances Remyelination Following Demyelination of Organotypic Cerebellar Slices. Am. J. Pathol. 176 (6), 2682-2694. doi:10.2353/ajpath.2010.091234

Moon, E., Han, J. E., Jeon, S., Ryu, J. H., Choi, J. W., and Chun, J. (2015). Exogenous S1P Exposure Potentiates Ischemic Stroke Damage that Is Reduced Possibly by Inhibiting S1P Receptor Signaling. Mediators Inflamm. 2015, 492659. doi:10. $1155 / 2015 / 492659$

Moon, H., Chon, J., Joo, J., Kim, D., In, J., Lee, H., et al. (2013). FTY720 Preserved Islet $\beta$-cell Mass by Inhibiting Apoptosis and Increasing Survival of $\beta$-cells in Db/db Mice. Diabetes Metab. Res. Rev. 29 (1), 19-24. doi:10.1002/dmrr.2341

Motyl, J., Przykaza, Ł., Boguszewski, P. M., Kosson, P., and Strosznajder, J. B. (2018). Pramipexole and Fingolimod Exert Neuroprotection in a Mouse Model of Parkinson's Disease by Activation of Sphingosine Kinase 1 and Akt Kinase. Neuropharmacology 135, 139-150. doi:10.1016/j.neuropharm. 2018.02.023

Müller, H. C., Hocke, A. C., Hellwig, K., Gutbier, B., Peters, H., Schönrock, S. M., et al. (2011). The Sphingosine-1 Phosphate Receptor Agonist FTY720 Dose Dependently Affected Endothelial Integrity In Vitro and Aggravated Ventilator-Induced Lung Injury in Mice. Pulm. Pharmacol. Ther. 24 (4), 377-385. doi:10.1016/j.pupt.2011.01.017

Naegelin, Y., Kuhle, J., Schädelin, S., Datta, A. N., Magon, S., Amann, M., et al. (2021). Fingolimod in Children with Rett Syndrome: the FINGORETT Study. Orphanet J. Rare Dis. 16 (1), 19. doi:10.1186/s13023-020-01655-7

Nagahara, Y., Ikekita, M., and Shinomiya, T. (2000). Immunosuppressant FTY720 Induces Apoptosis by Direct Induction of Permeability Transition and Release of Cytochrome C from Mitochondria. J. Immunol. 165 (6), 3250-3259. doi:10. 4049/jimmunol.165.6.3250

Nagahara, Y., Matsuoka, Y., Saito, K., Ikekita, M., Higuchi, S., and Shinomiya, T. (2001). Coordinate Involvement of Cell Cycle Arrest and Apoptosis Strengthen the Effect of FTY720. Jpn. J. Cancer Res. 92 (6), 680-687. doi:10.1111/j.13497006.2001.tb01148.x

Nagahashi, M., Takabe, K., Terracina, K. P., Soma, D., Hirose, Y., Kobayashi, T., et al. (2014). Sphingosine-1-phosphate Transporters as Targets for Cancer Therapy. Biomed. Res. Int. 2014, 651727. doi:10.1155/2014/651727
Nagahashi, M., Yamada, A., Katsuta, E., Aoyagi, T., Huang, W. C., Terracina, K. P., et al. (2018). Targeting the SphK1/S1P/S1PR1 Axis that Links Obesity, Chronic Inflammation, and Breast Cancer Metastasis. Cancer Res. 78 (7), 1713-1725. doi:10.1158/0008-5472.can-17-1423

Nagaoka, Y., Otsuki, K., Fujita, T., and Uesato, S. (2008). Effects of Phosphorylation of Immunomodulatory Agent FTY720 (Fingolimod) on Antiproliferative Activity against Breast and colon Cancer Cells. Biol. Pharm. Bull. 31 (6), 1177-1181. doi:10.1248/bpb.31.1177

Najafian, S. A., Farbood, Y., Sarkaki, A., and Ghafouri, S. (2021). FTY720 Administration Following Hypoxia-Induced Neonatal Seizure Reverse Cognitive Impairments and Severity of Seizures in Male and Female Adult Rats: The Role of Inflammation. Neurosci. Lett. 748, 135675. doi:10.1016/j. neulet.2021.135675

Nava, V. E., Hobson, J. P., Murthy, S., Milstien, S., and Spiegel, S. (2002). Sphingosine Kinase Type 1 Promotes Estrogen-dependent Tumorigenesis of Breast Cancer MCF-7 Cells. Exp. Cell Res 281 (1), 115-127. doi:10.1006/excr. 2002.5658

Nazari, M., Keshavarz, S., Rafati, A., Namavar, M. R., and Haghani, M. (2016). Fingolimod (FTY720) Improves Hippocampal Synaptic Plasticity and Memory Deficit in Rats Following Focal Cerebral Ischemia. Brain Res. Bull. 124, 95-102. doi:10.1016/j.brainresbull.2016.04.004

Noda, H., Takeuchi, H., Mizuno, T., and Suzumura, A. (2013). Fingolimod Phosphate Promotes the Neuroprotective Effects of Microglia. J. Neuroimmunol 256 (1-2), 13-18. doi:10.1016/j.jneuroim.2012.12.005

Norimatsu, Y., Ohmori, T., Kimura, A., Madoiwa, S., Mimuro, J., Seichi, A., et al. (2012). FTY720 Improves Functional Recovery after Spinal Cord Injury by Primarily Nonimmunomodulatory Mechanisms. Am. J. Pathol. 180 (4), 1625-1635. doi:10.1016/j.ajpath.2011.12.012

Novgorodov, A. S., El-Alwani, M., Bielawski, J., Obeid, L. M., and Gudz, T. I. (2007). Activation of Sphingosine-1-Phosphate Receptor S1P5 Inhibits Oligodendrocyte Progenitor Migration. Faseb j 21 (7), 1503-1514. doi:10. 1096/fj.06-7420com

Ntranos, A., Hall, O., Robinson, D. P., Grishkan, I. V., Schott, J. T., Tosi, D. M., et al. (2014). FTY720 Impairs CD8 T-Cell Function Independently of the Sphingosine-1-Phosphate Pathway. J. Neuroimmunol 270 (1), 13-21. doi:10. 1016/j.jneuroim.2014.03.007

O'Sullivan, S., and Dev, K. K. (2017). Sphingosine-1-phosphate Receptor Therapies: Advances in Clinical Trials for CNS-Related Diseases. Neuropharmacology 113 (Pt B), 597-607. doi:10.1016/j.neuropharm.2016. 11.006

Oaks, J., and Ogretmen, B. (2015). Regulation of PP2A by Sphingolipid Metabolism and Signaling. Front. Oncol. 4 (388), 388. doi:10.3389/fonc. 2014.00388

Obinata, H., and Hla, T. (2019). Sphingosine 1-phosphate and Inflammation. Int. Immunol. 31 (9), 617-625. doi:10.1093/intimm/dxz037

Ochi, R., Momose, Y., Oyama, K., and Giles, W. R. (2006). Sphingosine-1phosphate Effects on guinea Pig Atrial Myocytes: Alterations in Action Potentials and K+ Currents. Cardiovasc. Res. 70 (1), 88-96. doi:10.1016/j. cardiores.2006.01.010

Okura, I., Kamata, M., Asano, Y., Mitsui, A., Shimizu, T., Sato, S., et al. (2021). Fingolimod Ameliorates Imiquimod-Induced Psoriasiform Dermatitis by Sequestrating Interleukin-17-Producing ?d T Cells in Secondary Lymph Nodes. J. Dermatol. Sci. 102, 116-125. doi:10.1016/j.jdermsci.2021.04.004

Olesch, C., Ringel, C., Brüne, B., and Weigert, A. (2017). Beyond Immune Cell Migration: The Emerging Role of the Sphingosine-1-Phosphate Receptor S1PR4 as a Modulator of Innate Immune Cell Activation. Mediators Inflamm. 2017, 6059203. doi:10.1155/2017/6059203

Oo, M. L., Chang, S. H., Thangada, S., Wu, M. T., Rezaul, K., Blaho, V., et al. (2011). Engagement of S1P1-Degradative Mechanisms Leads to Vascular Leak in Mice. J. Clin. Invest. 121 (6), 2290-2300. doi:10.1172/JCI45403

Oo, M. L., Thangada, S., Wu, M. T., Liu, C. H., Macdonald, T. L., Lynch, K. R., et al. (2007). Immunosuppressive and Anti-angiogenic Sphingosine 1-phosphate Receptor-1 Agonists Induce Ubiquitinylation and Proteasomal Degradation of the Receptor. J. Biol. Chem. 282 (12), 9082-9089. doi:10.1074/jbc.M610318200

Ota, K., Okuma, T., Lorenzo, A., Yokota, A., Hino, H., Kazama, H., et al. (2019). Fingolimod Sensitizes EGFR Wild-type $\mathrm{N}$-on-small C-ell L-ung C-ancer C-ells to L-apatinib or S-orafenib and I-nduces C-ell C-ycle A-rrest. Oncol. Rep. 42 (1), 231-242. doi:10.3892/or.2019.7140 
Pankratz, N., Schick, U. M., Zhou, Y., Zhou, W., Ahluwalia, T. S., Allende, M. L., et al. (2016). Meta-analysis of Rare and Common Exome Chip Variants Identifies S1PR4 and Other Loci Influencing Blood Cell Traits. Nat. Genet. 48 (8), 867-876. doi:10.1038/ng.3607

Patnaik, A., Spiombi, E., Frasca, A., Landsberger, N., Zagrebelsky, M., and Korte, M. (2020). Fingolimod Modulates Dendritic Architecture in a BDNFdependent Manner. Int. J. Mol. Sci. 21 (9), 1. doi:10.3390/ijms21093079

Paugh, S. W., Payne, S. G., Barbour, S. E., Milstien, S., and Spiegel, S. (2003). The Immunosuppressant FTY720 Is Phosphorylated by Sphingosine Kinase Type 2. FEBS Lett. 554 (1), 189-193. doi:10.1016/S0014-5793(03)01168-2

Payne, S. G., Oskeritzian, C. A., Griffiths, R., Subramanian, P., Barbour, S. E., Chalfant, C. E., et al. (2007). The Immunosuppressant Drug FTY720 Inhibits Cytosolic Phospholipase A2 Independently of Sphingosine-1-Phosphate Receptors. Blood 109 (3), 1077-1085. doi:10.1182/blood-2006-03-011437

Pchejetski, D., Bohler, T., Brizuela, L., Sauer, L., Doumerc, N., Golzio, M., et al. (2010). FTY720 (Fingolimod) Sensitizes Prostate Cancer Cells to Radiotherapy by Inhibition of Sphingosine Kinase-1. Cancer Res. 70 (21), 8651-8661. doi:10. 1158/0008-5472.can-10-1388

Pépin, É., Jalinier, T., Lemieux, G. L., Massicotte, G., and Cyr, M. (2020). Sphingosine-1-Phosphate Receptors Modulators Decrease Signs of Neuroinflammation and Prevent Parkinson's Disease Symptoms in the 1Methyl-4-Phenyl-1,2,3,6-Tetrahydropyridine Mouse Model. Front. Pharmacol. 11, 77. doi:10.3389/fphar.2020.00077

Pérez-Jeldres, T., Alvarez-Lobos, M., and Rivera-Nieves, J. (2021). Targeting Sphingosine-1-Phosphate Signaling in Immune-Mediated Diseases: Beyond Multiple Sclerosis. Drugs 81, 985-1002. doi:10.1007/s40265021-01528-8

Perla, A. S., Fratini, L., Cardoso, P. S., de Farias, C. B., da Cunha Jaeger, M., and Roesler, R. (2020). Fingolimod (FTY720) Reduces Viability and Survival and Increases Histone H3 Acetylation in Medulloblastoma Cells. Pediatr. Hematol. Oncol. 37 (2), 170-175. doi:10.1080/08880018.2019.1699213

Permpongkosol, S., Wang, J. D., Takahara, S., Matsumiya, K., Nonomura, N., Nishimura, K., et al. (2002). Anticarcinogenic Effect of FTY720 in Human Prostate Carcinoma DU145 Cells: Modulation of Mitogenic Signaling, FAK, Cell-Cycle Entry and Apoptosis. Int. J. Cancer 98 (2), 167-172. doi:10.1002/ijc.10178

Pfeilschifter, W., Czech-Zechmeister, B., Sujak, M., Foerch, C., Wichelhaus, T. A., and Pfeilschifter, J. (2011). Treatment with the Immunomodulator FTY720 Does Not Promote Spontaneous Bacterial Infections after Experimental Stroke in Mice. Exp. Transl Stroke Med. 3, 2. doi:10. 1186/2040-7378-3-2

Pippa, R., Dominguez, A., Christensen, D. J., Moreno-Miralles, I., Blanco-Prieto, M. J., Vitek, M. P., et al. (2014). Effect of FTY720 on the SET-Pp2a Complex in Acute Myeloid Leukemia; SET Binding Drugs Have Antagonistic Activity. Leukemia 28 (9), 1915-1918. doi:10.1038/leu.2014.141

Pitsch, J., Kuehn, J. C., Gnatkovsky, V., Müller, J. A., van Loo, K. M. J., de Curtis, M., et al. (2019). Anti-epileptogenic and Anti-convulsive Effects of Fingolimod in Experimental Temporal Lobe Epilepsy. Mol. Neurobiol. 56 (3), 1825-1840. doi:10.1007/s12035-018-1181-y

Potenza, R. L., De Simone, R., Armida, M., Mazziotti, V., Pèzzola, A., Popoli, P., et al. (2016). Fingolimod: A Disease-Modifier Drug in a Mouse Model of Amyotrophic Lateral Sclerosis. Neurotherapeutics 13 (4), 918-927. doi:10.1007/ s13311-016-0462-2

Potì, F., Giorgio, C., Zini, I., Nofer, J. R., Vivo, V., Palese, S., et al. (2020). Impact of S1P Mimetics on Mesenteric Ischemia/Reperfusion Injury. Pharmaceuticals (Basel) 13 (10), 1. doi:10.3390/ph13100298

Pournajaf, S., Valian, N., Mohaghegh Shalmani, L., Khodabakhsh, P., Jorjani, M., and Dargahi, L. (2020). Fingolimod Increases Oligodendrocytes Markers Expression in Epidermal Neural Crest Stem Cells. Eur. J. Pharmacol. 885, 173502. doi:10.1016/j.ejphar.2020.173502

Proia, R. L., and Hla, T. (2015). Emerging Biology of Sphingosine-1-Phosphate: its Role in Pathogenesis and Therapy. J. Clin. Invest. 125 (4), 1379-1387. doi:10. $1172 /$ jci76369

Pyne, N. J., and Pyne, S. (2010). Sphingosine 1-phosphate and Cancer. Nat. Rev. Cancer 10 (7), 489-503. doi:10.1038/nrc2875

Qin, C., Fan, W. H., Liu, Q., Shang, K., Murugan, M., Wu, L. J., et al. (2017). Fingolimod Protects against Ischemic White Matter Damage by Modulating Microglia toward M2 Polarization via STAT3 Pathway. Stroke 48 (12), 3336-3346. doi:10.1161/strokeaha.117.018505
Qin, X., Yue, Z., Sun, B., Yang, W., Xie, J., Ni, E., et al. (2013). Sphingosine and FTY720 Are Potent Inhibitors of the Transient Receptor Potential Melastatin 7 (TRPM7) Channels. Br. J. Pharmacol. 168 (6), 1294-1312. doi:10.1111/bph. 12012

Quarta, S., Camprubí-Robles, M., Schweigreiter, R., Matusica, D., Haberberger, R. V., Proia, R. L., et al. (2017). Sphingosine-1-Phosphate and the S1P3 Receptor Initiate Neuronal Retraction via RhoA/ROCK Associated with CRMP2 Phosphorylation. Front. Mol. Neurosci. 10 (317), 317. doi:10.3389/fnmol. 2017.00317

Rausch, M., Hiestand, P., Foster, C. A., Baumann, D. R., Cannet, C., and Rudin, M. (2004). Predictability of FTY720 Efficacy in Experimental Autoimmune Encephalomyelitis by In Vivo Macrophage Tracking: Clinical Implications for Ultrasmall Superparamagnetic Iron Oxide-Enhanced Magnetic Resonance Imaging. J. Magn. Reson. Imaging 20 (1), 16-24. doi:10.1002/jmri.20057

Ren, M., Han, M., Wei, X., Guo, Y., Shi, H., Zhang, X., et al. (2017). FTY720 Attenuates 6-OHDA-Associated Dopaminergic Degeneration in Cellular and Mouse Parkinsonian Models. Neurochem. Res. 42 (2), 686-696. doi:10.1007/ s11064-016-2125-4

Riese, J., Gromann, A., Lührs, F., Kleinwort, A., and Schulze, T. (2021). Sphingosine-1-Phosphate Receptor Type 4 (S1P4) Is Differentially Regulated in Peritoneal B1 B Cells upon TLR4 Stimulation and Facilitates the Egress of Peritoneal B1a B Cells and Subsequent Accumulation of Splenic IRA B Cells under Inflammatory Conditions. Int. J. Mol. Sci. 22 (7), 3465. doi:10.3390/ ijms 22073465

Roggeri, A., Schepers, M., Tiane, A., Rombaut, B., Van Veggel, L., Hellings, N., et al. (2020). Sphingosine-1-Phosphate Receptor Modulators and Oligodendroglial Cells: Beyond Immunomodulation. Int. J. Mol. Sci. 21 (20), 7537. doi:10.3390/ ijms 21207537

Rohrbach, T. D., Asgharpour, A., Maczis, M. A., Montefusco, D., Cowart, L. A., Bedossa, P., et al. (2019). FTY720/fingolimod Decreases Hepatic Steatosis and Expression of Fatty Acid Synthase in Diet-Induced Nonalcoholic Fatty Liver Disease in Mice. J. Lipid Res. 60 (7), 1311-1322. doi:10.1194/jlr.M093799

Rolland, W. B., 2nd, Manaenko, A., Lekic, T., Hasegawa, Y., Ostrowski, R., Tang, J., et al. (2011). FTY720 Is Neuroprotective and Improves Functional Outcomes after Intracerebral Hemorrhage in Mice. Acta Neurochir Suppl. 111, 213-217. doi:10.1007/978-3-7091-0693-8_36

Rolland, W. B., Krafft, P. R., Lekic, T., Klebe, D., LeGrand, J., Weldon, A. J., et al. (2017). Fingolimod Confers Neuroprotection through Activation of Racl after Experimental Germinal Matrix Hemorrhage in Rat Pups. J. Neurochem. 140 (5), 776-786. doi:10.1111/jnc.13946

Rolland, W. B., Lekic, T., Krafft, P. R., Hasegawa, Y., Altay, O., Hartman, R., et al. (2013). Fingolimod Reduces Cerebral Lymphocyte Infiltration in Experimental Models of Rodent Intracerebral Hemorrhage. Exp. Neurol. 241, 45-55. doi:10. 1016/j.expneurol.2012.12.009

Romero Rosales, K., Singh, G., Wu, K., Chen, J., Janes, M. R., Lilly, M. B., et al. (2011). Sphingolipid-based Drugs Selectively Kill Cancer Cells by DownRegulating Nutrient Transporter Proteins. Biochem. J. 439 (2), 299-311. doi:10.1042/bj20110853

Roy, R., Alotaibi, A. A., and Freedman, M. S. (2021). Sphingosine 1-Phosphate Receptor Modulators for Multiple Sclerosis. CNS Drugs 35 (4), 385-402. doi:10. 1007/s40263-021-00798-w

Rupp, T., Pelouin, O., Genest, L., Legrand, C., Froget, G., and Castagné, V. (2021). Therapeutic Potential of Fingolimod in Triple Negative Breast Cancer Preclinical Models. Transl Oncol. 14 (1), 100926. doi:10.1016/j.tranon.2020.100926

Russo, M., Guarneri, C., Mazzon, E., Sessa, E., Bramanti, P., and Calabrò, R. S. (2015). Fingolimod-Associated Peripheral Vascular Adverse Effects. Mayo Clin. Proc. 90 (10), 1424-1427. doi:10.1016/j.mayocp.2015.07.019

Sada, N., Fujita, Y., Mizuta, N., Ueno, M., Furukawa, T., and Yamashita, T. (2020). Inhibition of HDAC Increases BDNF Expression and Promotes Neuronal Rewiring and Functional Recovery after Brain Injury. Cell Death Dis 11 (8), 655. doi:10.1038/s41419-020-02897-w

Salas-Perdomo, A., Miró-Mur, F., Gallizioli, M., Brait, V. H., Justicia, C., Meissner, A., et al. (2019). Role of the S1P Pathway and Inhibition by Fingolimod in Preventing Hemorrhagic Transformation after Stroke. Sci. Rep. 9 (1), 8309. doi:10.1038/s41598-019-44845-5

Sanchez, T., Estrada-Hernandez, T., Paik, J. H., Wu, M. T., Venkataraman, K., Brinkmann, V., et al. (2003). Phosphorylation and Action of the Immunomodulator FTY720 Inhibits Vascular Endothelial Cell Growth 
Factor-Induced Vascular Permeability. J. Biol. Chem. 278 (47), 47281-47290. doi:10.1074/jbc.M306896200

Sanna, M. G., Vincent, K. P., Repetto, E., Nguyen, N., Brown, S. J., Abgaryan, L., et al. (2016). Bitopic Sphingosine 1-Phosphate Receptor 3 (S1P3) Antagonist Rescue from Complete Heart Block: Pharmacological and Genetic Evidence for Direct S1P3 Regulation of Mouse Cardiac Conduction. Mol. Pharmacol. 89 (1), 176-186. doi:10.1124/mol.115.100222

Schappe, M. S., Szteyn, K., Stremska, M. E., Mendu, S. K., Downs, T. K., Seegren, P. V., et al. (2018). Chanzyme TRPM7 Mediates the Ca2+ Influx Essential for Lipopolysaccharide-Induced Toll-like Receptor 4 Endocytosis and Macrophage Activation. Immunity 48 (1), 59-e5. e55. doi:10.1016/j.immuni.2017.11.026

Schilling, T., Miralles, F., and Eder, C. (2014). TRPM7 Regulates Proliferation and Polarisation of Macrophages. J. Cel Sci 127 (Pt 21), 4561-4566. doi:10.1242/jcs. 151068

Schlunk, F., Pfeilschifter, W., Yigitkanli, K., Lo, E. H., and Foerch, C. (2016). Treatment with FTY720 Has No Beneficial Effects on Short-Term Outcome in an Experimental Model of Intracerebral Hemorrhage. Exp. Transl Stroke Med. 8, 1. doi:10.1186/s13231-016-0016-z

Schmid, G., Guba, M., Ischenko, I., Papyan, A., Joka, M., Schrepfer, S., et al. (2007). The Immunosuppressant FTY720 Inhibits Tumor Angiogenesis via the Sphingosine 1-phosphate Receptor 1. J. Cel Biochem 101 (1), 259-270. doi:10.1002/jcb.21181

Schmid, G., Guba, M., Papyan, A., Ischenko, I., Brückel, M., Bruns, C. J., et al. (2005). FTY720 Inhibits Tumor Growth and Angiogenesis. Transpl. Proc 37 (1), 110-111. doi:10.1016/j.transproceed.2004.12.278

Schuhmann, M. K., Krstic, M., Kleinschnitz, C., and Fluri, F. (2016). Fingolimod (FTY720) Reduces Cortical Infarction and Neurological Deficits during Ischemic Stroke through Potential Maintenance of Microvascular Patency. Curr. Neurovasc Res. 13 (4), 277-282. doi:10.2174/ 1567202613666160823152446

Schulze, T., Golfier, S., Tabeling, C., Räbel, K., Gräler, M. H., Witzenrath, M., et al. (2011). Sphingosine-1-phospate Receptor $4\left(\mathrm{~S}_{\mathrm{P}} 4\right)$ Deficiency Profoundly Affects Dendritic Cell Function and TH17-Cell Differentiation in a Murine Model. Faseb j 25 (11), 4024-4036. doi:10.1096/fj.10-179028

Schwab, S. R., and Cyster, J. G. (2007). Finding a Way Out: Lymphocyte Egress from Lymphoid Organs. Nat. Immunol. 8 (12), 1295-1301. doi:10.1038/ni1545

Schwab, S. R., Pereira, J. P., Matloubian, M., Xu, Y., Huang, Y., and Cyster, J. G. (2005). Lymphocyte Sequestration through S1P Lyase Inhibition and Disruption of S1P Gradients. Science 309 (5741), 1735-1739. doi:10.1126/ science. 1113640

Segura-Ulate, I., Yang, B., Vargas-Medrano, J., and Perez, R. G. (2017). FTY720 (Fingolimod) Reverses $\alpha$-synuclein-induced Downregulation of Brain-Derived Neurotrophic Factor mRNA in OLN-93 Oligodendroglial Cells. Neuropharmacology 117, 149-157. doi:10.1016/j.neuropharm.2017.01.028

Shang, K., He, J., Zou, J., Qin, C., Lin, L., Zhou, L. Q., et al. (2020). Fingolimod Promotes Angiogenesis and Attenuates Ischemic Brain Damage via Modulating Microglial Polarization. Brain Res. 1726, 146509. doi:10.1016/j.brainres.2019. 146509

Shen, Y., Cai, M., Xia, W., Liu, J., Zhang, Q., Xie, H., et al. (2007). FTY720, a Synthetic Compound from Isaria Sinclairii, Inhibits Proliferation and Induces Apoptosis in Pancreatic Cancer Cells. Cancer Lett. 254 (2), 288-297. doi:10. 1016/j.canlet.2007.03.013

Shichita, T., Sugiyama, Y., Ooboshi, H., Sugimori, H., Nakagawa, R., Takada, I., et al. (2009). Pivotal Role of Cerebral Interleukin-17-Producing gammadeltaT Cells in the Delayed Phase of Ischemic Brain Injury. Nat. Med. 15 (8), 946-950. doi:10.1038/nm.1999

Sica, F., Centonze, D., and Buttari, F. (2019). Fingolimod Immune Effects beyond its Sequestration Ability. Neurol. Ther. 8 (2), 231-240. doi:10.1007/s40120-01900162-7

Slowik, A., Schmidt, T., Beyer, C., Amor, S., Clarner, T., and Kipp, M. (2015). The Sphingosine 1-phosphate Receptor Agonist FTY720 Is Neuroprotective after Cuprizone-Induced CNS Demyelination. Br. J. Pharmacol. 172 (1), 80-92. doi:10.1111/bph.12938

Smith, P. A., Schmid, C., Zurbruegg, S., Jivkov, M., Doelemeyer, A., Theil, D., et al. (2018). Fingolimod Inhibits Brain Atrophy and Promotes Brain-Derived Neurotrophic Factor in an Animal Model of Multiple Sclerosis. J. Neuroimmunol 318, 103-113. doi:10.1016/j.jneuroim.2018.02.016
Sonoda, Y., Yamamoto, D., Sakurai, S., Hasegawa, M., Aizu-Yokota, E., Momoi, T., et al. (2001). FTY720, a Novel Immunosuppressive Agent, Induces Apoptosis in Human Glioma Cells. Biochem. Biophys. Res. Commun. 281 (2), 282-288. doi:10.1006/bbrc.2001.4352

Spiegel, S. (2000). Sphingosine 1-phosphate: a Ligand for the EDG-1 Family of G-Protein-Coupled Receptors. Ann. N. Y Acad. Sci. 905, 54-60. doi:10.1111/j. 1749-6632.2000.tb06537.x

Stepanovska, B., Zivkovic, A., Enzmann, G., Tietz, S., Homann, T., Kleuser, B., et al. (2020). Morpholino Analogues of Fingolimod as Novel and Selective S1P1 Ligands with In Vivo Efficacy in a Mouse Model of Experimental Antigen-Induced Encephalomyelitis. Int. J. Mol. Sci. 21 (18), 6463. doi:10.3390/ijms21186463

Sternberg, Z., Kolb, C., Chadha, K., Nir, A., Nir, R., George, R., et al. (2018). Fingolimod Anti-inflammatory and Neuroprotective Effects Modulation of RAGE axis in Multiple Sclerosis Patients. Neuropharmacology 130, 71-76. doi:10.1016/j.neuropharm.2017.11.047

Stockstill, K., Doyle, T. M., Yan, X., Chen, Z., Janes, K., Little, J. W., et al. (2018). Dysregulation of Sphingolipid Metabolism Contributes to Bortezomib-Induced Neuropathic Pain. J. Exp. Med. 215 (5), 1301-1313. doi:10.1084/jem.20170584

Subei, A. M., and Cohen, J. A. (2015). Sphingosine 1-phosphate Receptor Modulators in Multiple Sclerosis. CNS drugs 29 (7), 565-575. doi:10.1007/ s40263-015-0261-z

Subei, A. M., and Cohen, J. A. (2015). Sphingosine 1-Phosphate Receptor Modulators in Multiple Sclerosis. CNS Drugs 29 (7), 565-575. doi:10.1007/ s40263-015-0261-z

Sun, R. Z., Fan, Y., Liang, X., Gong, T. T., Wang, Q., Liu, H., et al. (2018). Rapamycin and FTY720 Alleviate Atherosclerosis by Cross Talk of Macrophage Polarization and Autophagy. Biomed. Res. Int. 2018, 1010248. doi:10.1155/ $2018 / 1010248$

Suzuki, S., Li, X. K., Shinomiya, T., Enosawa, S., Kakefuda, T., Mitsusada, M., et al. (1996). Induction of Lymphocyte Apoptosis and Prolongation of Allograft Survival by FTY720. Transpl. Proc 28 (4), 2049-2050.

Szepanowski, F., Derksen, A., Steiner, I., Meyer Zu Hörste, G., Daldrup, T., Hartung, H. P., et al. (2016). Fingolimod Promotes Peripheral Nerve Regeneration via Modulation of Lysophospholipid Signaling. J. Neuroinflammation 13 (1), 143. doi:10.1186/s12974-016-0612-9

Széplaki, G., and Merkely, B. (2012). Clinical Significance of the Cardiovascular Effects of Fingolimod Treatment in Multiple Sclerosis. Ideggyogy Sz 65 (11-12), 369-376.

Tai, N., Kuwabara, K., Kobayashi, M., Yamada, K., Ono, T., Seno, K., et al. (2010). Cytosolic Phospholipase A2 Alpha Inhibitor, Pyrroxyphene, Displays Antiarthritic and Anti-bone Destructive Action in a Murine Arthritis Model. Inflamm. Res. 59 (1), 53-62. doi:10.1007/s00011-009-0069-8

Takasugi, N., Sasaki, T., Ebinuma, I., Osawa, S., Isshiki, H., Takeo, K., et al. (2013). FTY720/fingolimod, a Sphingosine Analogue, Reduces Amyloid- $\beta$ Production in Neurons. PloS one 8 (5), e64050. doi:10.1371/journal.pone. 0064050

Tay, K. H., Liu, X., Chi, M., Jin, L., Jiang, C. C., Guo, S. T., et al. (2015). Involvement of Vacuolar $\mathrm{H}(+)$-ATPase in Killing of Human Melanoma Cells by the Sphingosine Kinase Analogue FTY720. Pigment Cel Melanoma Res 28 (2), 171-183. doi:10.1111/pcmr.12326

Tölle, M., Levkau, B., Keul, P., Brinkmann, V., Giebing, G., Schönfelder, G., et al. (2005). Immunomodulator FTY720 Induces eNOS-dependent Arterial Vasodilatation via the Lysophospholipid Receptor S1P3. Circ. Res. 96 (8), 913-920. doi:10.1161/01.Res.0000164321.91452.00

Tonelli, F., Lim, K. G., Loveridge, C., Long, J., Pitson, S. M., Tigyi, G., et al. (2010). FTY720 and (S)-FTY720 Vinylphosphonate Inhibit Sphingosine Kinase 1 and Promote its Proteasomal Degradation in Human Pulmonary Artery Smooth Muscle, Breast Cancer and Androgen-independent Prostate Cancer Cells. Cel Signal 22 (10), 1536-1542. doi:10.1016/j.cellsig.2010.05.022

Tsai, H. C., and Han, M. H. (2016). Sphingosine-1-Phosphate (S1P) and S1P Signaling Pathway: Therapeutic Targets in Autoimmunity and Inflammation. Drugs 76 (11), 1067-1079. doi:10.1007/s40265-016-0603-2

Valdés-Rives, S. A., and González-Arenas, A. (2017). Autotaxin-Lysophosphatidic Acid: From Inflammation to Cancer Development. Mediators Inflamm. 2017, 1-15. doi:10.1155/2017/9173090

van Doorn, R., Lopes Pinheiro, M. A., Kooij, G., Lakeman, K., van het Hof, B., van der Pol, S. M., et al. (2012). Sphingosine 1-phosphate Receptor 5 Mediates the Immune Quiescence of the Human Brain Endothelial Barrier. J. Neuroinflammation 9, 133. doi:10.1186/1742-2094-9-133 
van Meeteren, L. A., Brinkmann, V., Saulnier-Blache, J. S., Lynch, K. R., and Moolenaar, W. H. (2008). Anticancer Activity of FTY720: Phosphorylated FTY720 Inhibits Autotaxin, a Metastasis-Enhancing and Angiogenic Lysophospholipase D. Cancer Lett. 266 (2), 203-208. doi:10.1016/j.canlet. 2008.02.052

Vargas-Medrano, J., Yang, B., Garza, N. T., Segura-Ulate, I., and Perez, R. G. (2019). Up-regulation of Protective Neuronal MicroRNAs by FTY720 and Novel FTY720-Derivatives. Neurosci. Lett. 690, 178-180. doi:10.1016/j.neulet. 2018.10.040

Vessey, D. A., Kelley, M., Zhang, J., Li, L., Tao, R., and Karliner, J. S. (2007). Dimethylsphingosine and FTY720 Inhibit the SK1 Form but Activate the SK2 Form of Sphingosine Kinase from Rat Heart. J. Biochem. Mol. Toxicol. 21 (5), 273-279. doi:10.1002/jbt.20193

Vidal-Martinez, G., Najera, K., Miranda, J. D., Gil-Tommee, C., Yang, B., VargasMedrano, J., et al. (2019). FTY720 Improves Behavior, Increases Brain Derived Neurotrophic Factor Levels and Reduces $\alpha$-Synuclein Pathology in Parkinsonian GM2+/- Mice. Neuroscience 411, 1-10. doi:10.1016/j. neuroscience.2019.05.029

Vidal-Martínez, G., Vargas-Medrano, J., Gil-Tommee, C., Medina, D., Garza, N. T., Yang, B., et al. (2016). FTY720/Fingolimod Reduces Synucleinopathy and Improves Gut Motility in A53T Mice: Contributions of Pro-brain-derived Neurotrophic Factor (Pro-bdnf) and Mature Bdnf. J. Biol. Chem. 291 (39), 20811-20821. doi:10.1074/jbc.M116.744029

Volpi, C., Orabona, C., Macchiarulo, A., Bianchi, R., Puccetti, P., and Grohmann, U. (2019). Preclinical Discovery and Development of Fingolimod for the Treatment of Multiple Sclerosis. Expert Opin. Drug Discov. 14 (11), 1199-1212. doi:10.1080/17460441.2019.1646244

Wallington-Beddoe, C. T., Hewson, J., Bradstock, K. F., and Bendall, L. J. (2011). FTY720 Produces Caspase-independent Cell Death of Acute Lymphoblastic Leukemia Cells. Autophagy 7 (7), 707-715. doi:10.4161/auto.7.7.15154

Walzer, T., Chiossone, L., Chaix, J., Calver, A., Carozzo, C., Garrigue-Antar, L., et al. (2007). Natural Killer Cell Trafficking In Vivo Requires a Dedicated Sphingosine 1-phosphate Receptor. Nat. Immunol. 8 (12), 1337-1344. doi:10. $1038 /$ ni1523

Wang, J., Wang, J., Lu, P., Cai, Y., Wang, Y., Hong, L., et al. (2015). Local Delivery of FTY720 in PCL Membrane Improves SCI Functional Recovery by Reducing Reactive Astrogliosis. Biomaterials 62, 76-87. doi:10.1016/j.biomaterials.2015. 04.060

Wang, L., and Dudek, S. M. (2009). Regulation of Vascular Permeability by Sphingosine 1-phosphate. Microvasc. Res. 77 (1), 39-45. doi:10.1016/j.mvr. 2008.09.005

Wang, L., Sammani, S., Moreno-Vinasco, L., Letsiou, E., Wang, T., Camp, S. M., et al. (2014). FTY720 (S)-phosphonate Preserves Sphingosine 1-phosphate Receptor 1 Expression and Exhibits superior Barrier protection to FTY720 in Acute Lung Injury. Crit. Care Med. 42 (3), e189-99. doi:10.1097/ccm. 0000000000000097

Wang, P., Yuan, Y., Lin, W., Zhong, H., Xu, K., and Qi, X. (2019). Roles of Sphingosine-1-Phosphate Signaling in Cancer. Cancer Cel Int 19 (1), 295. doi:10.1186/s12935-019-1014-8

Wang, W., Graeler, M. H., and Goetzl, E. J. (2005). Type 4 Sphingosine 1phosphate G Protein-Coupled Receptor (S1P4) Transduces S1P Effects on T Cell Proliferation and Cytokine Secretion without Signaling Migration. Faseb j 19 (12), 1731-1733. doi:10.1096/fj.05-3730fje

Wang, Y., Zhou, S., Han, Z., Yin, D., Luo, Y., Tian, Y., et al. (2020a). Fingolimod Administration Improves Neurological Functions of Mice with Subarachnoid Hemorrhage. Neurosci. Lett. 736, 135250. doi:10. 1016/j.neulet.2020.135250

Wang, Z., Higashikawa, K., Yasui, H., Kuge, Y., Ohno, Y., Kihara, A., et al. (2020b). FTY720 Protects against Ischemia-Reperfusion Injury by Preventing the Redistribution of Tight Junction Proteins and Decreases Inflammation in the Subacute Phase in an Experimental Stroke Model. Transl Stroke Res. 11 (5), 1103-1116. doi:10.1007/s12975-020-00789-x

Wei, Y., Yemisci, M., Kim, H. H., Yung, L. M., Shin, H. K., Hwang, S. K., et al. (2011). Fingolimod Provides Long-Term protection in Rodent Models of Cerebral Ischemia. Ann. Neurol. 69 (1), 119-129. doi:10.1002/ana.22186

Weigert, A., Olesch, C., and Brüne, B. (2019). Sphingosine-1-Phosphate and Macrophage Biology-How the Sphinx Tames the Big Eater. Front. Immunol. 10 (1706), 1706. doi:10.3389/fimmu.2019.01706
Wen, Z. H., Su, Y. C., Lai, P. L., Zhang, Y., Xu, Y. F., Zhao, A., et al. (2013). Critical Role of Arachidonic Acid-Activated mTOR Signaling in Breast Carcinogenesis and Angiogenesis. Oncogene 32 (2), 160-170. doi:10.1038/onc.2012.47

White, C., Alshaker, H., Cooper, C., Winkler, M., and Pchejetski, D. (2016). The Emerging Role of FTY720 (Fingolimod) in Cancer Treatment. Oncotarget 7 (17), 23106-23127. doi:10.18632/oncotarget.7145

Xin, Q., Cheng, G., Kong, F., Ji, Q., Li, H., Jiang, W., et al. (2020). STAT1 Transcriptionally Regulates the Expression of S1PR1 by Binding its Promoter Region. Gene 736, 144417. doi:10.1016/j.gene.2020.144417

Yamazaki, K., Kawabori, M., Seki, T., Takamiya, S., Tateno, T., Konno, K., et al. (2020). FTY720 Attenuates Neuropathic Pain after Spinal Cord Injury by Decreasing Systemic and Local Inflammation in a Rat Spinal Cord Compression Model. J. Neurotrauma 37 (15), 1720-1728. doi:10.1089/neu. 2019.6905

Yang, T., Zha, Z., Yang, X., Kang, Y., Wang, X., Tong, Y., et al. (2021). Neuroprotective Effects of Fingolimod Supplement on the Retina and Optic Nerve in the Mouse Model of Experimental Autoimmune Encephalomyelitis. Front. Neurosci. 15, 663541. doi:10.3389/fnins.2021.663541

Yang, Z., Dong, S., Zheng, Q., Zhang, L., Tan, X., Zou, J., et al. (2019). FTY720 Attenuates Iron Deposition and Glial Responses in Improving Delayed Lesion and Long-Term Outcomes of Collagenase-Induced Intracerebral Hemorrhage. Brain Res. 1718, 91-102. doi:10.1016/j.brainres.2019.04.031

Yao, S., Li, L., Sun, X., Hua, J., Zhang, K., Hao, L., et al. (2019). FTY720 Inhibits MPP+-Induced Microglial Activation by Affecting NLRP3 Inflammasome Activation. J. Neuroimmune Pharmacol. 14 (3), 478-492. doi:10.1007/ s11481-019-09843-4

Yazdi, A., Baharvand, H., and Javan, M. (2015). Enhanced Remyelination Following Lysolecithin-Induced Demyelination in Mice under Treatment with Fingolimod (FTY720). Neuroscience 311, 34-44. doi:10.1016/j.neuroscience.2015.10.013

Yazdi, A., Ghasemi-Kasman, M., and Javan, M. (2020). Possible Regenerative Effects of Fingolimod (FTY720) in Multiple Sclerosis Disease: An Overview on Remyelination Process. J. Neurosci. Res. 98 (3), 524-536. doi:10.1002/ jnr.24509

Yee, N. S. (2017). Role of TRPM7 in Cancer: Potential as Molecular Biomarker and Therapeutic Target. Pharmaceuticals 10 (2), 39. doi:10.3390/ph10020039

Yeh, E. A., and Weinstock-Guttman, B. (2011). Fingolimod: an Oral DiseaseModifying Therapy for Relapsing Multiple Sclerosis. Adv. Ther. 28 (4), 270-278. doi:10.1007/s12325-011-0004-6

Yin, J., Li, R., Liu, W., Chen, Y., Zhang, X., Li, X., et al. (2018). Neuroprotective Effect of Protein Phosphatase 2A/Tristetraprolin Following Subarachnoid Hemorrhage in Rats. Front. Neurosci. 12, 96. doi:10.3389/fnins.2018.00096

Yoshida, Y., Mikami, N., Matsushima, Y., Miyawaki, M., Endo, H., Banno, R., et al. (2016). Combination Treatment with Fingolimod and a Pathogenic Antigen Prevents Relapse of Glucose-6-Phosphate Isomerase Peptide-Induced Arthritis. Immun. Inflamm. Dis. 4 (3), 263-273. doi:10.1002/iid3.111

Zemann, B., Kinzel, B., Müller, M., Reuschel, R., Mechtcheriakova, D., Urtz, N., et al. (2006). Sphingosine Kinase Type 2 Is Essential for Lymphopenia Induced by the Immunomodulatory Drug FTY720. Blood 107 (4), 1454-1458. doi:10. 1182/blood-2005-07-2628

Zhang, J., Zhang, A., Sun, Y., Cao, X., and Zhang, N. (2009). Treatment with Immunosuppressants FTY720 and Tacrolimus Promotes Functional Recovery after Spinal Cord Injury in Rats. Tohoku J. Exp. Med. 219 (4), 295-302. doi:10. $1620 /$ tjem.219.295

Zhang, L., Ding, K., Wang, H., Wu, Y., and Xu, J. (2016). Traumatic Brain InjuryInduced Neuronal Apoptosis Is Reduced through Modulation of PI3K and Autophagy Pathways in Mouse by FTY720. Cell Mol Neurobiol 36 (1), 131-142. doi:10.1007/s10571-015-0227-1

Zhang, L., Wang, H., Ding, K., and Xu, J. (2015). FTY720 Induces AutophagyRelated Apoptosis and Necroptosis in Human Glioblastoma Cells. Toxicol. Lett. 236 (1), 43-59. doi:10.1016/j.toxlet.2015.04.015

Zhang, L., and Wang, H. (2020). FTY720 in CNS Injuries: Molecular Mechanisms and Therapeutic Potential. Brain Res. Bull. 164, 75-82. doi:10.1016/j. brainresbull.2020.08.013

Zhang, N., Dai, L., Qi, Y., Di, W., and Xia, P. (2013). Combination of FTY720 with Cisplatin Exhibits Antagonistic Effects in Ovarian Cancer Cells: Role of Autophagy. Int. J. Oncol. 42 (6), 2053-2059. doi:10.3892/ijo.2013.1906

Zhang, N., Qi, Y., Wadham, C., Wang, L., Warren, A., Di, W., et al. (2010). FTY720 Induces Necrotic Cell Death and Autophagy in Ovarian Cancer Cells: a 
Protective Role of Autophagy. Autophagy 6 (8), 1157-1167. doi:10.4161/auto.6. 8.13614

Zhang, W., Xu, W., and Xiong, S. (2011). Macrophage Differentiation and Polarization via Phosphatidylinositol 3-kinase/Akt-ERK Signaling Pathway Conferred by Serum Amyloid P Component. J. Immunol. 187 (4), 1764-1777. doi:10.4049/jimmunol.1002315

Zhang, Z., Fauser, U., and Schluesener, H. J. (2008). Early Attenuation of Lesional Interleukin-16 Up-Regulation by Dexamethasone and FTY720 in Experimental Traumatic Brain Injury. Neuropathol. Appl. Neurobiol. 34 (3), 330-339. doi:10. 1111/j.1365-2990.2007.00893.x

Zhang, Z., Zhang, Z., Fauser, U., Artelt, M., Burnet, M., and Schluesener, H. J. (2007). FTY720 Attenuates Accumulation of EMAP-II+ and MHC-II+ Monocytes in Early Lesions of Rat Traumatic Brain Injury. J. Cell Mol Med 11 (2), 307-314. doi:10.1111/j.1582-4934.2007.00019.x

Zhao, P., Yang, X., Yang, L., Li, M., Wood, K., Liu, Q., et al. (2017a). Neuroprotective Effects of Fingolimod in Mouse Models of Parkinson's Disease. FASEB J. 31 (1), 172-179. doi:10.1096/fj.201600751r

Zhao, Y., Zhang, E., Lv, N., Ma, L., Yao, S., Yan, M., et al. (2018). Metformin and FTY720 Synergistically Induce Apoptosis in Multiple Myeloma Cells. Cell Physiol Biochem 48 (2), 785-800. doi:10.1159/000491908

Zhao, Z., Wang, R., Huo, Z., Li, C., and Wang, Z. (2017b). Characterization of the Anticoagulant and Antithrombotic Properties of the Sphingosine 1-Phosphate Mimetic FTY720. Acta Haematol. 137 (1), 1-6. doi:10.1159/000448837

Zheng, T., Meng, X., Wang, J., Chen, X., Yin, D., Liang, Y., et al. (2010). PTEN- and P53-Mediated Apoptosis and Cell Cycle Arrest by FTY720 in Gastric Cancer Cells and Nude Mice. J. Cell Biochem 111 (1), 218-228. doi: $10.1002 /$ jcb. 22691

Zhong, Y., Tian, F., Ma, H., Wang, H., Yang, W., Liu, Z., et al. (2020). FTY720 Induces Ferroptosis and Autophagy via PP2A/AMPK Pathway in Multiple Myeloma Cells. Life Sci. 260, 118077. doi:10.1016/j.lfs.2020.118077
Zhu, C., Wen, S., Li, J., Meng, H., Zhang, J., Zhao, K., et al. (2021). FTY720 Inhibits the Development of Collagen-Induced Arthritis in Mice by Suppressing the Recruitment of CD4+ T Lymphocytes. Drug Des. Devel Ther. 15, 1981-1992. doi: $10.2147 /$ dddt.s293876

Zhu, Z., Fu, Y., Tian, D., Sun, N., Han, W., Chang, G., et al. (2015). Combination of the Immune Modulator Fingolimod with Alteplase in Acute Ischemic Stroke: A Pilot Trial. Circulation 132 (12), 1104-1112. doi:10.1161/circulationaha.115. 016371

Zou, Y., Hu, J., Huang, W., Ye, S., Han, F., Du, J., et al. (2020). Non-Mitogenic Fibroblast Growth Factor 1 Enhanced Angiogenesis Following Ischemic Stroke by Regulating the Sphingosine-1-Phosphate 1 Pathway. Front. Pharmacol. 11, 59. doi:10.3389/fphar.2020.00059

Conflict of Interest: The authors declare that the research was conducted in the absence of any commercial or financial relationships that could be construed as a potential conflict of interest.

Publisher's Note: All claims expressed in this article are solely those of the authors and do not necessarily represent those of their affiliated organizations, or those of the publisher, the editors, and the reviewers. Any product that may be evaluated in this article, or claim that may be made by its manufacturer, is not guaranteed or endorsed by the publisher.

Copyright $\odot 2022$ Pournajaf, Dargahi, Javan and Pourgholami. This is an openaccess article distributed under the terms of the Creative Commons Attribution License (CC BY). The use, distribution or reproduction in other forums is permitted, provided the original author(s) and the copyright owner(s) are credited and that the original publication in this journal is cited, in accordance with accepted academic practice. No use, distribution or reproduction is permitted which does not comply with these terms. 